Illinois State University

ISU ReD: Research and eData

Theses and Dissertations

6-4-2015

\title{
Analysis Of Plant Lignin Formation And Engineering For Biofuels Production
}

Deborah Lynn Petrik

Illinois State University, petrikdeborah@yahoo.com

Follow this and additional works at: https://ir.library.illinoisstate.edu/etd

Part of the Biology Commons

\section{Recommended Citation}

Petrik, Deborah Lynn, "Analysis Of Plant Lignin Formation And Engineering For Biofuels Production" (2015). Theses and Dissertations. 432.

https://ir.library.illinoisstate.edu/etd/432

This Dissertation is brought to you for free and open access by ISU ReD: Research and eData. It has been accepted for inclusion in Theses and Dissertations by an authorized administrator of ISU ReD: Research and eData. For more information, please contact ISUReD@ilstu.edu. 


\title{
ANALYSIS OF PLANT LIGNIN FORMATION AND ENGINEERING FOR BIOFUELS PRODUCTION
}

\author{
Deborah L. Petrik
}

120 Pages

August 2015

Grasses such as switchgrass and Miscanthus are attractive feedstock candidates for second generation biofuels because they are perennials that can grow on less fertile or "marginal" lands not used for food crops, require little fertilizer and modest pest and disease management, and are not a human food source. Releasing the energy potential contained in plant-based cellulosic material requires either conversion to a liquid biofuel such as ethanol or burning. Thus, much of the current research focuses not only on understanding grass development as it relates to yield, but on how to best enhance traits affecting the quality of biomass for its efficient conversion to biofuels. In order to efficiently extract the sugars making up the cellulose and hemicelluloses components of the plant cell wall, the phenolic polymer lignin, in which they are embedded and to which they are crosslinked, must be removed. To lower the cost of biomass conversion, approaches to decrease lignin content or alter its structure to allow ease of removal may be employed. This work aims to study genes involved in lignin biosynthesis and modification, in order to identify points in the pathway that can be targeted to ease lignin recalcitrance. Efforts to modify plant cell walls must be done without harming plant 
fitness, thus cell wall related gene promoters hold value as switches for transgenic modification in specific cells and at specific times in development. Therefore, the second goal of this work was to clone three secondary cell wall gene promoters into monocot transformation vectors and thoroughly characterize their expression patterns. These utility vectors will be made available to the scientific community for use in driving genes of interest specifically in cells producing secondary cell walls. 


\title{
ANALYSIS OF PLANT LIGNIN FORMATION AND ENGINEERING FOR BIOFUELS PRODUCTION
}

\author{
DEBORAH L. PETRIK
}

A Dissertation Submitted in Partial

Fulfillment of the Requirements for the Degree of

DOCTOR OF PHILOSOPHY

School of Biological Sciences

ILLINOIS STATE UNIVERSITY 
Copyright 2015 Deborah L. Petrik 


\title{
ANALYSIS OF PLANT LIGNIN FORMATION AND ENGINEERING FOR BIOFUELS PRODUCTION
}

\author{
DEBORAH L. PETRIK
}

COMMITTEE MEMBERS:

John C. Sedbrook, Chair

Martha Cook

Erik Larson

Kevin Edwards

Viktor Kirik 


\section{ACKNOWLEDGMENTS}

The writer wishes to thank her friends, family and colleagues for their support and guidance.

D.L.P. 


\section{CONTENTS}

Page

ACKNOWLEDGMENTS $\quad$ i

$\begin{array}{ll}\text { CONTENTS } & \text { ii }\end{array}$

CHAPTER II TABLES $\quad$ v

CHAPTER III TABLES

CHAPTER II FIGURES Vii

CHAPTER III FIGURES $\quad$ ix

CHAPTER III SUPPLEMENTAL FIGURES $\quad$ x

CHAPTER

I. LIGNOCELLULOSIC DERIVED BIOFUEL: BACKGROUND 1

Current and Future Energy Demands 1

Ability of Lignocellulosic Derived Biofuels to

Partially Fill the Energy Supply Gap 2

Components of the Plant Cell Wall 2

Cellulose Biosynthesis $\quad 3$

Hemicellulose Biosynthesis $\quad 5$

Pectin Biosynthesis $\quad 5$

$\begin{array}{ll}\text { Lignin Biosynthesis } & 6\end{array}$

Lignin Caused Recalcitrance of Vegetative Biomass 7

$\begin{array}{ll}\text { Research Aims } & 7\end{array}$

$\begin{array}{ll}\text { References } & 9\end{array}$

II. P-COUMAROYL-COA:MONOLIGNOL TRANSFERASE (PMT) ACTS SPECIFICALLY IN THE LIGNIN BIOSYNTHETIC

PATHWAY IN BRACHYPODIUM DISTACHYON

Summary

12

Introduction

14

Results and Discussion

i

i

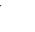

i

i

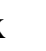

$\mathrm{X}$ 
$\begin{array}{ll}\text { Conclusion } & 27\end{array}$

Experimental Procedures 28

Transgenic Plant Generation 28

Seed Sterilization and Plant Growth 29

Quantitative RT-PCR (qRT-PCR) and RNA-Seq 30

Stem Sectioning, Phloroglucinol and Mäule Reagent

Staining 31

Digestibility Assays 31

Thioacidolysis Method 32

Mild Alkaline Hydrolysis of Extract-Free Senesced

Stems

DFRC Method to Quantitate $p$ CA Specifically Bound to Lignin $\quad 32$

Analysis of Arabinoxylan-Bound $p$ CA and FA 34

2D HSQC NMR Analysis of Cell Wall Components 34

Acknowledgments $\quad 35$

$\begin{array}{ll}\text { References } & 37\end{array}$

$\begin{array}{ll}\text { Figures } & 45\end{array}$

III. BDCESA7, BDCESA8, AND BDPMT UTILITY PROMOTER CONSTRUCTS FOR TARGETING GENE-OF-INTEREST EXPRESSION IN SECONDARY CELL WALL FORMING CELLS OF GRASSES

Abstract $\quad 53$

Introduction $\quad 54$

$\begin{array}{ll}\text { Materials and Methods } & 58\end{array}$

PCR Amplification of Promoters from Brachypodium distachyon Genomic DNA

Modification of pIPKb001 Cereal Transformation Vector for Optimal Expression of GUSPLUS Reporter Gene

Transformation of Promoter Characterization Vectors into Brachypodium distachyon via Agrobacterium tumefaciens Transformation

Seed Sterilization and Plant Growth

Tissue Collection for X-Gluc Staining

X-Gluc Staining for Detection of GUS Expression

Rescue of Bdpmt and Bdcesa8 Mutant Phenotypes

Results

Selection of Promoter Candidates 
BdPMT Promoter:GUSPLUS Transgenic Lines

BdPMT Promoter:GUSPLUS Expression in

Leaves

69

BdPMT Promoter:GUSPLUS Expression in Roots

BdPMT Promoter:GUSPLUS Expression in Floral Organs

BdCESA7 and BdCESA8 Promoter:GUSPLUS

Transgenic Lines

BdCESA7 and BdCESA8:GUSPLUS Expression in Stems

BdCESA7 and BdCESA8:GUSPLUS Expression in Leaves

BdCESA7 and BdCESA8:GUSPLUS Expression in Roots

BdCESA7 and BdCESA8:GUSPLUS Expression in Floral Organs

Bdpmt Phenotypic Rescue

Bdcesa8 Phenotypic Rescue

Discussion

References

81

Tables

86

Figures

93

Supplemental Figures 


\section{CHAPTER II TABLES}

Table

Page

1. Lignin Analyses for Wild-Type (WT) and BdPMT Misregulated Brachypodium Plants 


\section{CHAPTER III TABLES}

Table

1. PCR Primers Used to Amplify Promoter Sequences of BdCESA7 Bradi4g30540, BdCESA8 Bradi2g49912, BdPMT Bradi2g36910, and to Test Inheritance of Bdcesa8 T-DNA Insertion and BdCESA8 Phenotypic Rescue

2. BdPMT Promoter Annotation of Cell Wall, Vascular Expression, and Responsive Element Related Motifs

3. BdCESA7 Promoter Annotation of Cell Wall, Vascular Expression, and Responsive Element Related Motifs

4. BdCESA8 Promoter Annotation of Cell Wall, Vascular Expression, and Responsive Element Related Motifs 


\section{CHAPTER II FIGURES}

Figure Page

1. Pathway for Acylation of Monolignols 45

2a. $\quad B d P M T$ Transcript Levels in WT Brachypodium Tissues, as Determined by qRT-PCR

2b. Diagram of the BdPMT Gene Bradi2g36910 (Drawn to Scale; 300 bp Scale Bar)

2c. Alignment of the BdPMT Polypeptide Sequences Containing the HXXXD Motif with Sequences from BAHD Acyltransferases Representing Each of the Five Clades as Delineated by Phylogenetic Analysis (D’Auria, 2006)

3. Comparisons of Tallest Culm Heights and Total Above-Ground Biomass Weights of Senesced Mutant (a) and WT (b) Plants Grown Under Long Days

4. Graphs Showing the Amounts of $p \mathrm{CA}, \mathrm{FA}, p \mathrm{CA}$-Arabinose, and FA-Arabinose Released from Senesced Stem Biomass Lignin and Hemicelluloses Combined (a), Lignin only (b), or Arabinoxylan only (c), Using the Treatments Denoted in the Graph Titles

5. Schematic for Analytical Methods Used to Delineate Between Hydroxycinnamates, $p$-Coumarate, and Ferulate, on Lignin Versus on Polysaccharides

6. Solution-State HSQC NMR of Ball-Milled Plant Cell Walls (Top Row) and Cellulolytic Enzyme Lignin (CEL) Treatment (Bottom Row) in DMSO-d6/Pyridine-d5

7. BdPMT OX Stem Sections (b, d) Have Considerably Lighter Phloroglucinol (a, b) and Mäule Reagent (c, d) Staining Compared to WT $(\mathrm{a}, \mathrm{c})$, Which is Consistent with Relatively Less Cell Wall Lignin 
8. Digestibility of Stem Biomass, Comparing BdPMT OX and $B d P M T$ RNAi Line 4B to Transgenic Control Plants (UBIprom:GUS), and Bdpmt-1 to Wild-Type 


\section{CHAPTER III FIGURES}

Figure

Page

1. X-Gluc Stained Brachypodium distachyon Stem Cross Sections of Plants Transformed with the BdCESA7, BdCESA8, and $B d P M T$ Promoter Sequences Driving Expression of the GUSPLUS Reporter Gene

2. BdPMT Promoter::GUSPLUS Expression in Adult Plant Apical Internode Stem Sections as Compared to Lignin Deposition as Evidenced by Phloroglucinol Staining

3. Apical Leaf Snippet X-Glucuronidase Treated to Monitor GUS Activity Driven by the BdCESA7, BdCESA8, and BdPMT Promoters Cloned

4. BdCESA7 Promoter, BdCESA8 Promoter, BdPMT Promoter, ZmUBQ Promoter Driving GUSPLUS Expression in Seedling Roots X-Gluc Stained for GUS Activity 3 Days After Germination 96

5. Florets Stained for GUS Enzymatic Activity, Prior to Seed Fill 97

6. GUS Activity of Internal Floral Organs 98

7. Stem Sections Taken from the Bottom Region of the Apical Internode of BdCESA7 Promoter::GUSPLUS and WT Adult Plants

8. Stem Sections Taken from the Bottom Region of the Apical Internode of BdCESA8 Promoter::GUSPLUS and WT Adult Plants

9. X-Gluc Staining to Examine GUS Activity Driven by the BdPMT, $B d C E S A 7$ and BdCESA8 Promoters in Floral Stigmas and Anthers

10. Phylogenetic Tree of Brachypodium distachyon and Arabidopsis thaliana CESA Genes Based on Amino Acid Similarity 


\section{CHAPTER III SUPPLEMENTAL FIGURES}

Figure Page

S1. Sequence of 3,000 bp Cloned BdPMT Promoter Fragment 103

S2. Sequence of 2,385 bp Cloned BdCESA7 Promoter Fragment 105

S3. Sequence of 1,890 bp Cloned BdCESA8 Promoter Fragment 107

S4. Plasmid Maps of Utility Vectors Housing the GUSPLUS Gene in Order to Examine Expression Patterns of the Cloned Promoters in Transgenic Brachypodium distachyon

S5. BdPMT and BdCESA8 Phenotypic Rescue Constructs Plasmid Maps

S6. BdPMT, BdCESA7, and BdCESA8 Promoter Empty Vector Constructs

S7. X-Gluc Stained Juvenile Stage Stem Cross Sections Taken from the Longitudinal Median of the First Basal Internode 18 Days after Transfer from Hygromycin Selection Plates to Soil

S8. Comparison of Expression of BdPMT Promoter Driving GUSPLUS Expression Across Transgenic Lines in Juvenile and Adult Leaves

S9. Range of GUSPLUS Expression in 3 Days After Germination Seedling Roots Across Multiple Transgenic Lines of BdCESA7 Promoter (A-D), BdCESA8 Promoter (E-H), and BdPMT Promoter (I-L)

S10. Comparison of Expression Across BdCESA7 Promoter Driving GUSPLUS Transgenic Lines in Adult Leaves 
S11. Comparison of Expression Across BdCESA8 Promoter Driving GUSPLUS Transgenic Lines in Adult Leaves

S12. Range of Expression Across Multiple Transgenic Lines of BdCESA7 (Top Panel), BdCESA8 (Center Panel), and BdPMT (Bottom Panel) Promoters Driving GUSPLUS Expression in Adult Stems

S13. Height Comparison of Homozygous Bdcesa8 Mutant, Heterozygous Bdcesa8 Mutant, and Wild-Type Control Brachypodium distachyon

S14. Crystalline Cellulose Quantitations as Performed by Updegraff Assay on Homozygous Bdcesa8 Mutants, Heterozygous Bdcesa8 Mutants, and Wild-Type Controls

S15. Quantitation of $u \mathrm{~g} \mathrm{pCA} / \mathrm{mg}$ Extracted Sample of $P M T$ Phenotypic Rescue Transgenic Lines Versus Wild-Type and Bdpmt-1 Knockout Controls

S16. Genomic DNA PCR Results of BdCESA8 Phenotypic Rescue Transgenic Lines Compared to B258p9ioACT Empty Vector and Wild-Type Plant Controls 


\section{CHAPTER I}

\section{LIGNOCELLULOSIC DERIVED BIOFUEL: BACKGROUND}

\section{Current and Future Energy Demands}

In 2008 , oil, natural gas, and coal provided a total of $81.2 \%$ of the world's energy sources (Source: The USA Energy Information Administration). In the United States, military leaders and politicians recommend decreasing the nation's dependence on foreign oil as a means to improving political and economic stability. Yet, the level of fossil fuel consumption has lessened only slightly, despite the known environmental consequences due to the extraction methods used and the emission of greenhouse gases. The production of ethanol derived via fermentation of sugars harvested from corn endosperm shows the potential of using chemical compounds produced by plants as a renewable fuel resource. Currently, the only large-scale commercial production of bioethanol has been from corn seed in the US, and sugar cane in Brazil. In the US, the majority of corn produced is used as animal feed, and for the production of corn syrup used as sweeteners in many processed foods. This has led to debate over land usage for "fuel versus food" application, which has made the public wary to the expansion of highly productive crop land to grow corn purely for bioethanol production. 


\section{Ability of Lignocellulosic Derived Biofuels to Partially Fill the Energy Supply Gap}

In order to provide alternative feedstocks for biofuel production that will not compete with the food supply, scientists are exploring the feasibility of developing renewable and sustainable sources of energy, including generating biofuels from plant biomass. Plant biomass refers to the vegetative tissue of the plant, namely the leaves and stems. Most likely, plants would be harvested once senesced; therefore, the sugars in the plant biomass material would be extracted from plant cell walls.

\section{Components of the Plant Cell Wall}

Cell walls serve multiple functions to the plant including providing mechanical strength, a physical barrier against pathogens, and encasing the plasma membrane of the cell to aid in maintenance of turgor pressure. Plant cell walls consist of up to three specialized layers: the middle lamella, the primary cell wall, and the secondary cell wall. Understanding the makeup of each of these layers will allow the design of efficient methods to extract sugars contained in plant cell wall polymers. Further, knowledge of how the components of each layer are synthesized will foster innovative approaches to transgenic modification of the cell wall to permit efficient sugar extraction without weakening the health of the plant.

The outermost layer of the plant cell wall, the middle lamella, is located at the junction of two adjacent plant cells and the pectin it contains serves to glue adjacent cells together. Internal to the middle lamella, the primary cell wall consists of a network of linked cellulose and hemicellulose fibers embedded in a pectin matrix. The primary cell wall has the ability to expand during plant cell elongation via the movement of cellulose 
microfibrils within the loose hemicellulose/pectin matrix. Upon cessation of cell elongation and differentiation, certain plant cell walls synthesize a third internal layer, the secondary cell wall, which is made of cellulose, xylan containing hemicellulose (substituted with arabinoxylan in the case of grasses), and lignin. Cross-linking of the lignin polymer to hemicelluloses that coat the cellulose microfibrils makes the secondary cell wall mechanically strong to support a taller growth habit. The phenolic rings within lignin provide hydrophobicity within mature xylem vessels to allow for effective water movement across greater distances via the mechanism of transpiration.

\section{Cellulose Biosynthesis}

Extensive research to characterize the mechanisms of cellulose, hemicellulose, pectin, and lignin biosynthesis has reached a moderate level of understanding of the substrates, products, and enzymatic reactions involved. For example, it has been well characterized that cellulose consists of linear chains of B-1,4 D-glucose subunits that are linked together into parallel chains to form a crystalline structure. These parallel cellulose chains spontaneously bundle together to form cellulose microfibrils (Kumar and Turner, 2015; Carroll and Sommerville, 2009). Each cellulose microfibril is synthesized at the plasma membrane from its glucose subunits by a rosette shaped protein complex containing six cellulose synthase enzymes (Mueller and Brown, 1980). Verification of this rosette shaped structure of the cellulose synthase complex (CSC) came in 1999 when Kimura et al. (1999) successfully visualized CSCs in freeze fractured plasma membranes using immune-gold localization. Upon sequencing of the Arabidopsis thaliana genome, functional genomics was employed to identify ten different CESA genes (Richmond, 2000; Richmond and Somerville, 2000). 
In the primary cell wall of most tissues of Arabidopsis thaliana (the first plant species in which the CESA genes were characterized), the three enzymatic subunits of the cellulose synthase complex are encoded by the CESA1, CESA3, and CESA6 genes (with CESA2 and CESA5 able to substitute for CESA6) in the case of cellulose made in the primary cell wall (Li et al, 2014). Yet, expression of other CESA genes appears to occur in specialized tissues. For example, CESA1, CESA2, CESA3, and CESA9 are the only CESAs highly expressed in the Arabidopsis thaliana embryo. Interestingly a putative null mutation in the CESAl gene allowed primary cell walls to still be made in the embryo, but they were thin and fragmented (Beekman et al, 2002). This implies that another gene was able to substitute for $C E S A 1$, but its encoded enzyme subunit may not function as well as CESA1 in the CSC. In contrast to possible overlap of function of CESAs involved in making primary cell walls depending on tissue type, identification of Arabidopsis thaliana IRX mutants having irregular xylem phenotypes in the inflorescence, followed by the mapping, sequencing, and characterization of the responsible genes, led to identification of CESA4, CESA7, and CESA8 as the genes necessary and sufficient to encode the three subunits of the cellulose synthase complex in the secondary cell wall (Taylor et al, 1999, 2000; Turner and Sommerville, 1997). Knockout of one of these three genes led to the inability to produce cellulose in the secondary cell wall, although cellulose could still be synthesized in the primary cell wall, leading to the conclusion that other members of the CESA family were unable to substitute for BdCESA4, BdCESA7, or BdCESA8 to constitute a functional CSC at the secondary cell wall. 


\section{Hemicellulose Biosynthesis}

Hemicellulose consists of a more complex polysaccharide structure compared to cellulose. In contrast to cellulose's singular makeup of linear glucose subunits, hemicellulose is a branched structure made from several different polysaccharides including xylan, arabinoxylan, glucuronoxylan, xyloglucan, and glucomannan linked in an equatorial configuration (Scheller and Ulvskov, 2010). These polysaccharides are in

turn made from several sugar monomers including mannose, apiose, arabinose, galactose, rhamnose, and xylose, many of which are derived from UDP-GlcUA (Tenhaken and Thulke, 1996). The synthesis of hemicellulose from its sugar subunits occurs at the membrane of the Golgi, and is performed by transmembrane proteins. Upon synthesis, hemicellulose is transported via vesicular trafficking to the plasma membrane. Once there, it can be further transported across the apoplast to the primary or secondary cell wall. There are likely mechanistic discoveries still to be made regarding hemicellulose biosynthesis, but in the application of easing recalcitrance of digestion of plant cell walls to harvest cellulose for fermentation to bioethanol, the presence of hemicellulose is not a substantial problem because its random, amorphous structure makes it easily hydrolyzed (Tong et al, 2012).

\section{Pectin Biosynthesis}

Pectin is present in the middle lamella, primary cell wall, and in low abundance in the secondary cell walls of grasses, and consists of a complex heteropolysaccharide made of galacturonic acid, rhamnogalacturonan I, rhamnogalacturonan II, D-galactose, Larabinose, and D-xylose. The carboxyl groups of galacturonic acid are typically highly 
methyl esterified (Harholt et al, 2010). Those galacturonic acids which are not esterified can exist either as free acids or as calcium, potassium, or sodium salts. Pectins dissolve under high heat and low pH conditions. Furthermore, they are typically highly digestible by bacterial enzymes present in the gut of ruminants. This suggests that pectin does not pose a significant problem in the digestion of vegetative feedstocks by hydrolytic enzymes in biomass conversion processes. In fact, the sugars pectin contains could provide an additional food source to yeast or other microbes used for subsequent fermentation, as long as their gelling temperature is below that used during the fermentation. Pectins provide additional benefits to the plant besides helping to provide mechanical strength and a physical barrier against the outside environment. Upon pectin degradation due to plant pathogenesis, oligogalacturonides are produced, which serve as a trigger in a signaling cascade involving the production of radical oxidative species. These reactive oxygen species activate transcription factors of plant defense related genes (Ferrari et al, 2013).

\section{Lignin Biosynthesis}

In the area of lignin biosynthesis, prior work has shown that phenylalanine is the starting substrate, which is first deaminated by the enzyme PHENYLALANINE AMMONIA LYASE (PAL) to form cinnamic acid. This intermediate undergoes repeated rounds of hydroxylation of its aromatic ring catalyzed by multiple enzymes, followed by phenolic $O$-methylation performed by the CAFFEIC ACID O-METHYL-

TRANSFERASE (COMT) enzyme, and finally, reduction of the side-chain carboxyl on the cinnamaldehydes to an alcohol group catalyzed by the CINNAMYL ALCOHOL DEHYDROGENASE (CAD) enzyme (Boerjan et al, 2003). Depending on the flux of 
intermediates through the lignin biosynthetic pathway, which is affected by feedback modulation, three different monolignol alcohols are synthesized, namely p-coumaryl alcohol, coniferyl alcohol, and sinapyl alcohol. Side groups on these monolignol alcohols can be modified by acylation prior to their assisted transport to the apoplast, where polymerization occurs by radical oxidative coupling (Petrik et al, 2014). The addition of side groups via acylation provides alternate points for cross-linking to occur within lignin subunits, as well as a means for lignin to cross-link to hemicellulose.

\section{Lignin Caused Recalcitrance of Vegetative Biomass}

In the area of easing vegetative biomass recalcitrance to conversion to bioethanol, a major contributor to this recalcitrance is the presence of lignin in the secondary cell walls of plants. If this bottleneck to the use of lignocellulosic feedstocks can be overcome, conversion of senesced plant vegetative material to biofuel has the potential to contribute significantly to global transport fuel demand. The International Energy Agency projects that if $10 \%$ of available agricultural and forestry residues could be converted to biofuel in the year 2030, this could provide approximately $5 \%$ of the projected total transport fuel demand at that time. Greater allocation of global residues to biofuel production, $25 \%$ rather than $10 \%$, could provide $10-15 \%$ of transportation fuel demand by the same year (Eisentraut, 2010).

\section{Research Aims}

Towards the goal of producing plant feedstocks with improved lignin characteristics, we proposed generating and characterizing transgenic Brachypodium distachyon plants as a grass model, using RNAi technology to knock down expression of 
key monolignol biosynthesis enzymes. Given that Brachypodium is a new model system for monocots, this work is novel and will contribute to understanding important aspects of bioenergy crop grass cell walls. As a second research goal, three secondary cell wall specific gene promoters were cloned and thoroughly characterized for their patterns of gene expression in multiple tissues and developmental stages. These promoters, or gene switches, were subcloned into utility monocot transformation vectors. These utility vectors will be made available to the scientific community for use in driving genes of interest in a secondary cell wall-specific manner, specifically in such monocot bioenergy crops as corn, switchgrass, and Miscanthus. 


\section{REFERENCES}

Beeckman, T., Przemeck, G.K.H., Stamatiou, G., Lau, R., Terryn, N., De Rycke, R., Inze', D., Berleth, T. (2002) Genetic Complexity of Cellulose Synthase A Gene Function in Arabidopsis Embryogenesis. Plant Physiology, 130, 1883-1893.

Boerjan, W, Ralph, J, Baucher, M. (2003) Lignin biosynthesis. Annu Rev Plant Biol., 54, 519-46. Review.

Carroll, A., Sommerville, C. (2009). Cellulosic biofuels. Annu. Rev. Plant Biol., 60, $165-182$.

Cosgrove, DJ. (2005) Growth of the plant cell wall. Nat Rev Mol Cell Biol., 6, 850-861.

Eisentraut, A. (2010) Sustainable Production of Second Generation Biofuels: Potential and perspectives in major economies and developing countries. International Energy Agency Informational Paper, 1-221.

Energy in Sweden 2010, Facts and figures Table 46 Total world energy supply, 19902009, Table 48, World power generation by energy resource, 1990-2008 (TWh) nuclear 2,731 TWh in 2008.

Ferrari, S, Savatin, DV, Sicilia, F, Gramegna, G, Cervone, F, Lorenzo, GD. (2013) Oligogalacturonides: plant damage-associated molecular patterns and regulators of growth and development. Front Plant Sci.; 4, Article 49, 1-9.

Harholt, J., Suttangkakul, A., Vibe Scheller, H. (2010). Biosynthesis of Pectin. Plant Physiology, 153, 384-395.

Kimura, S., Laosinchai, W., Itoh, T., Cui, X., Linder, C.R., Brown, R.M., Jr. (1999). Immunogold labeling of rosette terminal cellulose-synthesizing complexes in the vascular plant Vigna angularis. Plant Cell, 11, 2075-2086. 
Kumar, M., Turner, S. (2015). Plant cellulose synthesis: CESA proteins crossing kingdoms. Phytochemistry 112, 91-99.

Li, S., Bashline, L., Lei, L., Gu, Y. (2014) Cellulose Synthesis and Its Regulation. The Arabidopsis Book. 12: e0169, 1-21.

Mueller, S.C., Brown, R.M. (1980). Evidence for an intramembrane component associated with a cellulose microfibril-synthesizing complex in higher-plants. $J$. Cell Biol., 84, 315-326.

Pederson, J.F., Vogel, K.P., Funnell, D.L., (2005). Impact of Reduced Lignin on Plant Fitness. Crop Science. 45, 812-819.

Petrik, DL, Karlen, SD, Cass, CL, Padmakshan, D, Lu, F, Liu, S, Le Bris, P, Antelme, S, Santoro, N, Wilkerson, CG, Sibout, R, Lapierre, C, Ralph, J, Sedbrook, JC. (2014) $p$-Coumaroyl-CoA:monolignol transferase (PMT) acts specifically in the lignin biosynthetic pathway in Brachypodium distachyon. Plant J.,77(5), 713-26.

Reiter, WD. (2002) Biosynthesis and properties of the plant cell wall. Curr Opin Plant Biol. 5(6), 536-42. Review.

Richmond, T. (2000) Higher plant cellulose synthases. Genome Biol., 1, 1-6.

Richmond, T.A., Somerville, C.R. (2000). The cellulose synthase superfamily. Plant Physiol., 124, 495-498.

Scheller, H.V., Ulvskov P. (2010) Hemicelluloses. Аппи Rev Plant Biol, 61, 263-289.

Somerville, C, Bauer, S, Brininstool, G, Facette, M, Hamann, T, Milne, J, Osborne, E, Paredez, A, Persson, S, Raab, T, Vorwerk, S, Youngs, H. (2004) Toward a systems approach to understanding plant cell walls. Science, 306, 2206-2211.

Taylor, N.G., Laurie, S., Turner, S.R. (2000) Multiple cellulose synthase catalytic subunits are required for cellulose synthesis in Arabidopsis. Plant Cell, 12, 2529-2539. 
Taylor, N.G., Scheible, W.R., Cutler, S., Somerville, C.R., Turner, S.R. (1999) The irregular xylem 3 locus of Arabidopsis encodes a cellulose synthase required for secondary cell wall synthesis. Plant Cell, 11, 769-779.

Tenenbaum, D.J. (2008). Food vs. Fuel: Diversion of Crops Could Cause More Hunger. Environmental Health Perspectives, 116(6), A254-A257.

Thenhaken, R., Thulke, O. (1996). Cloning of an Enzyme That Synthesizes a Key Nucleotide Sugar Precursor of Hemicellulose Biosynthesis from Soybean: UDPGlucose Dehydrogenase. Plant Physiol., 112, 1127-1134.

Tong, Z., Pullammanappallil, P., Teixeira, A. (2012). How Ethanol is Made from Cellulosic Biomass. Document AE493, Department of Agricultural and Biological Engineering, Florida Cooperative Extension Service, Institute of Food and Agricultural Sciences, University of Florida, 1-4.

Turner, S.R, Somerville, C.R. (1997). Collapsed xylem phenotype of Arabidopsis identifies mutants deficient in cellulose deposition in the secondary cell wall. Plant Cell, 9, 689-701.

Xiao, C., Anderson, C.T. (2013) Roles of pectin in biomass yield and processing for biofuels. Front Plant Sci., 4, Article 67, 1-7.

Zhao, H.Y., Wei, J.H., Song, Y.R. (2004) Advances in research on lignin biosynthesis and its genetic engineering. Zhi Wu Sheng Li Yu Fen Zi Sheng Wu Xue Xue Bao, 4, 361-70. Review. 
CHAPTER II

\title{
P-COUMAROYL-COA:MONOLIGNOL TRANSFERASE (PMT) ACTS SPECIFICALLY IN THE LIGNIN BIOSYNTHETIC PATHWAY IN
}

\author{
BRACHYPODIUM DISTACHYON
}

\begin{abstract}
Summary
Grass lignins contain substantial amounts of $p$-coumarate $(p \mathrm{CA})$ acylating the sidechains of the phenylpropanoid polymer backbone. An acyltransferase, named $p$ coumaroyl-CoA:monolignol transferase (OsPMT), that could acylate monolignols with $p \mathrm{CA}$ in vitro was recently identified from rice. In planta, such monolignol- $p \mathrm{CA}$ conjugates become incorporated into lignin via oxidative radical coupling, thereby generating the observed $p \mathrm{CA}$ appendages. However, $p$-coumarates also acylate arabinoxylans in grasses. To test the authenticity of PMT as a lignin biosynthetic pathway enzyme, we examined Brachypodium distachyon plants misregulated in the putative BdPMT gene. Using newly developed cell wall analytical methods, we determined that the transferase was specifically involved in lignin acylation. A sodium azide-generated Bdpmt-1 missense mutant had no $(<0.5 \%)$ residual $p$ CA on lignin, and BdPMT RNAi plants had levels as low as $10 \%$ of wild-type, whereas the amounts of $p \mathrm{CA}$ acylating arabinosyl units on arabinoxylans in these PMT-misregulated plants remained unchanged. $p \mathrm{CA}$ acylation of lignin from $B d P M T$ overexpressing plants was found to be more than
\end{abstract}


three-fold higher than that of wild-type, but again the level on arabinosyl units remained unchanged. Taken together, these data are consistent with a defined role for grass $P M T$ genes in encoding BAHD acyltransferases that specifically acylate monolignols with $p \mathrm{CA}$, producing monolignol $p$-coumarate conjugates that are used for lignification in planta.

Deborah L. Petrik, Steven D. Karlen, Cynthia L. Cass, Dharshana Padmakshan, Fachuang Lu, Sarah Liu, Philippe Le Bris, Sébastien Antelme, Nick Santoro, Curtis G. Wilkerson, Richard Sibout, Catherine Lapierre, John Ralph, and John C. Sedbrook. This article was accepted and published by The Plant Journal in 2014.

Petrik, D.L., Karlen, S.D., Cass, C.L., Padmakshan, D., Lu, F., Liu, S., Le Bris, P., Antelme, S., Santoro, N., Wilkerson, C.G., Sibout, R., Lapierre, C., Ralph, J., Sedbrook, J.C. (2014) $p$-Coumaroyl-CoA monolignol transferase (PMT) acts specifically in the lignin biosynthetic pathway in Brachypodium distachyon. Plant J., 77(5), 713-26.

Note: Additional supporting information may be found in the online version of this article.

http://www.ncbi.nlm.nih.gov/pmc/articles/PMC4282527 


\section{Introduction}

Lignocellulosic biomass from grasses could serve as a major feedstock for the generation of liquid biofuels, contributing more than half of the envisioned one billion tons of biomass available in the United States each year (Perlack et al., 2005; Carroll and Somerville, 2009; U.S. Department of Energy, 2011). Lignocellulosic biomass typically refers to the harvestable plant portions not consumed by humans (e.g., for grasses, the stems and leaves) and is primarily composed of secondary cell walls consisting of the polysaccharides cellulose and hemicelluloses embedded within the heterogeneous phenolic polymer lignin (Pauly and Keegstra, 2008). Lignin polymer "backbones" in grasses are composed of guaiacyl $(\mathrm{G})$ and syringyl $(\mathrm{S})$ units (derived from the monolignols coniferyl alcohol and sinapyl alcohol, respectively), together with a lesser amount of $p$-hydroxyphenyl $(\mathrm{H})$ units (derived from $p$-coumaryl alcohol), interconnected by $\beta-\mathrm{O}-4$-aryl ether and other inter-unit bonds, and cross-linked to hemicelluloses by ferulate (Ralph et al., 1995; Boerjan et al., 2003; Ralph et al., 2004; Zhang et al., 2009; Lapierre, 2010).

C3 grasses such as rice, wheat, rye, oat, and bamboo, and C4 grasses such as corn, switchgrass, and sorghum, all have lignin polymers that are partially acylated by $p$ coumarate "appendages" and, as more recently shown, by acetate (Ralph, 2010; Ralph and Landucci, 2010; del Río et al., 2012). It is now well established that such lignin acylation results from in planta lignification using pre-acylated monolignols (Ralph et al., 1994; Lu and Ralph, 1999; 2002; 2008; Hatfield et al., 2009; Ralph, 2010; Withers et $a l ., 2012)$; in the case of $p$-coumarate, this is via coniferyl and sinapyl $p$-coumarate ester 
conjugates 3 (Figure 1). As the $p$-coumarate acylates the monolignol $\gamma-\mathrm{OH}$, the resulting lignin is partially $\gamma$-p-coumaroylated (c.f., 5, Figure 1) (Ralph et al., 1994; Ralph, 2010). Although the role for these conjugated monolignols remains somewhat mysterious, evidence is that they are synthesized in the cell and exported to the wall along with the traditional monolignols $\mathbf{1}$, coniferyl and sinapyl alcohols (along with smaller amounts of $p$-coumaryl alcohol) where they undergo the radical coupling and cross-coupling reactions, mainly by so-called endwise polymerization in which the monomer radical couples to the growing polymer radical (Ralph, 2010). It was initially puzzling but is now clear why the $p$-coumarate moieties, as phenolic entities, remain as free-phenolic pendant units on the polymer and do not themselves undergo radical coupling reactions. Although they readily form radicals, such radicals preferentially undergo radical transfer reactions with phenols that produce more stable phenolic radicals, such as the monolignols themselves and the guaiacyl and syringyl phenolic endunits on the growing polymer, i.e., they undergo radical transfer reactions rather than participating in radical coupling (Takahama et al., 1996; Ralph et al., 2004; Hatfield et al., 2008; Ralph, 2010). This has been demonstrated in a model system involving the typically slow peroxidase- $\mathrm{H}_{2} \mathrm{O}_{2}$-mediated dehydrodimerization of sinapyl alcohol that is significantly sped up in the presence of catalytic levels of a $p$-coumarate ester (Ralph et al., 2004; Hatfield et al., 2008). Therefore, the polymerization whether from the monolignols $\mathbf{1}$ or from the $p$-coumaroylated monolignols $\mathbf{3}$, is solely via the monolignol moiety.

Current preliminary evidence, and more extensive evidence with monolignol acetates, shows that acylation does not greatly affect the coupling propensity of the 
monolignol moiety, i.e., radical coupling produces the same array of coupling products in approximately the same ratios whether the monolignols are acylated or not ( $\mathrm{Lu}$ and Ralph, 2008). The one difference is that, for the product of monolignol $\beta-\beta$-coupling or dehydrodimerization, the post-coupling rearomatization pathways are necessarily different because the $\gamma-\mathrm{OH}$ is no longer available for internal trapping of the quinone methide intermediate.

Recently, we identified from rice the first putative monolignol transferase gene, OsPMT. Heterologously expressed OsPMT had all the properties anticipated for a $p$ coumaroyl-CoA:monolignol transferase (PMT) enzyme responsible for $p$-coumaroylation of monolignols (Figure 1) (Withers et al., 2012). The enzyme produced, with favorable kinetics, monolignol $p$-coumarate conjugates 3 from $p$-coumaroyl-CoA 2 and $p$ coumaryl, coniferyl, and sinapyl alcohols 1H, 1G, and 1S (Hatfield et al., 2009; Withers et al., 2012). In this paper, we demonstrate the veracity of the hypothesized in planta action by misregulation of the closest gene homolog in Brachypodium, and furthermore demonstrate its selectivity for $p$-coumaroylation of monolignols, and thereby lignin, over the arabinoxylans that are also partially $p$-coumaroylated in grasses.

\section{Results and Discussion}

It was recently shown that bacterially expressed and purified OsPMT protein could acylate monolignols with $p$-coumarate ( $p \mathrm{CA})$, producing monolignol- $p \mathrm{CA}$ ester conjugates (Withers et al., 2012). We hypothesized that, in planta, this enzyme is therefore responsible for biosynthesizing the monolignol $p$-coumarate conjugates that become incorporated into the lignin polymer by oxidative radical coupling reactions 
(Figure 1). To validate the in planta activity of PMT, we employed a reverse genetic approach, using the model grass Brachypodium distachyon (Brachypodium).

To identify the likely Brachypodium PMT gene, the OsPMT (LOC_Os01g18744.1) amino acid sequence was used as a query in a BLASTP search of the Brachypodium proteome (http://www.gramene/org; http://mips.helmholtzmuenchen.de/plant/brachypodium/). The predicted Bradi2g36910 protein was found to have the highest sequence homology to OsPMT, sharing $63 \%$ amino acid sequence identity and $75 \%$ similarity. Recently published phylogenetic trees containing both Brachypodium and rice BAHD acyltransferases show that Bradi2g36910 is the most closely related Brachypodium protein to OsPMT (Bartley et al., 2013; Molinari et al., 2013).

As the Bradi2g36910 coding sequence was only partially supported by published expressed sequence tag sequences (Vogel et al., 2006), we generated and sequenced Bradi2g36910 cDNA clones (GenBank accession no. HG421450), from Brachypodium inbred line Bd21-3 stem tissue transcripts, finding the ORF sequence to be $100 \%$ identical to the annotated gene model Bradi2g36910.1.

qRT-PCR analysis was performed on transcripts isolated from various plant tissues, revealing that Bradi2g36910 (hereafter referred to as $B d P M T$ ) was expressed in all organs tested (spikelet, stem internodes, leaves, and root), with highest expression levels in the spikelet (Figure 2a). Co-expression analysis using PlaNet (http://aranet.mpimp-golm.mpg.de/index.html), a web-based platform that predicts transcriptomic co-expression networks based on temporal and spatial gene expression data (Mutwil et al., 2011; Harrington et al., 2012), revealed that BdPMT expression 
clustered with those of other predicted lignin biosynthetic genes including Phenylalanine Ammonia Lyase (PAL; Bradi3g49250 and Bradi3g49260), Cinnamoyl-CoA Reductase (CCR; Bradi3g36887), and Caffeic acid O-Methyltransferase (COMT; Bradi3g16530) (Table S1).

To study how altered $B d P M T$ expression and function affects cell wall composition and structure as well as plant growth, we generated Brachypodium BdPMT RNA interference (RNAi) as well as overexpression (OX) lines. We also identified a Brachypodium Bdpmt mutant in a sodium azide-mutagenized population generated by the Institut National de la Recherche Agronomique (INRA; Dalmais et al., 2013).

For the RNAi approach, two different hairpin constructs were generated, using $B d P M T$ coding sequences that were chosen based on their relatively low homologies to other Brachypodium genes (Figure S1). RNAi construct \#1 (BdPMT RNAi \#1) consisted of a 301 base pair fragment derived from the 3' UTR of the BdPMT coding sequence, whereas BdPMT RNAi \#2 consisted of a 258 base pair fragment derived from coding sequence positioned just upstream of the translational termination site (Figure 2b). These constructs were transformed into embryo-derived callus using Agrobacterium tumefaciens, from which transgenic plants were regenerated on hygromycin selection media. qRT-PCR analysis was performed on transcripts isolated from the stems of $\mathrm{T}_{1}$ and $\mathrm{T}_{2}$ generation plants from four independent transgenic lines, revealing average $B d P M T$ transcript level reductions of $53 \%$ to $92 \%$, i.e., residual levels of $47 \%$ to just $8 \%$ (Table S2).

The Brachypodium Bdpmt-1 mutant was isolated serendipitously during a Targeting Induced Local Lesions in Genomes (TILLING) screen for another gene 
(Bouvier d'Yvoire et al., 2013; Dalmais et al., 2013). One of the lines isolated in that screen had cell wall compositional changes consistent with those expected for a pmt mutant (described below). Subsequent DNA sequencing of the BdPMT gene in that line (hereafter named $B d p m t-1$ ) revealed a nucleotide base substitution at position 563 of the Bradi2g36910 ORF (guanine replaced by adenine), resulting in codon 188 of the 450codon ORF changed to encode aspartic acid instead of glycine (G188D). Incidentally, this base substitution disrupts a NarI restriction enzyme site, which allows one to track the mutation with a Cleaved Amplified Polymorphic Sequence (CAPS) marker (Neff et al., 2002).

The mutated codon in Bdpmt-1 is positioned three codons downstream of that encoding aspartic acid in the highly conserved HXXXD motif, which is considered the catalytic center of BAHD acyltransferases (Figure 2c) (St-Pierre and De Luca, 2000; D'Auria, 2006). Altering or deleting the HXXXD motif in BAHD acyltransferases was found to greatly reduce enzyme activities of those proteins (Suzuki et al., 2003; Bayer et al., 2004; D'Auria, 2006). A scan of the amino acid sequences of 20 known and putative BAHD acyltransferases that fall into five clades based on phylogenetic analysis (D'Auria, 2006) revealed that proteins belonging to Clade V (to which BdPMT belongs) all have a glycine at the position mutated in Bdpmt-1. Proteins in clades I through IV have a serine $(\mathrm{S})$, glycine $(\mathrm{G})$, or threonine $(\mathrm{T})$ at that position (Figure $2 \mathrm{c})$. The amino acids $\mathrm{S}, \mathrm{G}$, and T all have small and uncharged side-chains, whereas the aspartic acid (D) that substitutes for glycine in the Bdpmt-1 mutant protein has a negatively charged and slightly larger side-chain (Betts and Russell, 2003). 
Like $B d P M T$ RNAi plants, $B d p m t-1$ mutant plants grew similar to WT and empty vector transgenic control plants grown side by side under our controlled growth chamber conditions, with no obvious morphological differences (Figure 3a, b; Figure S2).

To determine if cell wall biomass from the aforementioned Bdpmt mutants had reduced levels of ester-linked $p \mathrm{CA}$, as was our hypothesis, pulverized senesced stems were solvent-extracted then subjected to mild alkaline hydrolysis. Figure 4a and Table S2 show that $B d p m t-1$ mutant plant cell walls had nearly an $80 \%$ reduction in the amount of released $p$ CA. Stem cell walls from all four RNAi lines also had reduced amounts of released $p \mathrm{CA}$ compared to $\mathrm{WT}$, with the relative levels of reduction coinciding with the relative reductions in BdPMT transcript levels. For example, Line 4B stems had the highest levels of reduction in $p C A$ and $B d P M T$ transcripts (51\% and 92\%, respectively) whereas Line 8A stems had the lowest levels of reduction (3\% and 53\%, respectively). The $3 \% p \mathrm{CA}$ reduction from Line $8 \mathrm{~A}$ plant cell walls was not significantly different from that of WT, whereas the $14 \% p \mathrm{CA}$ reduction from Line $1 \mathrm{~A}$ cell walls was significantly different; Line 1A stems had a 58\% reduction in BdPMT transcripts. These data suggest that the 53\% reduction in BdPMT transcript levels represents the approximate threshold at which significant cell wall compositional changes occur.

Analysis of $p$-coumarate levels is complicated by the fact that, unlike ferulate in Brachypodium mature stems, $p$-coumarate acylates both cell wall hemicelluloses (more specifically, arabinoxylans) and lignin (Mueller-Harvey et al., 1986). Although mild alkaline hydrolysis clearly detected reduced amounts of $p \mathrm{CA}$ liberated from alkali-treated Bdpmt-1 and BdPMT RNAi cell wall biomass compared to WT (Figure 4a; Table S2), it remained unclear whether that reduction was due to a decrease of the $p \mathrm{CA}$ ester levels on 
lignin and/or on arabinoxylan. To unambiguously parse apart these possibilities, we employed two methods: 1) DFRC (Derivatization Followed by Reductive Cleavage) (Lu and Ralph, 1997; Lu and Ralph, 1998c; Lu and Ralph, 1999), which cleaves $\beta$-aryl ether bonds in lignin while leaving ester bonds intact, thereby releasing diagnostic ligninderived coniferyl and sinapyl dihydro-p-coumarate conjugates $\mathbf{8}$ (Figure 5a), and 2) a newly-developed mild acidolysis method that allows for the purification and quantification of $p \mathrm{CA}$-arabinose $\mathbf{1 0}$ and FA-arabinose $\mathbf{1 1}$ ester moieties originating from arabinoxylans (Figure 5b).

The DFRC method releases monolignol units retaining their $\gamma$-acylation by $p$ CA, (conjugates $\mathbf{8}$ in Figure 5a), products that are obviously exclusively from lignin. In WT Brachypodium, in which the lignin has a $\sim 60: 40 \mathrm{~S}: \mathrm{G}$ ratio, the $p \mathrm{CA}$ was found on the syringyl units with no detectable amount of the $p \mathrm{CA}$ on guaiacyl units (Figure S3). Biomass stem tissue samples from Bdpmt-1, BdPMT RNAi Line 4B and Line 7A plants were found to have $0 \%(<0.5 \%), 8 \%$, and $50 \%$ residual lignin $p$ CA levels, respectively (Figure 4b; Table S3). The Bdpmt-1 mutant allele appears to be essentially a null, yielding a negligible amount of lignin-derived $p \mathrm{CA}$. These data strongly suggest that BdPMT is solely responsible for placing $p C A$ on stem lignin in Brachypodium.

Using a mild acidolysis method (Figure 5b; Figure S4), we quantified $p$ CAarabinose 10 and FA-arabinose 11 released from stem tissue biomass, these moieties being derived exclusively from the hemicellulose arabinoxylan. The mild acidolysis method released essentially the same amounts of $p \mathrm{CA}$-arabinose and FA-arabinose from Bdpmt-1 and BdPMT RNAi Line 4B stem cell wall samples as was released from WT samples (Figure 4c; Table S3). This result signifies that another enzyme(s) and not 
BdPMT acylates arabinosyl units with $p \mathrm{CA}$ and $\mathrm{FA}$, one of those enzymes perhaps being the Brachypodium orthologue to the rice OsAT10 enzyme (Bartley et al., 2013). Taken together with the DFRC results, these data unambiguously establish that $B d P M T$ is responsible for the acylation of lignin with $p \mathrm{CA}$ in planta and is not involved in the incorporation of $p \mathrm{CA}$ into hemicelluloses.

In order to obtain a more detailed picture of the cell wall compositional and structural differences between Bdpmt-1, BdPMT RNAi, and WT plants, whole cell walls of senesced stems were analyzed by gel-state 2D NMR (Kim and Ralph, 2010). Figure 6, top row, shows the spectral aromatic fingerprints obtained by this method, profiling S, G, and $\mathrm{H}$ lignin backbone units as well as pendent moieties, $p \mathrm{CA}$, FA, and tricin, in the cell wall; the latter mobile units on the periphery of polymer chains are over-represented due to their slower spin relaxation than units in the polymer backbone. As with total saponified hydroxycinnamate measurements, these spectra, being from the whole wall material, reflect the total levels of $p \mathrm{CA}$ and $\mathrm{FA}$ in the wall, i.e., without distinction between those components on lignins vs polysaccharides.

Compared to WT, and consistent with the alkaline treatment analysis results detailed above, the correlation peaks for $p C A$ are clearly reduced in Bdpmt- 1 and BdPMT RNAi Line 4B, whereas those of FA appear unchanged. In addition, the peaks for syringyl units are relatively lower in Line 4B and Bdpmt-1 cell walls compared to WT, whereas those for guaiacyl units and $p$-hydroxyphenyl units appear relatively unchanged, denoting a relative decrease in $\mathrm{S}$ lignin in Line $4 \mathrm{~B}$ cell walls and a reduced S/G units ratio. This altered $S / G$ units ratio result was corroborated by thioacidolysis data, where 
we found Bdpmt- 1 as well as BdPMT RNAi plant cell walls had reduced S/G units ratios compared to WT (Table 1).

The lignin-bound $p \mathrm{CA}$ (and FA moieties, if there were any) are more clearly delineated after enzymatic digestion of the wall polysaccharides using crude polysaccharidases (Chang et al., 1975; Wagner et al., 2007). The resulting 'milled wood enzyme lignins' (MWELs) are lignin-enriched (retaining essentially the entire lignin component), and are devoid of the hemicellulosic polysaccharides that are also acylated with $p \mathrm{CA}$ and FA, i.e., most or all of the hydroxycinnamates remaining are on the lignin component only. NMR spectra of these CELs compellingly confirm the conclusions made from examining the saponification, polysaccharide-specific, and lignin-specific analyses above. Consistent with ferulates' solely acylating wall arabinoxylans, signals corresponding to ferulate are absent in both WT and mutant lines, with the possible exception of a trace in the overexpression line (BdPMT OX), which bears further scrutiny. $p$-Coumarates remain, but at a lower level, because those acylating arabinoxylans are no longer in this fraction and only those acylating lignin remain. Comparisons to the WT material indicated that $11 \%$, and $0 \%$ residual levels (compared to WT) remain in BdPMT RNAi Line 4B and the Bdpmt-1 mutant. Such data are in line with the reduced levels in these materials determined by the lignin-specific DFRC method. The data from both analysis methods therefore compellingly demonstrate that the PMT activity is associated solely with $p$-coumaroylation of lignin and not arabinoxylan.

To more fully explore how PMT influences lignin biosynthetic fluxes and cell wall composition, we generated transgenic plants overexpressing $B d P M T$ in the form of 
an EYFP:BdPMT fusion protein, with expression driven by the maize UBIQUITIN promoter and intron; these lines are hereafter referred to as BdPMT OX. qRT-PCR analysis of $\mathrm{T}_{2}$ generation plants from two independent transformation events (initially chosen as having high expression based on EYFP fluorescence and Western blot analysis; Figure S5a) revealed $B d P M T$ transcript levels to be, on average, 35-fold or more higher than in WT (Table S2). In our climate-controlled growth chambers, BdPMT OX plants grew like WT, attaining comparable culm heights and above-ground biomass weights (Figure 3a, b; Figure S5b, c). However, for five lines with the highest BdPMT expression including BdPMT OX lines 57A and 67B but not 23A, a small percentage of the plants were stunted. This stunted phenotype displayed high penetrance (was commonly observed) when BdPMT OX plants were grown in a greenhouse, where growth conditions were variable and perhaps more challenging to the plants (Figure S5d).

In growth chambers as well as in the greenhouse, BdPMT OX leaf collars commonly became blackened (never observed with WT) and leaf blades grew along the stems, whereas WT leaf blades grew at about $60^{\circ}$ angles from the stems (Figure S5e, f). The blackened collar phenotype might be due to a pathogen infection, deposition of a phenolic compound, and/or spontaneous necrosis. We note that all of the gene expression experiments and cell wall analyses described herein were performed on $B d P M T$ OX plants that grew to be the same sizes as WT plants grown side by side in climatecontrolled chambers.

Whereas BdPMT OX and WT stem cross-sections revealed no morphological differences and no collapsed vascular bundle cells (Figure 7a-d), BdPMT OX stem section tissues stained considerably less with both phloroglucinol (Weisner test) and 
Mäule reagent compared to WT (Figure 7a-d). Phloroglucinol stains cinnamaldehyde end groups of lignin, whereas Mäule reagent is used as a diagnostic of S lignin units (Lin and Dence, 1992). Consistent with these observed staining differences, Klason lignin analysis revealed that senesced $B d P M T$ OX stems contained, on average, $23 \%$ less lignin than WT stems (Table 1). This reduced lignin was corroborated by gel-state 2D NMR analysis (Figure 6), and may be due to excessive BdPMT activity drawing $p$-coumaroyl-CoA away from monolignol biosynthesis, thereby lowering the amounts of monolignols available for polymerization. We speculate the above-noted stunted growth phenotype observed with the highest overexpressing BdPMT OX plants might be due to lignin amounts being reduced below levels necessary for normal plant growth.

Using the above-mentioned mild alkaline hydrolysis, cell wall $p \mathrm{CA}$ levels were found to be more than two-fold higher in BdPMT OX plants stem biomass compared to WT (Figure 4a; Table S2). As expected, the increased amounts of $p$ CA were determined to be exclusively due to higher $p \mathrm{CA}$ levels on lignin (3.4-fold higher, Table S3; Figure S3) and not on polysaccharides (Figure 4b, c; Table S3), reinforcing our conclusion that $B d P M T$ exclusively catalyzes the acylation of monolignols. With the increased level of $p C A$, a small but notable amount of acylation on the guaiacyl subunits was observed (Figure S3); p-coumaroylation was, however, found to favor S over G units ( 99:1).

FA levels were found to be as much as $40 \%$ higher in BdPMT OX stem biomass compared to WT. These higher FA levels mirrored the slightly lower FA levels detected in the Bdpmt-1 loss of function mutant (Figure 4a; Table S2). At least part of the relative cell wall FA content increase can be explained as being a consequence of the reduced amounts of lignin in BdPMT OX plant stems; ferulate in the cell wall is on 
polysaccharides (arabinoxylans), so an increase in the ratio of arabinoxylan to lignin would lead to a relative FA level increase. It seems unlikely that these altered FA levels are directly due to altered $B d P M T$ activity, given that in vitro studies of OsPMT substrate specificity revealed that the PMT enzyme utilizes the thioester feruloyl-CoA only poorly as a substrate (Withers et al., 2012). We cannot rule out the possibility that the expression and/or activity of a currently unknown transferase responsible for feruloylating arabinosyl units on arabinoxylans may be altered in the $B d P M T$ mutants, or that $P M T$ related flux alterations in the phenylpropanoid biosynthetic pathway result in altered FA availability and/or incorporation.

To determine how the $B d P M T$ misexpression-related cell wall alterations affect biomass digestibility, we first subjected the WT and BdPMT OX extract-free senesced stems to simple cellulolysis assays, as previously described (Berthet et al., 2011). The susceptibility of stem cell walls to enzymatic hydrolysis was roughly evaluated by the induced weight loss. Comparing BdPMT OX to WT, we observed a $33 \%$ higher weight loss upon hydrolysis with a commercial cellulase preparation containing both cellulase and hemicellulase activities (mean weight loss from BdPMT OX samples $45.6 \pm 1.9$, versus $34.3 \pm 1.2$ for $\mathrm{WT}$ samples; $\mathrm{p}<0.0001 ; \mathrm{n}=5$ ). This result was consistent with an expectation that $B d P M T$ OX biomass would have improved digestibility owing to a significant reduction in cell wall lignin (Chen and Dixon, 2007; Chapple et al., 2007; Fu et al., 2011).

As a more encompassing evaluation of cell wall degradability, we subjected pulverized stem biomass to a range of pretreatments and enzyme hydrolysis using a highthroughput lignocelluloses digestibility assay (Santoro et al., 2010). With the exception of 
$62 \mathrm{mM} \mathrm{NaOH}$, these methods were designed to be mild and incomplete so as to identify possible differences in rates of biomass digestion. We found BdPMT OX senesced stem tissue to consistently have higher cell wall polysaccharides sugar release compared to controls, in particular with base pretreatments (Figure 8; on average, $21 \%$ to $36 \%$ more glucose and $10 \%$ to $69 \%$ more pentose sugars released with $62 \mathrm{mM}$ and $6.2 \mathrm{mM} \mathrm{NaOH}$, respectively). By contrast, the amounts of sugars released from BdPMT RNAi and $B d p m t-1$ tissues were not consistently different from controls, suggesting that the abolishment of $p \mathrm{CA}$ on lignin has limited if any effects on stem biomass digestibility (Figure 8).

\section{Conclusion}

Diagnostic analytical methods provide compelling support for our contention that the $P M T$ gene $B d P M T$ identified in Brachypodium, a homolog of the $O S P M T$ gene in rice, is specifically involved in the acylation of monolignols with $p$-coumarate. Its upregulation roughly doubles the total $p \mathrm{CA}$ and more than triples the $p \mathrm{CA}$ on lignin level. Conversely, RNAi downregulation results in $p \mathrm{CA}$ total levels down to as low as $50 \%$, with $\sim 10 \%$ on lignin, whereas a PMT mutant likely to be a null, with $\sim 24 \%$ total $p \mathrm{CA}$, has zero (or at least $<0.5 \%$ ) on lignin. In all cases, $p \mathrm{CA}$ levels on arabinoxylan remain statistically unchanged. Thus, we appear to have finally identified and authenticated the first transferase, PMT, involved in acylating monolignols. BdPMT OX plant biomass was found to have about $23 \%$ less lignin compared to WT and a higher S:G lignin ratio; Bdpmt loss of function mutants had a lower S:G lignin ratio, suggesting $P M T$ integrally affects phenylpropanoid biosynthetic fluxes in grasses. 


\section{Experimental Procedures}

\section{Transgenic Plant Generation}

Two BdPMT RNAi constructs were generated by PCR amplification of Bradi2g36910 coding sequences from Brachypodium accession $\mathrm{Bd} 21-3$ purified genomic DNA using the primer pairs listed in Table S4. The PCR products were restriction digested and cloned into both the BamHI-AscI and KpnI-SpeI sites of the pStarling vector (http://www.plantindustry.csiro.au/RNAi/vectors.htm). The resulting hairpin cassettes were removed as NotI fragments and ligated into the pWBVec8 binary vector backbone (Wang et al., 1998).

The BdPMT OX construct (Zea mays Ubiqitin-1 promoter:EYFP:BdPMT) was generated by performing Reverse Transcription-PCR (RT-PCR) on Bd21-3 stem RNA using oligo(dT) ${ }_{18}$, then amplifying the $1.35 \mathrm{~kb}$ Bradi2g36910 ORF. The PCR product was digested with BamHI-XhoI, cloned into pENTR2B, then Gateway (Invitrogen) cloned into a modified pH7WGY2 (Karimi et al., 2002) binary vector that had the 35S promoter replaced with the Zea mays Ubiquitin-1 promoter plus intron 1 from pStarling (Christensen and Quail, 1996). All constructs were sequenced to validate accuracy.

Plants harboring the $B d P M T$ RNAi or $B d P M T$ OX construct were regenerated from Bd21-3 embryonic callus tissue transformed using Agrobacterium tumefaciens strain AGL-1, as described by Vogel and Hill (2008); media were supplemented with 40 U/ml hygromycin B (Phytotechnology Laboratories).

Transgenic BdPMT RNAi plants were identified and confirmed by both seed selection on hygromycin and PCR amplification of RNAi construct portions from leaf genomic DNA using the ExtractNAmp Plant PCR kit (Sigma-Aldrich) and the following 
primers: pStarling_F1 + pStarling_R1 and pStarling_F2 + pStarling_R2 flanking BdPMT RNAi DNA in the sense and antisense orientations, respectively.

BdPMT OX plants were identified by tracking EYFP fluorescence from the EYFP:BdPMT fusion protein using a Leica MZ8 fluorescence dissecting scope. The EYFP:BdPMT protein in these plants was found to be the expected size based on Western blot analysis of stem tissue protein extracts detected with an anti-YFP antibody $(1: 2,500$

dilution, Allele Biotech catalog \# ABG-MP-MMGFP10; secondary antibody: 1:5,000 goat anti-mouse IgG-HRP, Thermofisher catalog \# 31430).

\section{Seed Sterilization and Plant Growth}

Seeds were surface sterilized and plated on selective plates $(1.5 \%$ agar/one halfstrength Murashige and Skoog salts (Caisson Laboratories)/40 U/mL hygromycin B), stratified for three days $\left(4^{\circ} \mathrm{C}\right.$, dark), then moved to a growth chamber $\left(22^{\circ} \mathrm{C}, 16 \mathrm{~h}\right.$ light $)$ until hygromycin selection was apparent.

Plants were grown in a 50:50 mix of SunGro Rediearth and MetroMix 510 soil in 4 inch pots in growth chambers $\left(20 \mathrm{~h}\right.$ light: $4 \mathrm{~h}$ dark photoperiod, $22^{\circ} \mathrm{C}, 50 \%$ humidity). Control plants were either WT Bd21-3 seedlings plated on non-selective plates or planted directly in soil, or hygromycin-selected plants harboring a Zea mays Ubiquitin-1 promoter with intron driving GUSPlus (Cambia Labs) in pWBVec8. The UBIprom:GUS control was used for the Klason lignin analysis and the digestibility analyses. 


\section{Quantitative RT-PCR (qRT-PCR) and RNA-Seq}

Total stem RNA was extracted from the top two internodes of transgenic and control plants by grinding in liquid nitrogen, followed by RNA extraction using the Plant RNeasy Extraction Kit (Qiagen Ltd.) following the manufacturer's protocol. $0.5 \mu \mathrm{g}$ of DNaseI-treated (Fermentas) RNA was reverse transcribed using oligo(dT) ${ }_{18}$ in a $20 \mu \mathrm{L}$ MMLV (Promega) reaction volume.

BdPMT expression analysis was performed by qRT-PCR using a DyNAmo HS SYBR Green qPCR kit (Thermo-Fisher), cDNA samples diluted to $10 \mathrm{ng} / \mu \mathrm{L}$ and primers listed in Table S4. Thermal cycling conditions: $95{ }^{\circ} \mathrm{C}$ for $6 \mathrm{~min} ; 40$ cycles of $95{ }^{\circ} \mathrm{C}$ for 30 $\mathrm{s}, 60{ }^{\circ} \mathrm{C}$ for $30 \mathrm{~s}, 72{ }^{\circ} \mathrm{C}$ for $30 \mathrm{~s}$; followed by a dissociation stage $95{ }^{\circ} \mathrm{C}$ for $15 \mathrm{~s}, 60{ }^{\circ} \mathrm{C}$ for $30 \mathrm{~s}, 95^{\circ} \mathrm{C}$ for $15 \mathrm{~s}$. PCR reactions were analyzed in triplicate by an Applied Biosystems 7300 Real Time PCR system. Relative expression ratios of target genes were determined by normalizing to wild-type samples using an efficiency calibrated model (Pfaffl, 2001; Equation 1 in Yuan et al., 2006); BdUBC18 (Bradi4g00660) or EF1 $\alpha$ (Bradi1g06860) were used as reference genes. Primer efficiency (E), defined as $2^{-(1 / \text { slope })}$, was calculated from $\log _{2}$ cDNA concentration vs. Ct value plot slopes of serially-diluted cDNA samples across treatment groups (Yuan et al., 2006).

For RNA-seq analysis, Poly(A) RNA and libraries were quality-checked before 2x100bp sequencing with an Illumina HiSeq2000 instrument. Gene expression data were computed using the CLC Genomics Workbench version 6.5. Reads were trimmed and filtered on quality with the Trim Sequences algorithm (Limit: 0.05, Maximum ambiguities: 2). RPKM was generated by aligning ESTs to Gene annotations using the RNA-Seq Analysis algorithm for annotated sequence. (Parameters: Similarity 0.8; Length 
fraction 0.9). Genome sequence and annotations were downloaded from NCBI (http://www.ncbi.nlm.nih.gov/bioproject/PRJNA74771). Genome sequence, annotation, and expression data were stored in an Oracle relational database and displayed using a custom web application.

\section{Stem Sectioning, Phloroglucinol and Mäule Reagent Staining}

Hand-cut stem sections from the first internode $(1 \mathrm{~cm}$ below first node below spikelet) of plants 39 days after planting were made with a Teflon-coated razor blade (GEM, Ted Pella). Sections were stained 15 minutes in acid phloroglucinol (2\% (w/v) phloroglucinol/20\% (v/v) ethanol/2.4 M HCl), mounted on microscope slides, and then photographed using a Leica DMRBE microscope with brightfield illumination. Care was taken to stain each section the same duration of time before imaging. Mäule method analysis was performed as in Bouvier d'Yvoire et al. (2013).

\section{Digestibility Assays}

Digestibility assays were performed as in Santoro et al., (2010). Ball millpulverized senesced culms having spikelets and leaves at leaf collars removed were analyzed. Free glucose amounts in the undigested biomass was determined by extracting the glucose from ground biomass with distilled water and quantifying using an alditol acetate/gas chromatography method (Blakeney et al., 1983). Free glucose values were subtracted from the glucose values obtained after the chemical and enzymatic treatments so as to have digestibility values reflecting sugars released exclusively from cell wall polysaccharides. Free glucose values did not need to be subtracted for $\mathrm{NaOH}$ treated 
samples, since those treatments degraded any free glucose in the ground biomass before enzyme hydrolysis. No detected glucose originated from starch, since the hydrolytic enzyme mixes contained no amyloglucosidase or $\alpha$-amylase activity.

The cellulolysis protocol was performed as described in Berthet et al. (2011).

\section{Thioacidolysis Method}

The thioacidolysis protocol was performed as described in Lapierre et al., (1995). Lignin-derived thioacidolysis monomers were identified by gas chromatography-mass spectrometry as their trimethylsilylated derivatives.

\section{Mild Alkaline Hydrolysis of Extract-Free Senesced Stems}

The determination of ester-linked $p$ CA and FA was via mild alkaline hydrolysis, following previously published procedures (Ralph et al., 1994; Bouvier d'Yvoire et al., 2013).

\section{DFRC Method to Quantitate $p$ CA Specifically Bound to Lignin}

The quantification of lignin-bound $p$ CA was performed using the DFRC method, which is capable of cleaving lignin ethers while retaining esters (Lu and Ralph, 1997; 1998b; a; Lu and Ralph, 1999). Dried extract-free whole cell walls (20-40 mg) were treated with acetyl bromide in acetic acid $(5 \mathrm{~mL}, 1: 4 \mathrm{v} / \mathrm{v})$ at $50{ }^{\circ} \mathrm{C}$ for $3 \mathrm{~h}$. The benzyl $(\alpha-$ carbon) brominated lignin solution was evaporated to dryness on a rotary evaporator (water bath at $50{ }^{\circ} \mathrm{C}$ ). The dry film was suspended in $2 \mathrm{~mL}$ absolute ethanol and the 
ethanol was evaporated. The dry sample was then immediately dissolved in a mixture of 1,4-dioxane:acetic acid:water ( $5 \mathrm{~mL}, 5: 4: 1$ by volume), and a stir bar and zinc dust (150 $\mathrm{mg}$ ) was added to the flask. The reaction was stirred for $1 \mathrm{~h}$ at room temperature and then quenched with saturated ammonium chloride. The sample was spiked with $50 \mu \mathrm{g}$ diethyl 5,5'-diferulate diacetate and the organics were extracted with dichloromethane (4 x 15 $\mathrm{ml})$. The combined organic fraction was dried over sodium sulfate, filtered, and the solvent was removed under vacuum. The residue was treated with a mixture of acetic anhydride and pyridine (4 mL, 1:1 v:v) at room temperature overnight. Solvents were removed on a rotary evaporator. The crude product was loaded on a Supelco Supelclean LC-SI SPE tube (Sigma-Aldrich part \#505048) with DCM (3 x $1 \mathrm{~mL})$, eluted using a mixture of 1,4-dioxane:ethyl acetate $(5 \mathrm{~mL}, 1: 1 \mathrm{v}: \mathrm{v})$, and concentrated to dryness. The dry film was dissolved in DCM (1 mL) and analyzed on a GC-MS (Shimadzu QP2010 Plus) using a $0.25 \mu \mathrm{m} \times 0.25 \mathrm{~mm} \times 30 \mathrm{~m}$ DB-1701 (Agilent) column with He as a carrier gas $\left(0.85 \mathrm{~mL} / \mathrm{min}, 10: 1\right.$ split ratio). The column temperature was held at $150{ }^{\circ} \mathrm{C}$ for $1 \mathrm{~min}$ then increased at $20{ }^{\circ} \mathrm{C} \min ^{-1}$ to $300{ }^{\circ} \mathrm{C}$ and held for $24 \mathrm{~min}$. The injector was set at $250{ }^{\circ} \mathrm{C}$, the ion source was set at $260{ }^{\circ} \mathrm{C}$ and the detector voltage was $0.99 \mathrm{kV}$. The detector was run in selective ion monitoring (SIM) mode, acquiring three masses per target compound: coniferyl dihydro-p-coumarate diacetate (the diacetate of $\mathbf{8 G}$, Figure 5a) m/z: 370, 163, 131; sinapyl dihydro- $p$-coumarate diacetate (the diacetate of $\mathbf{8 S}$, Figure 5a) m/z: 400, 193, 161; diethyl 5,5'-diferulate diacetate (DEDF) m/z: 484, 442, 350. Authentic standards of $\mathbf{8 G}, \mathbf{8 S}$, and DEDF were used to generate a 6-point calibration curve, with the DEDF used as an internal reference. 


\section{Analysis of Arabinoxylan-Bound $p \mathrm{CA}$ and FA}

Mild acidolysis was carried out on 5-10 mg of extractive-free sample using $2 \mathrm{ml}$ dioxane/water $0.2 \mathrm{M} \mathrm{HCl}$ containing $0.05 \mathrm{mg} \mathrm{C} 21$ internal standard in a Teflon-lined screwed cap tube overnight at $50{ }^{\circ} \mathrm{C}$ on a carousel. Then $2 \mathrm{ml}$ water was added and samples were extracted with $3 \times 4 \mathrm{ml}$ EtOAc. The combined organic extracts were dried over $\mathrm{Na}_{2} \mathrm{SO}_{4}$ and then concentrated to $\sim 0.5-1 \mathrm{ml}$. For GC-MS analyses, a $10 \mu \mathrm{l}$ aliquot of the sample solution was silylated with $100 \mu \mathrm{l} \mathrm{BSTFA}+10 \mu \mathrm{l}$ pyridine for $1 \mathrm{~h}$ at $50{ }^{\circ} \mathrm{C}$ before injection into a GC-MS system (Supelco) methylsilicone $15 \mathrm{~m}$ x $0.32 \mathrm{~mm}$ x 0.25 $\mu \mathrm{m}$ film thickness column, using $\mathrm{He}(1.5 \mathrm{ml} / \mathrm{min}$ flow rate $)$ as the carrier gas, and with the following temperature program: from 45 to $180{ }^{\circ} \mathrm{C}$ at $30{ }^{\circ} \mathrm{C} / \mathrm{min}$, then from 180 to $280{ }^{\circ} \mathrm{C}$ at $+3{ }^{\circ} \mathrm{C} / \mathrm{min}$. Quantitative determinations were made from ion chromatograms reconstructed at $\mathrm{m} / \mathrm{z}(57+71+85)$ for the internal standard C21 (heneicosane), at $(308+293)$ for pCA-TMS, at $(338+323)$ for FA-TMS, and at 219 for $p$ CA-Ara-TMS, the per-TMS ether of 5-O-p-coumaroyl arabinose 10, and at 249 for FA-Ara-TMS, the perTMS ether of 5-O-feruloyl arabinose 11.

\section{D HSQC NMR Analysis of Cell Wall Components}

The preparation of the extract-free whole cell walls and the cellulolytic enzyme lignin was performed as described previously (Lu and Ralph, 2003; Wagner et al., 2007; Kim and Ralph, 2010)). Ball milled, extract-free whole cell wall samples (40 mg) were

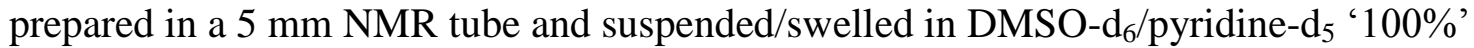
$(4: 1,500 \mu \mathrm{L})$. 
The milled wood enzyme lignin (MWEL) was prepared from ball-milled material (50-70 mg) as described previously (Chang et al., 1975; Wagner et al., 2007). The material was digested at room temperature with $2 \mathrm{mg}$ of crude cellulases (Cellulysin; Calbiochem), in pH 5.0 acetate buffer $(30 \mathrm{~mL})$ on a shaker for 3 days. The samples were then centrifuged (Sorval biofuge primo; 8,500 rpm/10,016 xG for $10 \mathrm{~min}$ ), and decanted. The cellulase digestion was then repeated. After decanting the second batch of acetate buffer, the sample was rinsed with RO water $(3 \times 40 \mathrm{~mL})$ and the sample lyophilized. The resulting brown powder (5-10 $\mathrm{mg}$ ) was transferred to a $5 \mathrm{~mm}$ NMR tube and dissolved in DMSO-d ${ }_{6} /$ pyridine- $\mathrm{d}_{5}$ ' $100 \%$ ' $(4: 1,500 \mu \mathrm{L})$.

HSQC NMR spectroscopy was performed as previously (Kim and Ralph, 2010; Mansfield et al., 2012) on a Bruker Biospin (Rheinstetten, Germany) Avance $700 \mathrm{MHz}$ NMR spectrometer equipped with an inverse gradient $5 \mathrm{~mm}$ TXI ${ }^{1} \mathrm{H} /{ }^{13} \mathrm{C} /{ }^{15} \mathrm{~N}$ cryoprobe. The central DMSO solvent peak was used as internal reference $\left(\delta_{\mathrm{c}} 39.5, \delta_{\mathrm{H}} 2.49 \mathrm{ppm}\right)$. Peak assignments for syringyl (S), guaiacyl (G), and p-hydroxyphenyl $(\mathrm{H})$ lignin units, as well as $p$-coumarate $(p \mathrm{CA})$, ferulate $(\mathrm{FA})$, and tricin $(\mathrm{T})$, were made by comparison with previously assigned spectra (Lu and Ralph, 2003; Marita et al., 2003; Kim et al., 2008; Kim and Ralph, 2010; Ralph and Landucci, 2010; del Río et al., 2012; del Rio et al., 2012; Mansfield et al., 2012; Rencoret et al., 2013).

\section{Acknowledgments}

We thank Frédéric Legée for performing the Klason lignin analyses, Cliff Foster for performing thioacidolysis analyses, Hoon Kim for his help with gel-NMR methods, Nick Thrower for help processing RNAseq datasets, and Stephen Lutgen, Heather Welch, 
and Michael Krzyskowski for prepping tissue samples. We thank Marek Mutwil and Staffan Persson for providing access to AraNet Brachypodium co-expression tools before their publication. This work was supported by the Department of Energy's Great Lakes Bioenergy Research Center (Department of Energy, Biological and Environmental Research, Office of Science grant no. DE-FC02-07ER64494).

Additional Supporting information may be found in the online version of this article. http://www.ncbi.nlm.nih.gov/pmc/articles/PMC4282527/ 


\section{REFERENCES}

Bartley, L.E., Peck, M.L., Kim, S.R., Ebert, B., Manisseri, C., Chiniquy, D.M., Sykes, R., Gao, L., Rautengarten, C., Vega-Sánchez, M.E., Benke, P.I., Canlas, P.E., Cao, P., Brewer, S., Lin, F., Smith, W.L., Zhang, X., Keasling, J.D., Jentoff, R.E., Foster, S.B., Zhou, J., Ziebell, A., An, G., Scheller, H.V., and Ronald, P.C. (2013) Overexpression of a BAHD acyltransferase, OsAt10, alters rice cell wall hydroxycinnamic acid content and saccharification. Plant Physiol. 161, 1615-1633.

Bayer, A., Ma, X.Y. and Stockigt, J. (2004) Acetyltransfer in natural product biosynthesis - functional cloning and molecular analysis of vinorine synthase. Bioorganic \& Medicinal Chemistry, 12, 2787-2795.

Berthet, S., Demont-Caulet, N., Pollet, B., Bidzinski, P., Cézard, L., Le Bris, P., Borrega, N., Hervé, J., Blondet, E., Balzergue, S., Lapierre, C., and Jouanin, L. (2011) Disruption of LACCASE4 and 17 results in tissue-specific alterations to lignification of Arabidopsis thaliana stems. Plant Cell. 23, 1124-1137.

Betts, M.J. and Russell, R.B. (2003) Amino acid properties and consequences of substitutions. In Bioinformatics for Geneticists (Barnes, M.R. and Gray, I.C., eds). Chichester, UK: John Wiley and Sons, pp. 289-316.

Blakeney, A.B., Harris, P.J., Henry, R.J., and Stone, B.A. (1983) A simple and rapid preparation of alditol acetates for monosaccharide analysis. Carbohydr. Res. 113, 291-299.

Boerjan, W., Ralph, J. and Baucher, M. (2003) Lignin Biosynthesis. Ann. Rev. Plant Biol. 54, 519-549.

Bouvier d'Yvoire, M., Bouchabke-Coussa, O., Voorend, W., Antelme, S., Cézard, L., Legée, F., Lebris, P., Legay, S., Whitehead, C., McQueen-Mason, S.J., Gomez, L.D., Jouanin, L., Lapierre, C., and Sibout, R. (2013) Disrupting the cinnamyl alcohol dehydrogenase 1 gene $(B d C A D 1)$ leads to altered lignification and improved saccharification in Brachypodium distachyon. Plant J. 73, 496-508. 
Carroll, A. and Somerville, C.R. (2009) Cellulosic biofuels. Annu. Rev. Plant Biol. 160, $165-82$

Chang, H.-M., Cowling, E.B., Brown, W., Adler, E. and Miksche, G. (1975) Comparative studies on cellulolytic enzyme lignin and milled wood lignin of sweetgum and spruce. Holzforschung, 29, 153-159.

Chapple, C., Ladisch, M., and Meilan, R. (2007) Loosening lignin's grip on biofuel production. Nat. Biotechnol. 25, 746-748.

Chen, F. and Dixon, R.A. (2007) Lignin modification improves fermentable sugar yields for biofuel production. Nat. Biotechnol. 25, 759-761.

Christensen, A.H. and Quail, P.H. (1996) Ubiquitin promoter-based vectors for high-level expression of selectable and/or screenable marker genes in monocotyledonous plants. Transgenic Res, 5, 213-218.

D'Auria, J.C. (2006) Acyltransferases in plants: a good time to be BAHD. Curr. Opin. Plant Biol., 9, 331-340.

Dalmais, M., Antelme, S., Ho-Yue-Kuang, S., Wang, Y., Darracq, O., d'Yvoire, M.B., Cézard, L., Légée, F., Blondet, E., Oria, N., Troadec, C., Brunaud, V., Jouanin, L., Höfte, H., Bendahmane, A., Lapierre, C. and Sibout, R. (2013) A TILLING platform for functional genomics in Brachypodium distachyon. PLoS ONE, 8, e65503 (65501$65510)$.

del Rio, J.C., Rencoret, J., Prinsen, P., Martínez, Á.T., Ralph, J. and Gutiérrez, A. (2012) Structural characterization of wheat straw lignin as revealed by analytical pyrolysis, 2D-NMR, and reductive cleavage methods. J. Agr. Food Chem., 60, 5922-5935.

del Río, J.C., Prinsen, P., Rencoret, J., Nieto, L., Jiménez-Barbero, J., Ralph, J., Martínez, Á.T. and Gutiérrez, A. (2012) Structural characterization of the lignin in the cortex and pith of elephant grass (Pennisetum purpureum) stems. J. Agr. Food Chem., 60, 3619-3634. 
Fu, C., Mielenz, J.R., Xiao, X., Ge, Y., Hamilton, C.Y., Rodriguez, M. Jr., Chen, F., Foston, M., Ragauskas, A., Bouton, J., Dixon, R.A., and Wang, Z.Y. (2011) Genetic manipulation of lignin reduces recalcitrance and improves ethanol production from switchgrass. Proc. Natl. Acad. Sci. U. S. A. 108, 3803-3808.

Harrington, M.J., Mutwil, M., Barriere, Y. and Sibout, R. (2012) Molecular Biology of Lignification in Grasses. Adv Bot Res, 61, 77-112.

Hatfield, R.D., Helm, R.F. and Ralph, J. (1991) Synthesis of methyl 5-O-trans-feruloyl$\alpha$-L-arabinofuranoside and its use as a substrate to assess feruloyl esterase activity. Anal. Biochem., 194, 25-33.

Hatfield, R.D., Ralph, J. and Grabber, J.H. (2008) A potential role of sinapyl p-coumarate as a radical transfer mechanism in grass lignin formation. Planta, 228, 919-928.

Hatfield, R.D., Marita, J.M., Frost, K., Grabber, J.H., Lu, F., Kim, H. and Ralph, J. (2009) Grass lignin acylation: $p$-coumaroyl transferase activity and cell wall characteristics of C3 and C4 grasses. Planta, 229, 1253-1267.

Karimi, M., Inze, D. and Depicker, A. (2002) GATEWAY ${ }^{\mathrm{TM}}$ vectors for Agrobacteriummediated plant transformation. Trends Plant Sci., 7, 193-195.

Kim, H., Ralph, J. and Akiyama, T. (2008) Solution-state 2D NMR of ball-milled plant cell wall gels in DMSO- $\mathrm{d}_{6}$. BioEnergy Research, 1, 56-66.

Kim, H. and Ralph, J. (2010) Solution-state 2D NMR of ball-milled plant cell wall gels in DMSO-d 6 /pyridine- $\mathrm{d}_{5}$. Org. Biomol. Chem., 8, 576-591.

Lapierre, C. (2010) Determining lignin structure by chemical degradations. In Lignin and Lignans - Advances in Chemistry (Heitner, C., Dimmel, D. and Schmidt, J.A., eds). Boca Raton, FL: CRC Press/Taylor \& Francis Group, pp. 11-48.

Lin, S. Y., and Dence, C. W. (1992) Methods in Lignin Chemistry, Springer-Verlag, Heidelberg. 
Lu, F. and Ralph, J. (1997) The DFRC method for lignin analysis. Part 1. A new method for $\beta$-aryl ether cleavage: lignin model studies. J. Agr. Food Chem., 45, 4655-4660.

Lu, F. and Ralph, J. (1998a) The DFRC method for lignin analysis. Part 3. NMR studies. J. Wood Chem. Technol., 18, 219-233.

Lu, F. and Ralph, J. (1998b) The DFRC method for lignin analysis. Part 2. Monomers from isolated lignins. J. Agr. Food Chem., 46, 547-552.

Lu, F. and Ralph, J. (1998c) Efficient ether cleavage in lignins: the "DFRC" method as a basis for new analytical methods. In Lignin and Lignan Biosynthesis (Lewis, N.G. and Sarkanen, S., eds). Washington, DC: American Chemical Society, pp. 294-322.

Lu, F. and Ralph, J. (1999) Detection and determination of $p$-coumaroylated units in lignins. J. Agr. Food Chem., 47, 1988-1992.

Lu, F. and Ralph, J. (2002) Preliminary evidence for sinapyl acetate as a lignin monomer in kenaf. Chem. Commun., 90-91.

Lu, F. and Ralph, J. (2003) Non-degradative dissolution and acetylation of ball-milled plant cell walls; high-resolution solution-state NMR. Plant J., 35, 535-544.

Lu, F. and Ralph, J. (2008) Novel tetrahydrofuran structures derived from $\beta$ - $\beta$-coupling reactions involving sinapyl acetate in Kenaf lignins. Org. Biomol. Chem., 6, 36813694.

Mansfield, S.D., Kim, H., Lu, F. and Ralph, J. (2012) Whole plant cell wall characterization using solution-state 2D-NMR. Nature Protocols, 7, 1579-1589.

Marita, J.M., Vermerris, W., Ralph, J. and Hatfield, R.D. (2003) Variations in the cell wall composition of maize brown midrib mutants. J. Agr. Food Chem., 51, 13131321.

Molinari, H.B., Pellny, T.K., Freeman, J., Shewry, P.R., and Mitchell, R.A. (2013) Grass cell wall feruloylation: distribution of bound ferulate and candidate gene expression in Brachypodium distachyon. Front. Plant Sci. 4, 50. 
Mueller-Harvey, I., Hartley, R.D., Harris, P.J., and Curzon, E.H. (1986) Linkage of pcoumaryl and feruloyl groups to cell wall polysaccharides of barley straw.

Carbohydrate Research, 148, 71-85.

Mutwil, M., Klie, S., Tohge, T., Giorgi, F.M., Wilkins, O., Campbell, M.M., Fernie, A.R., Usadel, B., Nikoloski, Z. and Persson, S. (2011) PlaNet: Combined Sequence and Expression Comparisons across Plant Networks Derived from Seven Species. Plant Cell, 23, 895-910.

Neff, M., Turk, E., and Kalishman, M. (2002) Web-based primer design for single nucleotide polymorphism analysis. Trends in Genetics, 18, 613-615.

Pauly, M. and Keegstra, K. (2008) Cell-wall carbohydrates and their modification as a resource for biofuels. Plant J. 54, 559-568.

Perlack, R.D, Wright, L.L., Turhollow, A.F., Graham, R.L., Stokes, B.J., and Erbach, D.C. (2005). Biomass as feedstock for a biomass and bioproducts industry: the technical feasibility of a 1 billion ton annual feedstock supply. ORNL/TM-2005/66. Oak Ridge, TN: Oak Ridge Natl. Lab./US DOE/USDA.

Pfaffl, M.W. (2001) A new mathematical model for relative quantification in real-time RT-PCR. Nuc. Acids Res., 29, 2004-2007.

Ralph, J. (2010) Hydroxycinnamates in lignification. Phytochem. Revs., 9, 65-83.

Ralph, J., Bunzel, M., Marita, J.M., Hatfield, R.D., Lu, F., Kim, H., Schatz, P.F., Grabber, J.H. and Steinhart, H. (2004) Peroxidase-dependent cross-linking reactions of $p$-hydroxycinnamates in plant cell walls. Phytochem. Revs., 3, 79-96.

Ralph, J., Grabber, J. H., and Hatfield, R. D. (1995) Lignin-ferulate crosslinks in grasses: active incorporation of ferulate polysaccharide esters into ryegrass lignins. (1995) Carbohydr. Res. 275, 167-178.

Ralph, J., Hatfield, R.D., Quideau, S., Helm, R.F., Grabber, J.H. and Jung, H.-J.G. (1994) Pathway of $p$-coumaric acid incorporation into maize lignin as revealed by NMR. $J$. Am. Chem. Soc., 116, 9448-9456. 
Ralph, J. and Landucci, L.L. (2010) NMR of Lignins. In Lignin and Lignans; Advances in Chemistry (Heitner, C., Dimmel, D.R. and Schmidt, J.A., eds). Boca Raton, FL: CRC Press (Taylor \& Francis Group), pp. 137-234.

Rencoret, J., Ralph, J., Marques, G., Gutiérrez, A., Martínez, Á.T. and del Rio, J.C. (2013) Structural characterization of the lignin from coconut (Cocos nucifera) coir fibers. J. Agr. Food Chem., 61, 2434-2445.

Santoro, N., Cantu, S.L., Tornqvist, C.E., Falbel, T.G., Bolivar, J.L., Patterson, S.E., Pauly, M. and Walton, J.D. (2010) A high-throughput platform for screening milligram quantities of plant biomass for lignocellulose digestibility. Bioenergy Research, 3, 93-102.

St-Pierre, B. and De Luca, V. (2000) Evolution of acyltransferase genes: Origin and diversification fo the BAHD superfamily of acyltransferases involved in secondary metabolism. In Recent Advances in Phytochemistry. Evolution of Metabolic Pathways, Vol. 34 (Romeo, J.T., Ibrahim, R., Varin, L. and De Luca, V., eds): Elsevier, pp. 285-315.

Suzuki, H., Nakayama, T. and Nishino, T. (2003) Proposed mechanism and functional amino acid residues of malonyl-CoA : anthocyanin 5-O-glucoside-6"'- $O$ malonyltransferase from flowers of Salvia splendens, a member of the versatile plant acyltransferase family. Biochem., 42, 1764-1771.

Takahama, U., Oniki, T. and Shimokawa, H. (1996) A possible mechanism for the oxidation of sinapyl alcohol by peroxidase-dependent reactions in the apoplast: Enhancement of the oxidation by hydroxycinnamic acids and components of the apoplast. Plant Cell Physiol., 37, 499-504.

U.S. Department of Energy. (2011) U.S. Billion-Ton Update: Biomass Supply for a Bioenergy and Bioproducts Industry. R.D. Perlack and B.J. Stokes (Leads), ORNL/TM-2011/224. Oak Ridge National Laboratory, Oak Ridge, TN. 227p.

Vogel, J. and Hill, T. (2008) High-efficiency Agrobacterium-mediated transformation of Brachypodium distachyon inbred line Bd21-3. Plant Cell Rep, 27, 471-478. 
Vogel, J.P., Gu, Y.Q., Twigg, P., Lazo, G.R., Laudencia-Chingcuanco, D., Hayden, D.M., Donze, T.J., Vivian, L.A., Stamova, B. and Coleman-Derr, D. (2006) EST sequencing and phylogenetic analysis of the model grass Brachypodium distachyon. Theor Appl Genet, 113, 186-195.

Wagner, A., Ralph, J., Akiyama, T., Flint, H., Phillips, L., Torr, K.M., Nanayakkara, B. and Te Kiri, L. (2007) Exploring lignification in conifers by silencing hydroxycinnamoyl-CoA:shikimate hydroxycinnamoyltransferase in Pinus radiata. Proc. Natl. Acad. Sci., 104, 11856-11861.

Wang, M.-B., Li, Z.-Y., Matthews, P., Upadhyaya, N. and Waterhouse, P. (1998) Improved vectors for Agrobacterium tumefaciens-mediated transformation of monocot plants. Acta Horticulturae, 461, 401-407.

Withers, S., Lu, F., Kim, H., Zhu, Y., Ralph, J. and Wilkerson, C.G. (2012) Identification of a grass-specific enzyme that acylates monolignols with $p$-coumarate. J. Biol. Chem., 287, 8347-8355.

Yuan, J.S., Reed, A., Chen, F. and Stewart, C.N. (2006) Statistical analysis of real-time PCR data. BMC Bioinformatics, 7, 85-97.

Zhang, A., Lu, F., Sun, R., and Ralph, J. (2009) Ferulate-coniferyl alcohol cross-coupled products formed by radical coupling reactions. Planta. 229, 1099-1108. 
Table 1. Lignin Analyses for Wild-Type (WT) and BdPMT Misregulated Brachypodium Plants. Lignin Content and Composition for Extract-Free Senesced Stems as Determined by Klason and Thioacidolysis Methods.

\begin{tabular}{ccccc}
\hline \multirow{2}{*}{ Genotype } & $\begin{array}{c}\text { Lignin content } \\
(\%)\end{array}$ & \multicolumn{3}{c}{ Relative frequency of lignin-derived thioacidolysis } \\
monomers \\
\cline { 3 - 5 } & & $\% \mathrm{H}$ & $\% \mathrm{G}$ & $\% \mathrm{~S}$ \\
\hline WT & $16.85 \pm 0.07$ & $3.5 \pm 0.2$ & $31.8 \pm 0.0$ & $64.8 \pm 0.1$ \\
Bdpmt-1 & $16.71 \pm 1.60$ & $4.6 \pm 0.2$ & $36.7 \pm 3.4$ & $58.8 \pm 3.2$ \\
\hline WT & $18.53 \pm 0.16$ & $4.6 \pm 0.1$ & $42.9 \pm 1.1$ & $52.5 \pm 1.2$ \\
RNAi\#2 4B & $18.48 \pm 0.39$ & $4.9 \pm 0.1$ & $45.8 \pm 1.2$ & $49.4 \pm 1.3$ \\
RNAi\#2 7A & $\mathrm{ND}$ & $6.0 \pm 0.9$ & $45.7 \pm 1.6$ & $48.3 \pm 2.1$ \\
\hline WT & $17.12 \pm 0.38$ & $4.3 \pm 0.2$ & $35.8 \pm 0.7$ & $59.9 \pm 0.9$ \\
BdPMT OX & $13.20 \pm 0.26^{*}$ & $3.4 \pm 0.4^{*}$ & $24.9 \pm 2.4^{*}$ & $71.8 \pm 2.6^{*}$ \\
\hline
\end{tabular}

Note: Values are means $\pm \mathrm{SD}$ from individually analyzed plants $(\mathrm{n} \geq 3)$. Asterisks denote statistically significant differences (Student's test) compared to the WT values at $\mathrm{p}<0.0001$. For the lignin content analysis (Klason method), UBIprom:GUS transgenic plants were used as WT. 


\section{CHAPTER II FIGURES}

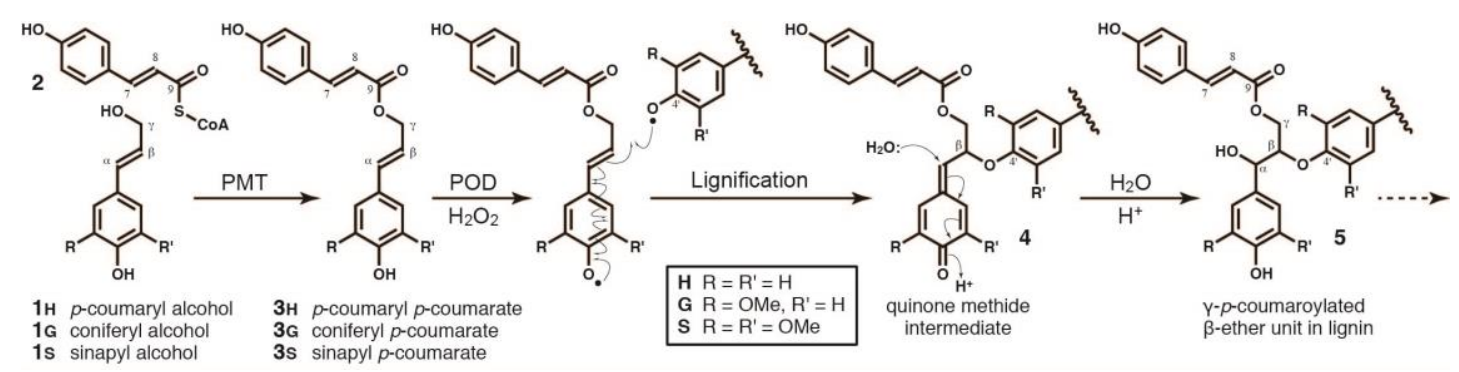

Figure 1. Pathway for the acylation of monolignols. Acylation of monolignols 1 by $p$ coumarate, via its CoA derivative $\mathbf{2}$, to form monolignol $p$-coumarate conjugates $\mathbf{3}$, and an example (using the favored $\beta-\mathrm{O}-4$-coupling, following rearomatization of the quinone methide intermediate 4 ) of how the monolignol moiety undergoes radical coupling reactions during lignification resulting in lignin units such as $\mathbf{5}$ in which $p$-coumarate acylates the $\gamma$-position of lignin unit side-chains; monolignol $p$-coumarate conjugates $\mathbf{3}$ can also (not shown) $\beta-5$-couple (with a $\mathbf{G}$ or $\mathbf{H}$ unit) or $\beta-\beta$-couple with a monolignol $\mathbf{1}$ or another monolignol $p$-coumarate 3 . Further lignification via coupling with additional monomers can etherify the phenolic unit of 5, via either $5-\beta$ - (when the phenolic ring is H or $\mathbf{G}$ ) or $4-\mathrm{O}-\beta$-coupling. 


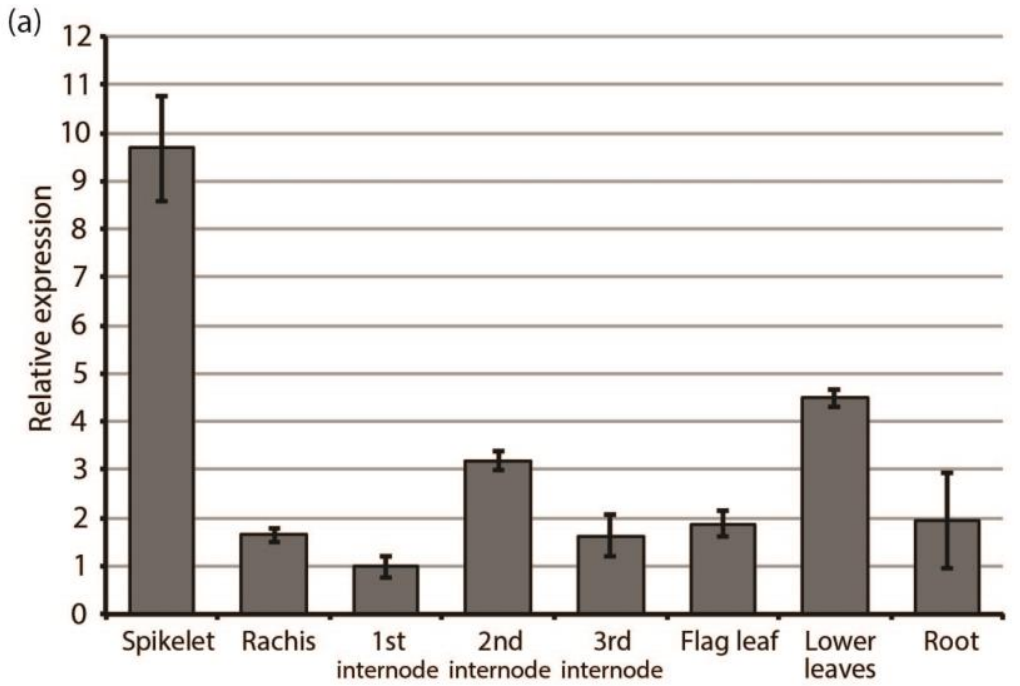

(b)

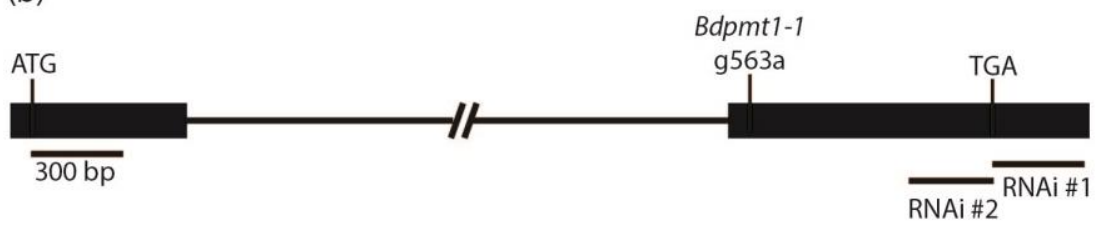

(c)

BdPMT Bradi2g36910 OSPMT LOC Os01g18744 BAA7 4428 (Clade I) AAM64817 CER2 (Clade II) CAD89104 (Clade III) AA073071 (Clade IV) CAC09063 (Clade V)

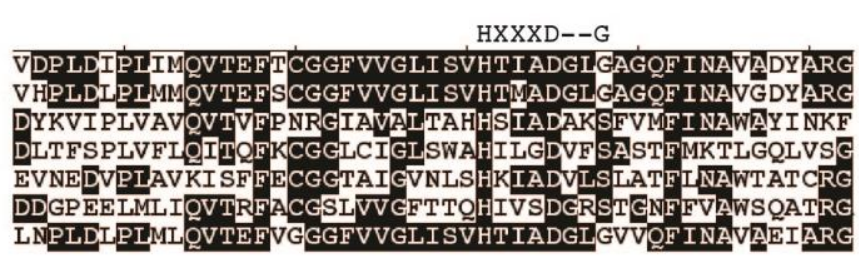

Figure 2. (a) BdPMT transcript levels in WT Brachypodium tissues, as determined by qRT-PCR. Columns represent means $(n=3)$, bars, standard deviations. Means were normalized to the first internode mean transcript level value, which was set to one. (b) Diagram of the BdPMT gene Bradi2g36910 (drawn to scale; 300 bp scale bar). Solid rectangles represent the two exons, connected by a 4,009 bp intron. Labeled are relative locations of translational start/stop codons, Bdpmt-1 transition mutation, and the RNAi constructs. (c) Alignment of BdPMT polypeptide sequences containing the HXXXD motif with sequences from BAHD acyltransferases representing each of the five clades as delineated by phylogenetic analysis (D'Auria, 2006). Consensus amino acids are boxed in black. The HXXXD motif is delineated along with the position of the $\mathrm{G}$ that was mutated in the Bdpmt-1 mutant allele. References for the acyltransferases (delineated by accession numbers) are in D'Auria, 2006. 

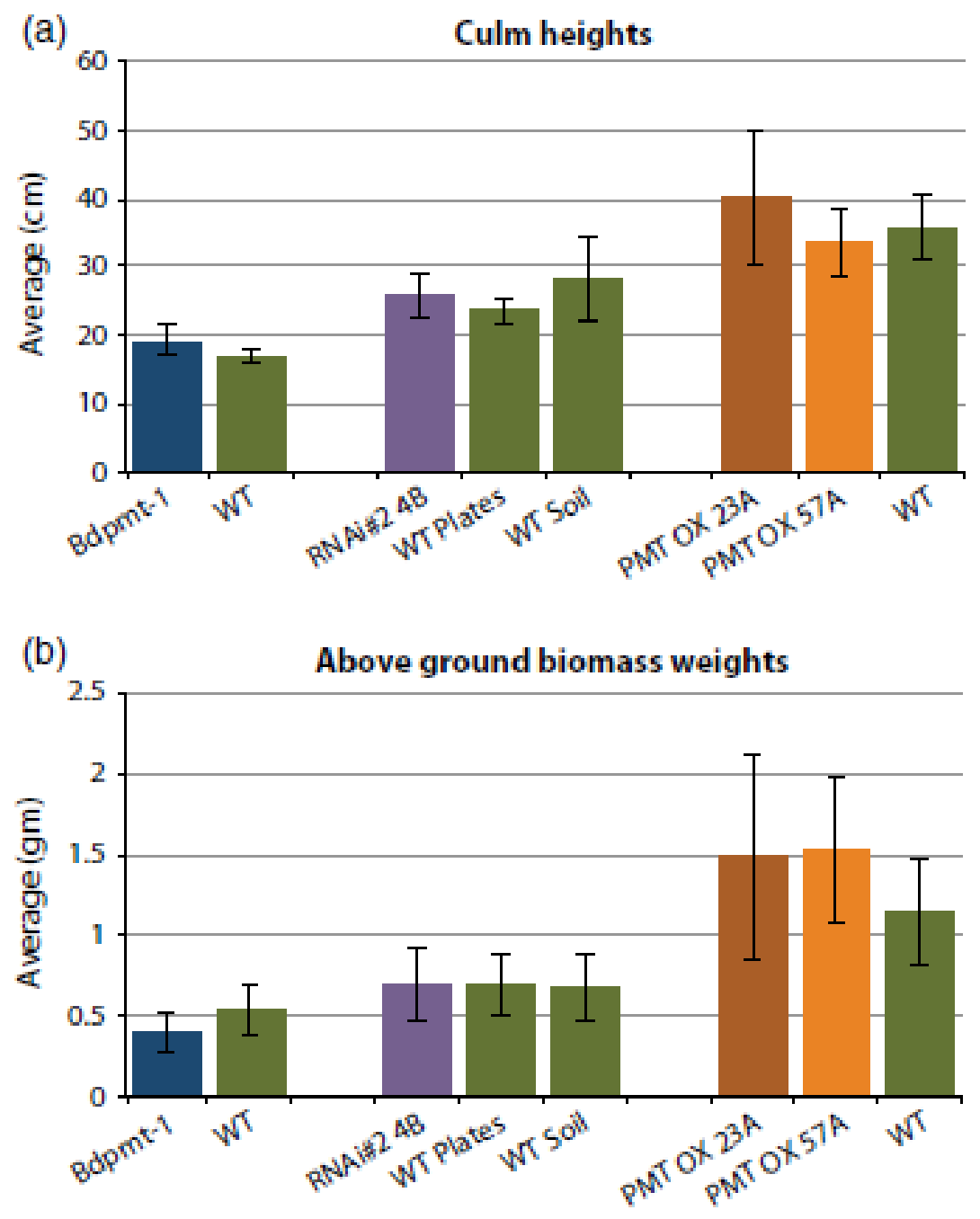

Figure 3. Comparisons of tallest culm heights and total above-ground biomass weights of senesced mutant (a) and WT (b) plants grown under long days. Columns represent means plus/minus standard deviations. Samples grouped together in the graphs represent plants grown side by side. Note that subtle growth chamber and/or epigenetic differences affect Brachypodium average plant growth, so only plants grown side by side and having similar seed histories should be compared to each other. $11<\mathrm{n}<63$. 

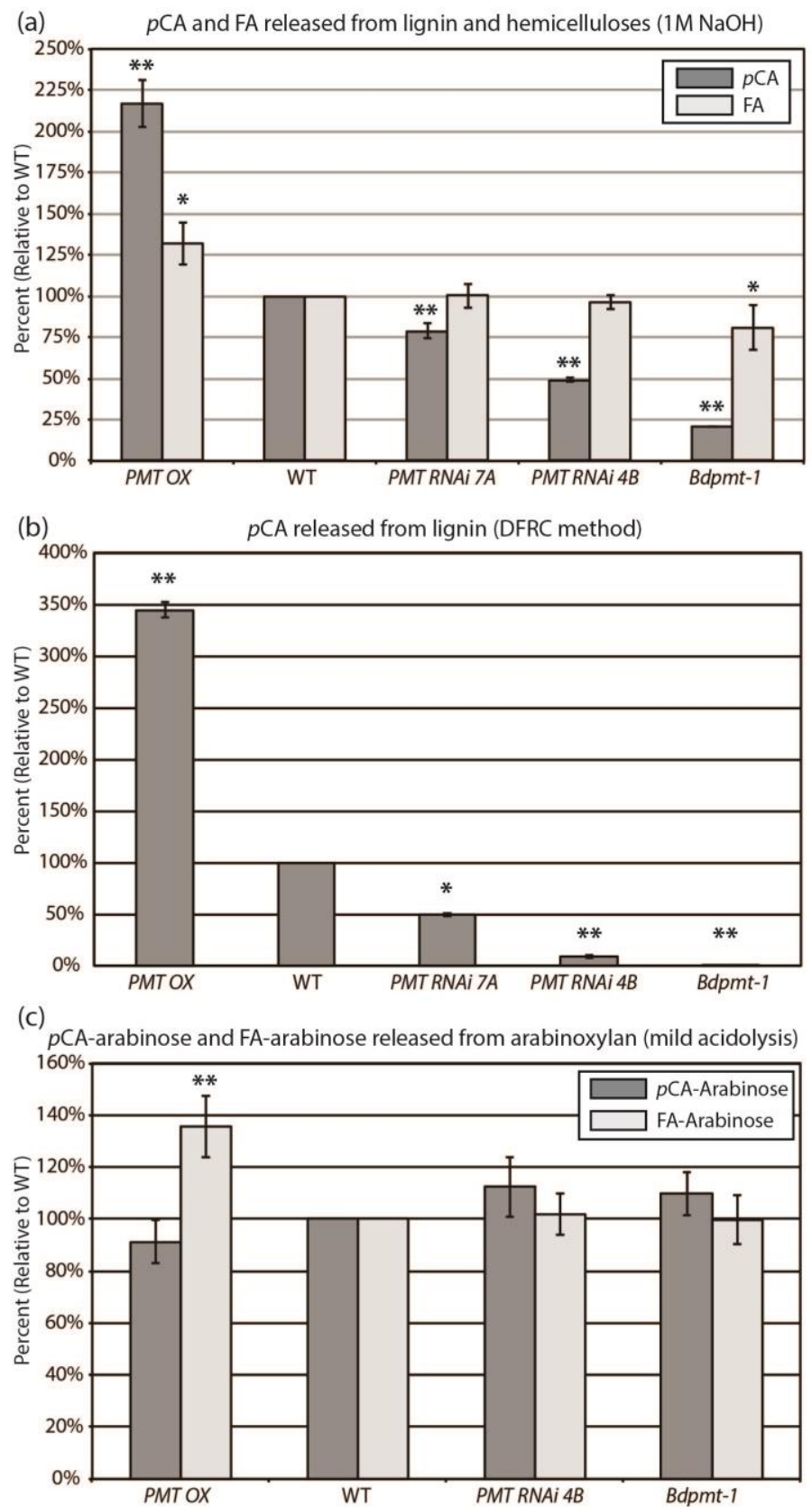

Figure 4. Graphs showing the amounts of $p \mathrm{CA}$, FA, $p$ CA-Arabinose, and FA-Arabinose released from senesced stem biomass lignin and hemicelluloses combined (a), lignin only (b), or arabinoxylan only (c), using the treatments denoted in the graph titles. Columns represent mean percents relative to WT, with mean WT amounts normalized to $100 \%$. Bars denote standard deviations. Asterisks denote statistically significant differences compared to WT plants that were grown alongside, as determined by Student's t-tests, where $*$ represents $\mathrm{p}<0.02$ and $* *$ represents $\mathrm{p}<1 \times 10^{-4}$. PMT OX denotes plants from transgenic lines 23A, 57A, 64A, and 79A. See Tables S2 and S3 for actual values. $n \geq 3$. 

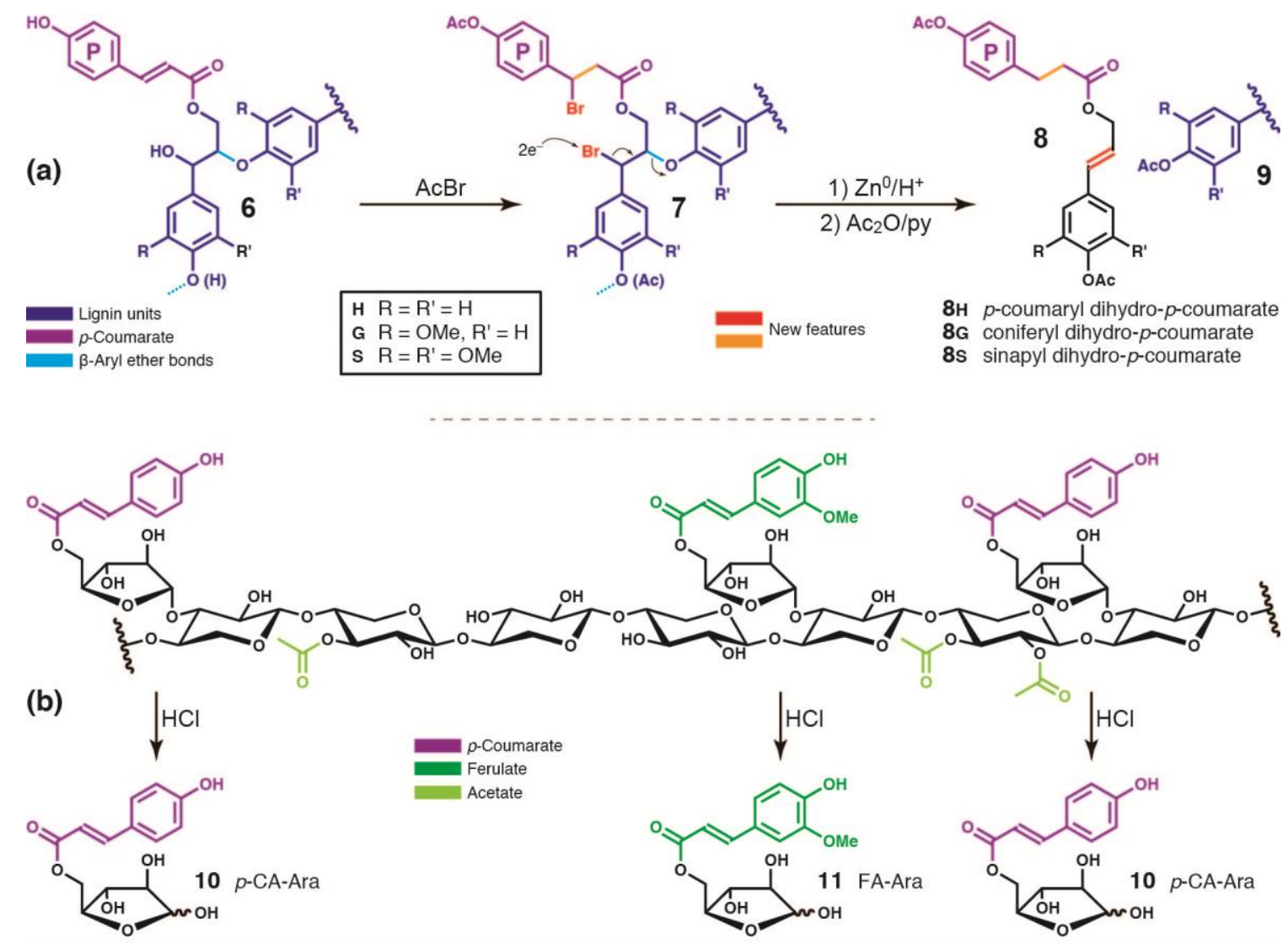

Figure 5. Schematic for analytical methods used to delineate between hydroxycinnamates, $p$-coumarate and ferulate, on lignin versus on polysaccharides. a) The derivatization following by reductive cleavage (DFRC) method cleaves lignin ethers while leaving the $\gamma$-esters intact, releasing quantifiable, lignin-diagnostic acylated units, the monolignol dihydro- $p$-coumarate ester conjugates 8. b) Mild hydrolysis cleaves arabinose units from arabinoxylans and, at least in large part, leaves esters intact, therefore releasing 5-O-p-coumaroyl arabinose 10 and 5-O-feruloyl arabinose 11. Free $p$ coumaric and ferulic acids are also released and detected/quantitated; the $p$-coumarate may derive from either its ester on lignin or arabinoxylan, but compounds $\mathbf{1 0}$ and $\mathbf{1 1}$ are specifically derived from acylated arabinoxylan. 

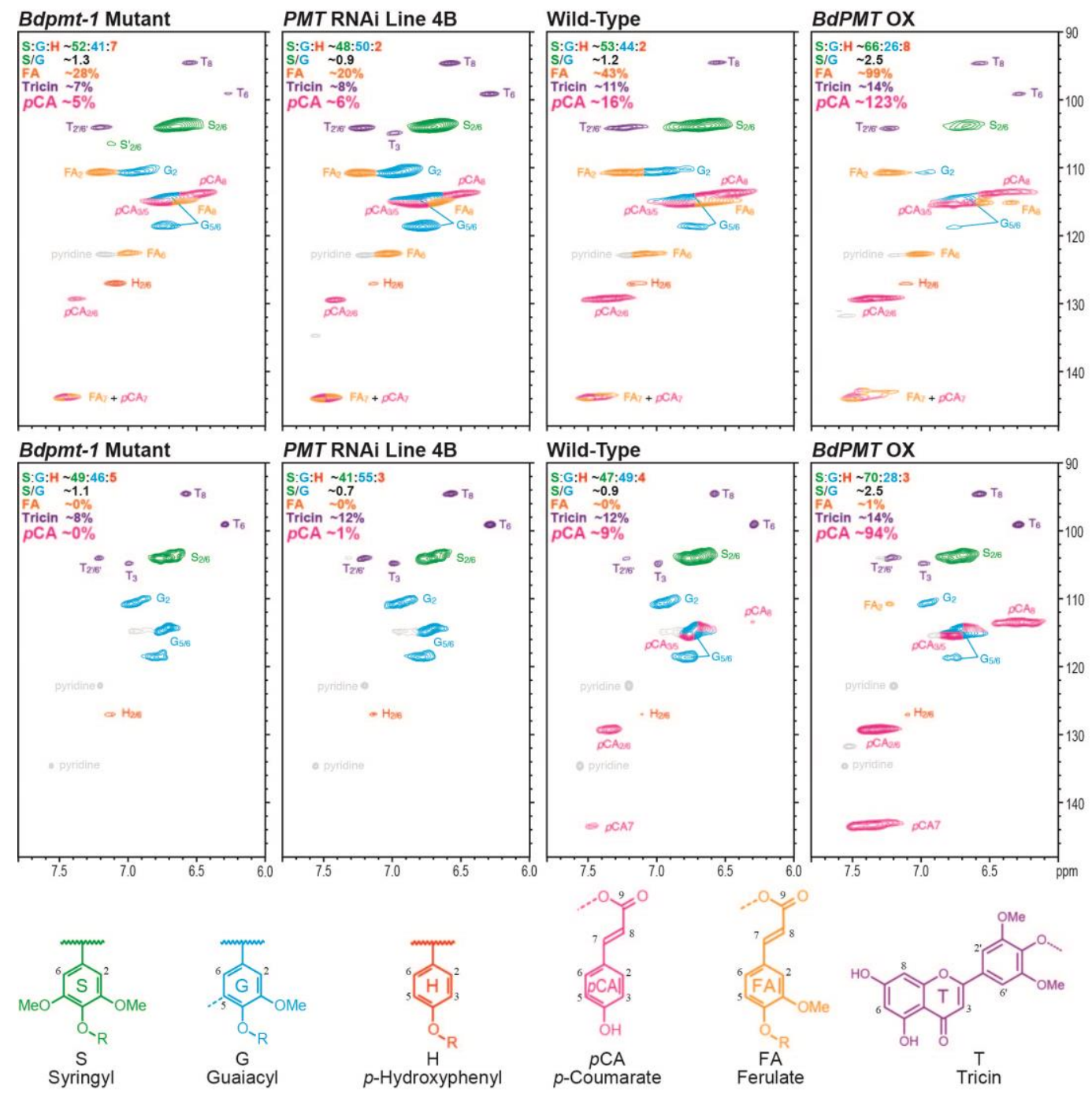

Figure 6. Solution-state HSQC NMR of ball-milled plant cell walls (top row) and cellulolytic enzyme lignin (CEL) treatment (bottom row) in DMSO- $\mathrm{d}_{6} /$ pyridine- $_{5}$. From left to right are the Bdpmt-1 mutant, BdPMT downregulated line 4B (PMT RNAi line $4 \mathrm{~B}$ ), wild-type and BdPMT overexpressed (BdPMT OX). Sample peaks have been colorcoded according to the lignin substructures below the plots. The percentages and ratios reported for each spectrum are integrals relative to total $\mathrm{H}+\mathrm{G}+\mathrm{S}$ aromatic units. 


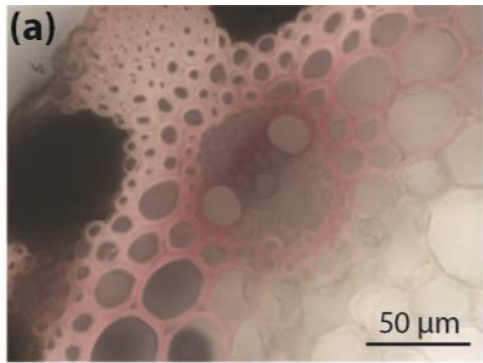

(c)
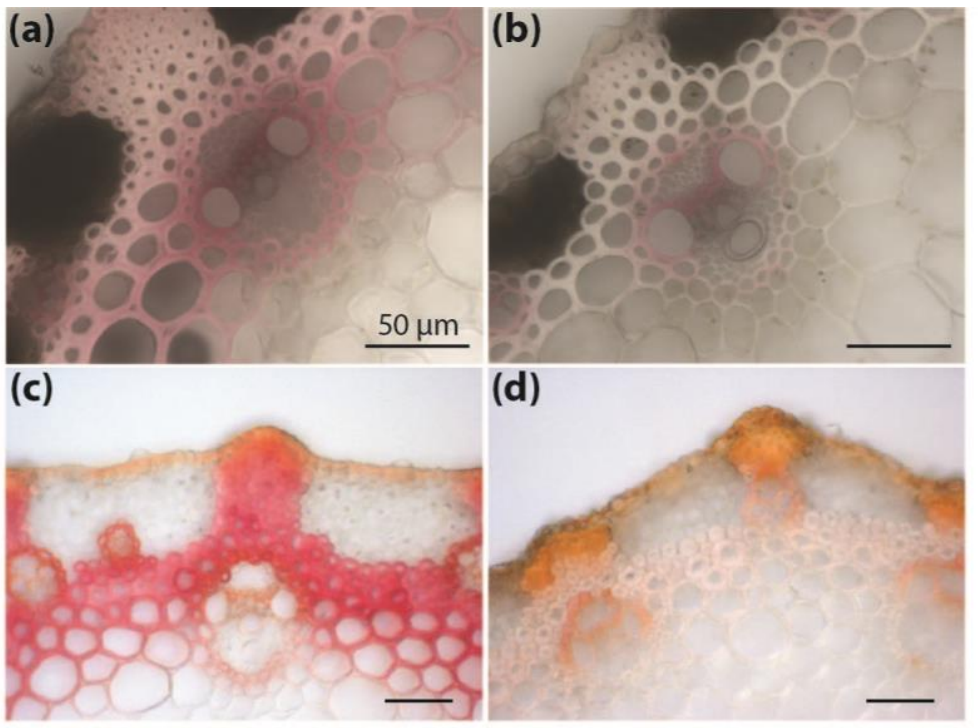

(d)

Figure 7. BdPMT OX stem sections (b, d) have considerably lighter phloroglucinol (a, b) and Mäule Reagent (c, d) staining compared to WT (a, c), which is consistent with relatively less cell wall lignin. Scale bars represent $50 \mu \mathrm{m}$. 
Glucose Release

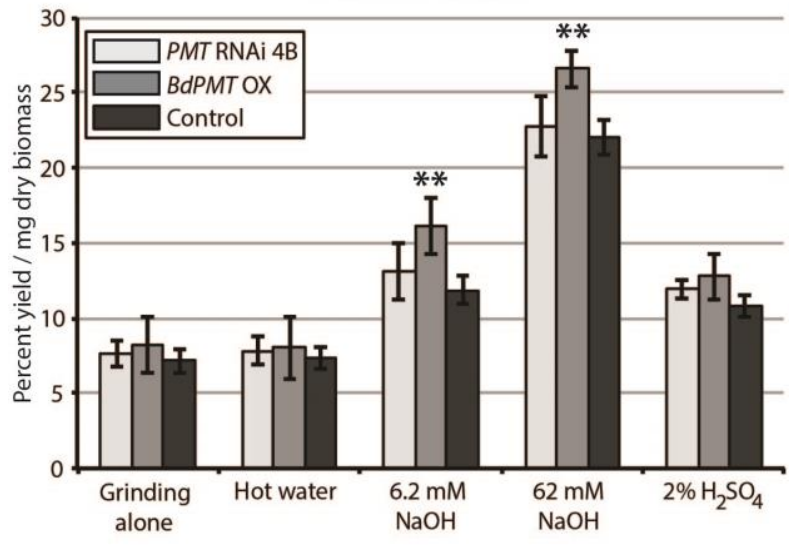

Pentose Release

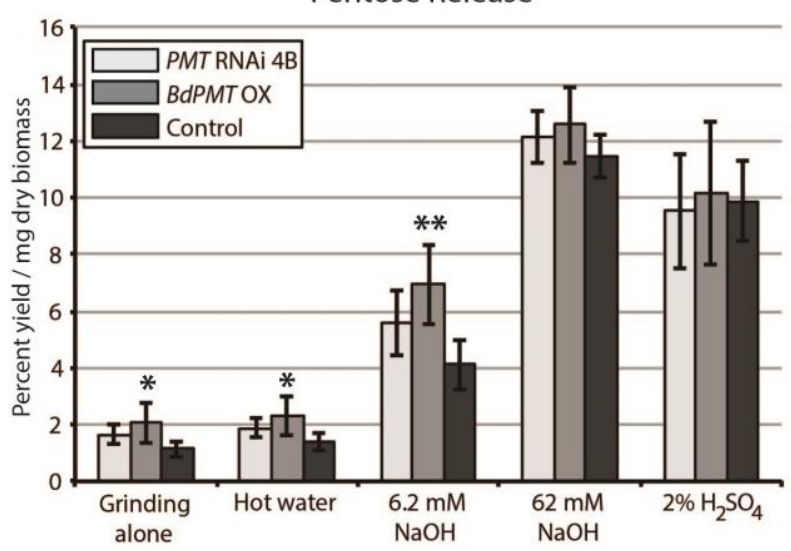

Glucose Release

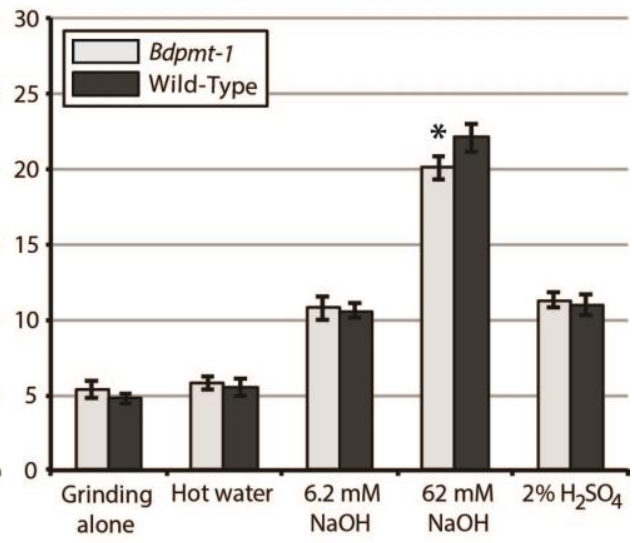

Pentose Release

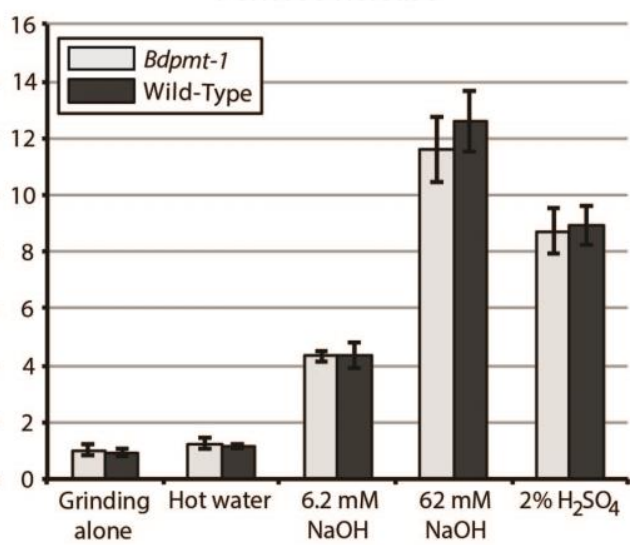

Figure 8. Digestibility of stem biomass, comparing BdPMT OX and BdPMT RNAi Line 4B to transgenic control plants (UBIprom:GUS), and Bdpmt-1 to wild-type. Shown are the average amounts of glucose (top two charts; non-cell wall glucose subtracted from totals) and pentose sugars (bottom two charts) released per mg of senesced ground biomass using the various pretreatments along with enzyme hydrolysis. Vertical bars represent standard deviations. Asterisks represent Student's t-test $(*: \mathrm{p}<0.03$; **: $\mathrm{p}<0.005) . \mathrm{n}=5$ biological reps, 3 technical reps. 


\title{
CHAPTER III
}

\section{BDCESA7, BDCESA8, AND BDPMT UTILITY PROMOTER CONSTRUCTS FOR}

TARGETING GENE-OF-INTEREST EXPRESSION IN SECONDARY CELL WALL FORMING CELLS OF GRASSES

\begin{abstract}
The spatial and temporal control of gene-of-interest expression is a useful tool for studying gene and cellular function and for industrial applications. For targeting gene-ofinterest expression to plant biomass-generating secondary cell wall forming cells, upstream regulatory sequences of the Brachypodium distachyon lignin biosynthetic gene BdPMT and cellulose synthase genes $B d C E S A 7$ and $B d C E S A 8$ were isolated and cloned into binary vectors designed for Agrobacterium-mediated transformation of monocots. Expression patterns were assessed using the B-glucuronidase gene GUSPLUS and X-glucuronide staining. In stem cross-sections, expression of all three promoters was detected strongest in xylem vessels and tracheary elements of the vascular bundles and in interfascicular and epidermal tissues, with expression less pronounced in developmentally older tissues. In leaves, $B d C E S A 7$ and $B d C E S A 8$ promoter expression was strongest in leaf veins, leaf margins, and trichomes; relatively weaker and patchy expression was observed in regions of the epidermis. BdPMT promoter expression was similar to the BdCESA promoters' expression patterns, but was not detected in leaf epidermal cells. The intensity and extent of
\end{abstract}


GUS staining varied considerably between transgenic lines, suggesting that chromosomal location greatly affected the promoters' expression. In floral buds, all three promoter::GUSPLUS constructs expressed strongly in the outer glume, moderately to faintly in the palea, and moderately in the feathery styles, at the base of the ovary, and in pollen grains. The functionality of these constructs will be validated by demonstrating that $B d P M T$ promoter::BdPMT cDNA and BdCESA 8 promoter::BdCESA 8 cDNA constructs can rescue the mutant phenotypes of Brachypodium pmt and cesa 8 mutants, respectively.

Keywords: Binary vectors; Brachypodium distachyon; cellulose; cellulose synthase; lignin; tissue-specific expression

\section{Introduction}

Efforts are underway to engineer plant vegetative biomass, such as stems and leaves of grasses, to be more easily deconstructed and converted to liquid biofuels via fermentation of secondary cell wall-derived polysaccharide sugars. In this process, the highly recalcitrant phenolic polymer lignin poses challenges in that it encapsulates and crosslinks cellulose and hemicelluloses thereby interfering with their chemical and enzymatic hydrolysis. One approach to improving biomass deconstructability is to engineer genetic changes that alter flux through the lignin biosynthetic pathway, e.g. by overexpressing or knocking down key monolignol biosynthetic pathway genes resulting in lower lignin quantities, altered lignin composition, and/or altered cell wall polymer crosslinking (Vanholme et al., 2012; Eudes et al., 2014). Plant biomass yields and/or deconstruction properties can also be improved by introducing genetic changes that increase deposition of secondary cell wall polysaccharides 
and/or that result in the deposition of less tightly packed (amorphous) polysaccharides. However, plant phenotypic problems can arise when genes-of-interest are misexpressed in a non-targeted fashion. Those problems include tissue structures lacking proper strength resulting in collapsed xylem elements and/or lodging of stems, or developmental abnormalities or toxicity that negatively impacts plant growth and fitness (Yang et al., 2013). The creation of a "toolbox" of gene promoters that drive expression of transgenes in desired cells (e.g. only in cells involved in secondary cell wall formation) would be of benefit to molecular biologists aiming to improve plant biomass digestibility and yields while minimizing plant fitness costs.

Multiple approaches exist to identify genes whose promoters and cis-acting regulatory sequences drive expression with specific spatial and temporal patterns. For example, transcriptome profiling was recently employed to determine the cellular expression patterns of the ten members of the Brachypodium distachyon CELLULOSE SYNTHASE A (CESA) gene family (Handakumbura et al., 2013). In that study, CESA4, CESA7, and CESA8 were determined to be expressed at high levels in plant organs known to be active in secondary cell wall biosynthesis. The expression patterns of CESA4 and CESA7 were characterized and validated by performing in situ hybridization in stem cross-sections, using labeled CESA4 and CESA7 antisense sequences as probes; expression was found to be highest in vascular bundles and surrounding interfascicular fibers as well as in nearby epidermal cells (Handakumbura et al., 2013). Wang et al. (2014) recently characterized the Poplar trichocarpa R2R3 MYB transcription factor PtrMYB152, finding that it activates genes involved in secondary cell wall biosynthesis. To verify that a PtrMYB152 promoter fragment drove expression similarly to that of the validated secondary cell wall forming 
Arabidopsis thaliana (Arabidopsis) AtCESA8 gene promoter (Chen et al, 2005), the PtrCESA8 promoter was fused to the $\beta$-GLUCURONIDASE (GUS) gene and transformed into Arabidopsis. X-Gluc staining verified expected expression in the veins of leaves and stele of seedling roots. Stem sections from the upper (developmentally younger) as well as lower (developmentally older) internodes of the inflorescence showed PtrCESA8 expression of GUS in the vascular bundles and interfascicular fibers (Wang et al., 2014).

Bioinformatic resources that are now available for Brachypodium distachyon (Brachypodium) have allowed its transcriptome to be mined for promising gene promoter candidates. Recently, Coussens et al. (2012) searched the publically available Expressed Sequence Tag (EST) database available at PlantGDB for Brachypodium accession Bd21 genes that were either constitutively expressed across tissues and development, or uniquely expressed in leaf, stem and leaf sheath, roots, flowers, or callus. Putative candidates were then tested for levels of expression across multiple organs using quantitative real-time reverse-transcription PCR (qRT-PCR). In that publication, promoters that were predicted by in silico analysis of the EST database to be constitutive, and an endosperm-specific promoter, were cloned into a monocot transformation vector harbouring the $G U S$ reporter gene. The corresponding maize transformants exhibited the expected expression patterns as viewed by X-Gluc staining and 4-methylumbelliferyl-ß-D-glucuronide (MUG) fluorometry. That work showed that a combined approach of bioinformatic purveyance of all expressed genes and whittling down of promoter candidates based on qRT-PCR analysis was a useful means by which to identify gene promoters with desired expression patterns for a particular transgenic application. 
An elegant example of the power of tissue-specific gene expression can be found in Yang et al. (2012). In an Arabidopsis CINNAMATE 4-HYDROXYLASE (C4H) mutant background, functional $\mathrm{C} 4 \mathrm{H}$ expression was reintroduced under the control of the xylem vessel-specific VASCULAR-RELATED NAC-DOMAIN6 (VND6) gene promoter. These genome edits directed normal lignin biosynthesis to xylem vessels, while lignin reductions in interfascicular fiber cells allowed for easier extraction of polysaccharide sugars (Yang et al., 2012). This example provides evidence that promoter substitution can be successfully used to transgenically alter cell wall phenotypes including lignin deposition while avoiding negative growth effects.

For the present study, the expression patterns produced by Brachypodium BdPMT, $B d C E S A 7$, and $B d C E S A 8$ gene promoter fragments were determined by introducing those fragments into a binary vector designed for monocots, upstream of the GUSPLUS reporter gene. Brachypodium plants transformed with each of these utility promoter vectors displayed GUS staining patterns that one would expect for promoters involved in secondary cell wall formation. In addition, to validate the functionality of these utility promoter vectors, the GUSPLUS gene in the BdPMT and BdCESA8 vectors was replaced by the $B d P M T$ cDNA and BdCESA8 cDNA, respectively, and the constructs transformed into the Bdpmt-1 loss-of-function mutant (Petrik et al., 2014) and a Bradi2g49912 BdCESA8 loss-offunction T-DNA mutant that we identified. Given the observed GUSPLUS reporter gene expression patterns, it is expected that the $B d P M T$ promoter::BdPMT cDNA construct will rescue the reduced cell wall para-coumarate $(p \mathrm{CA})$ and ferulate $(\mathrm{FA})$ phenotypes of the Bdpmt-1 mutant and that the $B d C E S A 8$ promoter::BdCESA8 cDNA construct will rescue the reduced cellulose and stunted growth phenotypes that we identified in the Bdcesa8 mutant. 


\section{Materials and Methods}

\section{PCR Amplification of Promoters from Brachypodium distachyon Genomic DNA}

DNA sequence beginning (-) 2385 bp upstream and continuing to (-) 1 of the Bradi4g30540 ATG start site was PCR amplified using accession Bd21-3 genomic DNA as template and the primers listed in Table 1. The BdCESA7 promoter PCR product was sequenced then cloned into the transformation vector SwaI/AscI restriction sites, followed by re-sequencing in the purified plasmid clone. For the $B d C E S A 8$ promoter, DNA sequence beginning at (-) 1890 bp upstream of the Bradi2g49912 gene translational start site and extending to (-) 1 was PCR amplified, sequenced, subcloned into the StuI/AscI restriction sites in the transformation vector and re-sequenced in the purified plasmid clone. For the BdPMT promoter, 3000 bp was PCR amplified from (-) 3045 to (-) 45 of the Bradi2g36910 gene, sequenced, cloned using SwaI/AscI into the transformation vector, then re-sequenced in the purified plasmid clone. An exogenous pair of restriction enzyme sites was added to the 5 ' end of the sequence specific regions of the primers to allow subcloning of the PCR amplified promoter sequences into a modified pIPKb001cereal transformation vector (Himmelbach et al, 2008). Restriction enzymes were chosen based on the sites present upstream of the recombination sites in pIPKb001, and the lack of the restriction enzyme site internally within the PCR amplified promoter sequence. The DNA sequences of the $B d P M T, B d C E S A 7$, and BdCESA8 cloned promoter sequences can be found in Supplemental Figures S1, S2, S3, respectively. 


\section{Modification of pIPKb001 Cereal Transformation Vector for Optimal Expression of GUSPLUS Reporter Gene}

To create the base vector to which the gene promoters would be inserted, two modifications of the cereal transformation vector pIPKb001 (Himmelbach et al, 2008) were made. The unmodified pIPKb001 vector was provided by the Leibniz Institute of Plant Genetics and Crop Plant Research (Himmelbach et al, 2008). First, the maize ubiquitin intron 1 (ZmUbiIN1) was inserted in the HindIII site of the multiple cloning site, then screened for proper orientation by PCR. It has been reported that the addition of an intron sequence improves exogenous gene expression in grasses (Mann et al, 2011; Sivamani, 2006; Mascarenhas et al, 1990; Plesse et al, 2001). Second, the $c c d B$ gene was then replaced by the GUSPLUS (Figure 2.1C) reporter gene using LR recombination based cloning (Invitrogen). This construct was then ready for promoter insertion upstream of the ZmUbiINI using either the SwaI/AscI or StuI/AscI restriction enzyme sites.

Following creation of the modified Pipkb001 transformation vectors housing the GUSPLUS reporter gene, the BdPMT (Bradi2g36910), BdCESA7 (Bradi4g30540), BdCESA8 (Bradi2g49912) gene promoters were cloned in upstream of the reporter genes, as shown in Supplemental Figure S4. SwaI/AscI were used in the case of the BdPMT and BdCESA7 promoters, while StuI/AscI was used in the case of the BdCESA8 promoter due to the presence of an internal SwaI site in the promoter sequence. 
Transformation of Promoter Characterization Vectors into Brachypodium distachyon via Agrobacterium tumefaciens Transformation

Plants harboring the BdPMT promoter: ZmUbi INI: GUSPLUS, BdCESA7promoter: ZmUbi IN1: GUSPLUS, or BdCESA8 promoter: ZmUbi IN1: GUSPLUS constructs were regenerated from $\mathrm{Bd} 21-3$ embryonic callus tissue transformed using Agrobacterium tumefaciens strain AGL-1, as described by Vogel and Hill (2008); media were supplemented with $40 \mathrm{U} / \mathrm{ml}$ hygromycin B (Phytotechnology Laboratories).

\section{Seed Sterilization and Plant Growth}

Seeds were surface sterilized and plated on selective plates (1.5\% agar/one halfstrength Murashige and Skoog salts (Caisson Laboratories)/40 U/mL hygromycin B), stratified for three days $\left(4{ }^{\circ} \mathrm{C}\right.$, dark), then moved to a growth chamber $\left(22{ }^{\circ} \mathrm{C}, 16 \mathrm{~h}\right.$ light $)$ until hygromycin selection was apparent.

Plants were grown in a 50:50 mix of SunGro Rediearth and MetroMix 510 soil in 4 inch pots in growth chambers ( $20 \mathrm{~h}$ light: $4 \mathrm{~h}$ dark photoperiod, $22{ }^{\circ} \mathrm{C}, 50 \%$ humidity). Control plants were either WT Bd21-3 seedlings plated on non-selective plates or planted directly in soil, or hygromycin-selected plants harboring a Zea mays Ubiquitin-1 promoter with intron driving GUSPLUS (Cambia Labs) in pWBVec8.

\section{Tissue Collection for X-Gluc Staining}

A one centimeter section of the leaf tip was taken for X-Gluc colorimetric detection of GUS expression in the leaf. For juvenile leaf sections, the uppermost leaf 
was chosen for sectioning, 18 days after planting the seedling germinated on $1 / 2 \mathrm{MS}+40$ $\mathrm{U} / \mathrm{ml}$ hygromycin plates.

In the case of adult leaf sections, the lowest fully expanded leaf with no cell death at the leaf tip, typically the first or second leaf from the crown, was chosen for sectioning. Again, a one centimeter section of the leaf tip was used for X-Gluc staining. Additionally, a small experiment was performed to compare $G U S$ expression of $1.0 \mathrm{~cm}$ leaf tips taken from both upper and lower leaves sampled from adult plants 32 days after transplantion from hygromycin selection plates.

Free-hand cross sections were taken from both juvenile and adult Brachypodium distachyon stems. Because GUSPLUS would be localized in the cytoplasm (no localization signal was added to the GUSPLUS gene), hand sections were taken to be several cell layers thick to allow blue colored product from the X-Glucuronidase assay to be maintained in the cytoplasm of internal cell layers.

Juvenile stage stem sections were taken from the bottom $0.5 \mathrm{~cm}$ of the first internode of plants 18 days after transplanting from hygromycin selection plates. To make sectioning easier of this juvenile, less lignified stem tissue, the leaf sheath enwrapping the internode stem was removed prior to stem sectioning. This allowed less crushing of the soft stem inside of the leaf sheath.

Adult stage stem sections were taken from the bottom $1.0 \mathrm{~cm}$ of the uppermost internode of the inflorescence stem. These were sampled 32 days after transplantion of hygromycin selected seedlings to soil. 
To examine GUSPLUS expression along every internode of the adult plant, sections were taken at the median of every internode; at the apical internode, sections were taken within the basal $2 \mathrm{~cm}$, the median, and the apical $2 \mathrm{~cm}$.

Transgenic seeds were germinated on $1 / 2$ MS plates minus sucrose plates with 40 $\mathrm{U} / \mathrm{ml}$ hygromycin B for three days at $22 \mathrm{C}$ in the light. After 3 days, seedling roots approximately $2 \mathrm{~cm}$ in length were excised from the seed and immediately placed in $\mathrm{X}$ Gluc staining solution with $10 \mathrm{mM}$ L-ascorbic acid added. Incubations were performed overnight at room temperature, then rinsed in water prior to visualization.

All florets from spikelets which included 1-3 filling seeds were separated and XGluc stained overnight at room temperature overnight. This allowed a full range of floret development from 2 spikelets per plant to be tested for $G U S$ expression patterns. Staining was performed at room temperature because preliminary tests showed intensive blue staining of the outer glume, actually allowing blue precipitate to form and collect between trichome hairs of the glume and in solution when incubation was performed overnight at $37 \mathrm{C}$. The strongest expressing transgenic lines were tested overnight at room temperature both with and without potassium ferri- and ferrocyanide addition. Addition of these compounds both lessens intensity of GUS staining, allowing difference across floral organs to be visualized, and lessens leakage of blue product from cell to neighboring cells.

\section{X-Gluc Staining for Detection of GUS Expression}

Leaf, stem section, and floral buds were immersed in an X-Gluc staining solution consisting of $0.1 \mathrm{M} \mathrm{NaPO} 4$ buffer PH 7.0, $10 \mathrm{mM}$ EDTA, 0.1\% Trition X-114, and $0.1 \mathrm{M}$ 
X-Gluc dissolved in N,N-DMF (Jefferson, R.. (1987) Plant Mol. Biol. Reporter, 5:387405). Roots were stained similarly, except for the addition of ascorbic acid to the X-Gluc staining solution to a final concentration of $10 \mathrm{mM}$, which prevented oxidative browning of the tissue. No vacuum infiltration was performed; incubations were typically done overnight at 37C, followed by removal of chlorophyll by 2 incubations in $70 \%$ EtOH until the wash solution was clear.

In the case of very strongly GUSPLUS expressing transgenic lines, $1.0 \mathrm{mM}$ potassium ferricyanide and $1.0 \mathrm{mM}$ potassium ferrocyanide was added to the staining solution to limit "bleeding" of blue product into neighboring cells. Additionally, when ascertaining cell specificity in these strongly expressing transgenic plant lines, incubation was performed overnight at room temperature rather than $37 \mathrm{C}$. The chlorophyll removal using $70 \%$ EtOH was identical.

\section{Rescue of Bdpmt and Bdcesa8 Mutant Phenotypes}

The cDNA sequence (+1 to stop codon) of BdPMT Bradi2g36910 was LR cloned into the empty pIPKb001 vector housing the cloned BdPMT promoter sequence:: ZmUbi IN1:: $c c d B::$ NOS TER cassette. The BdPMT promoter::ZmUbi IN1::BdPMT cDNA::NOS TER vector was then transformed into embryogenic callus derived from the homozygous Bdpmt-1 mutant using Agrobacterium tumefaciens mediated transformation.

To perform the phenotypic rescue of $B d C E S A 8$, a T-DNA mutant inserted into Bradi2g49912 was used as the genetic background. This mutant JJ18282 was obtained from the Brachypodium distachyon T-DNA mutant library created by John Vogel (Bragg et al, 2012). 
Similar to BdPMT, the BdCESA8 cDNA was cloned from the +1 to the stop codon initially into the pENTR2B entry vector (Invitrogen), prior to LR cloning into the transformation vector. Due to the presence of the hygromycin resistance gene in the TDNA inserted into the BdCESA8 Bradi2g49912 gene, a transformation vector using a different selectable marker needed to be used to select for the presence of the BdCESA8 promoter sequence::ZmUbi IN1::BdCESA8 cDNA::NOS TER rescue cassette. Therefore, the B258 p9ioACT vector available from DNA Cloning Service (http://www.dnacloning.com/) was used, which allowed for paromomycin selection. Empty vector and phenotypic rescue constructs are shown in Supplemental Figures S5 and S6, respectively. The BdCESA8 promoter sequence:: ZmUbi IN1:: BdCESA8 cDNA.:NOS TER transformation vector was transformed into embryogenic callus heterozygous for the TDNA insertion in the Bradi2g49912 gene. This was done because homozygotes grown and screened by genomic DNA PCR showed a fertility problem which caused seeds to abort, thereby preventing harvest of homozygous embryos for callus creation.

Upon senescence of $B d P M T$ phenotypic rescue $\mathrm{T} 0$ regenerants, dry stem tissue was cut into $2 \mathrm{~mm}$ long pieces, bead milled, and tested for $\mathrm{pCA}$ and FA content in total secondary cell wall extracts by mild hydrolysis followed by GC-FID (Petrik et al, 2014). Bdpmt- 1 and WT plants, grown together with the rescue plants, were used as controls.

For the $B d C E S A 8$ phenotypic rescue experiment, initial regenerants obtained were segregating for both the T-DNA insertion in the Bradi2g49912 gene which rendered them BdCESA8 mutants, and the BdCESA8 cloned promoter::ZmUbi IN1::BdCESA8 cDNA:: NOS TER rescue cassette which was inserted by Agrobacterium tumefaciens mediated transformation. Therefore, these initial regenerants were allowed to self-pollinate, and 
progeny were selected using paromomycin resistance. Approximately $1 / 4$ of the progeny obtained were homozygous for the T-DNA insertion in the BdCESA8 Bradi2g49912 gene, and $3 / 4$ of these would be expected to be homozygous or heterozygous for the BdCESA8 rescue T-DNA insertion, inserted randomly into the genome. Zygosity of the T-DNA insertion into the BdCESA8 Bradi2g49912 gene was confirmed by genomic DNA PCR, with one primer in the T-DNA, and one primer in the 3' flanking genomic sequence. Inheritance of at least one allele of the $B d C E S A 8$ rescue cassette was selected for by paromomycin resistance and confirmed by genomic DNA PCR for the BdCESA8 rescue T-DNA insertion. This was done using a forward primer in BdCESA8 exon 13, and a reverse primer in the NOS terminator. Plants which were homozygous for the TDNA insertion in the BdCESA8 Bradi2g49912 gene were normally stunted; thus, BdCESA8 T-DNA insertion homozygotes that obtained a height similar to WT would be suggestive of a successful phenotypic rescue if they had also inherited at least one integrated allele of the $B d C E S A 8$ rescue cassette somewhere in their genome. Cellulose was quantitated in the BdCESA8 rescued progeny, as well as the BdCESA8 T-DNA mutants, and WT controls using the Updegraff method (Updegraff, 1969).

\section{Results}

\section{Selection of Promoter Candidates}

A targeted approach was used to choose gene promoters for isolation and subsequent expression specificity characterization. Due to the previous characterization of the Bradi2g36910 BdPMT gene necessary for $p$-coumarylation of monolignol alcohols prior to polymerization to form lignin in the secondary cell wall (Petrik et al, 2014), it was deemed a 
prudent candidate to further study its expression patterns. Real-time PCR data of the BdPMT gene across multiple wildtype tissues 34 days after planting showed expression in multiple internodes of the stem, as well as in the spikelet. Also chosen were the BdCESA7 (Bradi4g30540) and BdCESA8 (Bradi2g49912) gene promoters, as these genes have been identified to be involved in cellulose synthesis in the secondary cell wall (Handakumbura et al, 2013; Chen et al, 2005; Wang et al, 2014). The sequences of the BdPMT, BdCESA7, and BdCESA8 promoters are shown in Supplemental Figures S1, S2, and S3. Included 5' UTR sequence of the downstream gene was marked in boldface when this information was available via Phytozome or Gramene websites (which was not the case for the BdCESA7 promoter). The motifs in the promoter sequences which were identified as over-represented in primary and secondary cell wall related genes (Cell-wall Related Promoter Elements, CRPEs) by Creux et al (2008) were queried for in each promoter sequence in both the 5 ' to 3' direction on the sense strand and the 3' to 5' direction on the antisense strand (in relation to the downstream respective gene). Due to the abundance of these motifs in each promoter, they were not marked on the promoter sequences themselves, but rather annotation tables citing each motif found, the number of instances it was identified in the forward or reverse direction, and its putative function, are provided in Tables 2, 3, and 4 for the BdPMT, $B d C E S A 7$, and BdCESA8 promoters, respectively. Also included in these tables are vascular expression, cell-wall related, and responsive element motifs (allowing the plant to respond to biotic and abiotic conditions such as cold temperature, pathogen attack, changes in light intensity, etc.) identified by querying the Plant Cis-acting DNA regulatory Elements (PLACE) database (http://www.dna.affrc.go.jp/PLACE/). Due to the lengthy nature of the gene co-expression tables for $B d P M T, B d C E S A 7$, and BdCESA8, these can be referred to 
using the PlaNet platform of web-tools dedicated to the visualization and analysis of plant co-function networks. The BdPMT Bradi2g36910 gene expression profile and its table of co-expressed genes can be found at http://aranet.mpimpgolm.mpg.de/responder.py?name=gene!bdi!15780. The BdCESA7 Bradi4g30540 gene expression profile and table of co-expressed genes can be found at http://aranet.mpimpgolm.mpg.de/responder.py?name=gene!bdi!13203. Lastly, the BdCESA8 Bradi2g49912 gene expression profile and table of co-expressed genes can be found at http://aranet.mpimp-golm.mpg.de/responder.py?name=gene!bdi!18830.

A phylogenetic tree of the CesA gene family based on amino acid similarity of the proteins is provided in Figure 10. As shown, the closest Brachypodium ortholog to AtCESA7 (At5g17420) was identified as Bradi4g30540, while the closest Brachypodium ortholog to AtCESA8 (At4g18780) was identified as Bradi2g49912.

\section{BdPMT Promoter:GUSPLUS Transgenic Lines}

The $B d P M T$ promoter, consisting of a $3 \mathrm{~kb}$ fragment of DNA spanning from (-) 3,045 to (-) 45 upstream of the Bradi2g36910 gene translational start site was cloned upstream of the maize UBIQUITIN1 intron fused to the GUSPLUS reporter gene in the pIPKb001 monocot transformation vector (Himmelbach et al., 2007). The construct was transformed into Brachypodium embryo-derived callus, and four independent T0-generation transgenic plants were regenerated. T1- and T2-generation plants were analyzed for X-Gluc (GUS) staining, at juvenile and adult developmental stages. 


\section{BdPMT Promoter:GUSPLUS Expression in Stems}

In stem sections sampled from juvenile (18 days after planting) plants, taken from the first internode, $B d P M T$ promoter:GUSPLUS-related GUS staining was observed in vascular bundles, particularly in the xylem vessels and tracheids (Supplemental Figure S7). Only occassionaly was staining observed in schlerenchyma cells in the ring surrounding the vascular bundles. GUS staining was also evident in epidermal cells, including trichomes.

Examination of apical internodes of adult (32 days after planting) $B d P M T$ promoter:GUSPLUS plants displayed GUS staining along the outer epidermis of the stem in the microhair trichomes, with indigo product extending into underlying cells (Figures 2B and $2 \mathrm{C}$ ). Potassium ferri- and ferro-cyanide were added to the X-Gluc solution when staining sample (2C), in order to reduce colorimetric product diffusion (Vitha et al, 1995) in this strongly expressing line, yet in both $2 \mathrm{~B}$ and $2 \mathrm{C}$, staining was seen in the epidermis subdermal to the trichomes. Since similar results were obtained with or without potassium ferri- and ferro-cyanide addition, this indicates that the staining observed in epidermal cells subdermal to the trichomes is due to true GUSPLUS expression in these epidermal cells when driven by the $B d P M T$ promoter.

X-Gluc staining was also detected in sclerenchyma fiber cells (Figure 2, SFs) located in a ring surrounding the vascular bundles. Schlerenchyma-specific staining appeared sporadically in the lower (developmentally mature) internode cells, and was more pronounced in the upper internode cells where secondary cell wall biosynthesis is more active (Figure 1).

Vascular bundle staining was detected in both xylem vessels and tracheid elements and was particularly evident under high magnification (Figure 2, VBs). With respect to 
vascular bundles exhibiting relatively light GUS staining, indigo coloring was not visible in the cell walls of the phloem or in xylary parenchyma cells. The stem section staining pattern correlated well with the pattern of lignin deposition as detected by phloroglucinol staining of stem sections at the same adult developmental stage (Figure 2A).

\section{BdPMT Promoter:GUSPLUS Expression in Leaves}

In BdPMT promoter:GUSPLUS T1 generation plants' leaves, production of colorimetric product was strongest at the leaf margins, the leaf tip, and in major leaf veins. Strong staining was also apparent in trichome macrohairs $(\mathrm{mh})$, whereas lighter staining occurred in developing and mature bicellular microhairs (bm) and in prickle hair cells (ph) at the leaf margin (Figure 3, Supplemental Figure S8). Trichome macrohairs, microhairs, and prickle hair cells are described and documented by scanning electron microscopy (SEM) in maize by Moose et al, 2004. Note that BdPMT expression in these trichome subtypes was as expected given that lignification has been documented in the walls of these cell types (Marks et al, 2008). BdPMT promoter-driven GUS expression was not detected in non-trichome epidermal cells except at the leaf margin, or in the guard cells of stomata.

\section{BdPMT Promoter:GUSPLUS Expression in Roots}

GUSPLUS expression driven by the BdPMT promoter was assayed in 3 day old roots of seedlings which had been germinated on vertically-oriented $1 / 2 \mathrm{MS}$ minus sucrose plus 40U/ml Hygromycin agar media plates. In all transgenic lines, GUS staining was visible in the vasculature and weakly in the root cap (Figure 4, Supplemental Figure S9). In the strongest expressing lines, staining was also detected weakly in the root hairs (Figure 
4H). Overall, staining was stronger in older tissues proximal to the seedling shoot compared to younger tissues closer to the root tip. This suggests that $B d P M T$ promoter-driven expression of GUSPLUS begins in the elongation zone and continues into the mature zone.

\section{BdPMT Promoter:GUSPLUS Expression in Floral Organs}

Immature florets were removed from spikelets of adult plants approximately 35 days after seedling planting into soil. Microscopic examination of whole florets after overnight X-Gluc staining revealed strong GUS staining in the lemma (le), often to the degree that indigo precipitate became deposited in the solution between trichomes (Figure 5). Lesser staining was observed in the palea (pa). For more exact view of wildtype, nonstained palea, reference (Garvin, 2009, http://www.ars.usda.gov/SP2UserFiles/person/1931/BrachypodiumCrossing.pdf). The lemma and palea were carefully dissected away, and the internal floral organs removed and immediately photographed. BdPMT promoter::GUSPLUS-related staining was visible at the base of the ovary, in the feathery stigma, and lightly in pollen grains (Figure 6).

\section{$B d C E S A 7$ and BdCESA8 Promoter:GUSPLUS Transgenic Lines}

As with the $B d P M T$ promoter fragment, a 2,385 bp BdCESA7 promoter fragment and a 1,890 bp BdCESA8 promoter fragment (both of which extended to the genes' translational start sites) were PCR amplified and cloned into the pIPKb001 vector upstream of the maize UBIQUITIN1 intron and GUSPLUS gene. The resultant constructs were used to generate transgenic Brachypodium plants. T1 and T2-generation plants from eight independent lines each were analyzed. Overall, the GUS staining patterns observed in plants 
from these lines were very similar. However, plants from the BdCESA7

promoter:GUSPLUS transgenic lines tended to stain more strongly.

\section{BdCESA7 and BdCESA8:GUSPLUS Expression in Stems}

In BdCESA7 and BdCESA8 promoter:GUSPLUS plants' first internode stem sections, strong GUS staining was observed in epidermal cells and vascular bundles, whereas moderate GUS staining was visible in schlerenchyma cells. Staining appeared more ubiquitous in comparison to the staining observed in BdPMT promoter:GUSPLUS plants' first internode stem sections (Supplemental Figure S7).

In BdCESA7 and BdCESA8 promoter:GUSPLUS T1 adult stem sections, GUS staining was visible in sclerenchyma cells flanking the vascular bundles, within vascular bundles, and in epidermal cells (Figures 1, 7, 8). Strong expression in the vascular bundles occurred in internodes where secondary cell wall biosynthesis was actively occurring; thus, in adult plants just prior to seed fill, GUSPLUS expression driven by the $B d C E S A 7$ and $B d C E S A 8$ promoters occurred in the apical internode, while less expression occurred in more basal internodes. In internodes where GUSPLUS expression-derived staining was witnessed in the vascular bundles, staining was visible in the xylem vessels and tracheids (Figures 7 and 8). Staining in bundle sheath cells was sometimes visible in the strongest expressing lines, but not visible in moderately expressing lines. This corresponded to the weak expression of $B d C E S A 7$ in bundle sheath cells visualized by in situ hybridization, as determined by Handakumbura et al. (Figure 4E, Handakumbura et al., 2013). GUS staining was not detected in phloem or xylary parenchyma cells of BdCESA7 and BdCESA8 promoter:GUSPLUS plants (Figures 7B and 8B). 


\section{BdCESA7 and BdCESA8:GUSPLUS Expression in Leaves}

In leaves of T1-generation plants, significant differences in the intensity of staining were observed, likely due to positional effects of the transgene integration site. Specifically, regulatory sequences which were already present in the host plant's genomic DNA may have cis- or trans- regulatory effects on expression of the transgene. In moderately staining $B d C E S A 7$ and BdCESA8 promoter lines, GUS expression-related staining was detected in leaf veins, macrohair trichomes, microhair trichomes, and faintly in the cell walls between adjacent epidermal cells (Figure 3, Supplemental Figures S11 \& S12). This is consistent with CESA7 and CESA8 expression being involved in cellulose biosynthesis in the cell wall, and cellulose deposition being noted to occur in trichomes.

\section{BdCESA7 and BdCESA8:GUSPLUS Expression in Roots}

GUSPLUS expression driven by the BdCESA7 and BdCESA8 promoters was assayed in 3 day old roots of seedlings which had been germinated on $1 / 2$ MS minus sucrose plus 40U/ml Hygromycin agar plates. In all transgenic lines, GUS staining was detected in the vasculature and weakly in the root cap (Figure 4, Supplemental Figure S9). Weak root hair staining was also detected in the strongest expressing lines (Figures 4F, 4G). Overall, expression was stronger in older tissues proximal to the seedling shoot compared to younger tissue closer to the root tip. This suggests that BdCESA7 and BdCESA8 promoter driven expression of GUSPLUS begins to occur in the elongation zone and continues strongly into the mature zone. 


\section{$B d C E S A 7$ and $B d C E S A 8$ :GUSPLUS Expression in Floral Organs}

$B d C E S A 7$ and $B d C E S A 8$ promoter driven expression of the GUSPLUS reporter gene was detected in multiple tissues of immature florets. Strong expression was observed in the lemma (le), to the extreme of having blue precipitate deposited in the solution between the trichomes after overnight incubation (Figure 5). Staining was weak on the palea (dorsal side of palea shown in Figure 5, (pa)), For exact view of wildtype, non-stained palea, reference (Garvin, 2009, http://www.ars.usda.gov/SP2UserFiles/person/1931/BrachypodiumCrossing.pdf, page 3). Although weak palea staining could be dismissed as lesser exposure to the X-Gluc staining solution, this is contraindicated by efficient penetration of the stain to the internal floral organs. Upon dissection of the lemma and palea, the floral organs were removed, placed in a thin film of water to prevent the style from dessicating, and immediately photographed. $B d C E S A 7$ and $B d C E S A 8$ promoter driven expression of GUSPLUS resulted similar patterns of staining, with strong staining visible at the base of the ovary, moderate staining in the stigma and style, and weak staining in the pollen grains (Figures 6 and 9).

\section{Bdpmt Phenotypic Rescue}

In order to validate that the $B d P M T$ promoter sequence cloned was complete and sufficient to drive expression of any gene inserted its corresponding empty vector construct, a phenotypic rescue experiment was performed in which the $B d P M T$ cloned promoter sequence was used to drive expression of the BdPMT cDNA in a Bdpmt mutant genetic background.The BdPMT phenotypic rescue construct (Supplemental Figure S5) was transformed using Agrobacterium tumefaciens mediated transformation into a Bdpmt mutant 
Brachypodium distachyon line obtained from Richard Sibout and described previously (Petrik et al, 2014). Regeneration was performed under hygromycin B selection, to obtain only regenerants inheriting the $B d P M T$ rescue T-DNA insert. The $B d p m t$ mutant was received as a homozygous line, and thus, once the $B d P M T$ rescue construct was transformed into this genetic background, the initial regenerants could be analyzed for restoration of $p$ coumarate $(p \mathrm{CA})$ levels in the cell wall back to wildtype levels. Senesced stem tissue from fifteen independent transgenic lines were quantitated for average $u \mathrm{~g} p \mathrm{CA} / \mathrm{mg}$ sample, in comparison to six wildtype non-transgenic controls and three Bdpmt-1 mutant lines serving as positive and negative controls, respectively. Of the fifteen transgenic line analyzed, two lines successfully showed restoration of the wildtype level of $p$-coumarate (Supplemental Figure S15). This indicates that although positional effects of the transgene insertion site were likely affecting expression levels of the $B d P M T$ rescue construct, that the sequence cloned of the $B d P M T$ promoter was sufficient to drive $B d P M T$ expression similar to expression of the endogenous BdPMT gene by its promoter sequence at its native locus.

\section{Bdcesa8 Phenotypic Rescue}

In order to validate that the $B d C E S A 8$ promoter sequence cloned was complete and sufficient to drive expression of any gene inserted into its corresponding empty vector construct, a phenotypic rescue experiment was performed in which the BdCESA 8 cloned promoter sequence was used to drive expression of the $B d C E S A 8$ cDNA in a $B d c e s a 8$ mutant genetic background. The BdCESA8 phenotypic rescue construct (Supplemental Figure S5) was transformed using Agrobacterium tumefaciens mediated transformation into a Bdcesa 8 mutant genetic background. This Bdcesa 8 mutant was obtained from a library of 
T-DNA insertational mutants created by Dr. John Vogel (Bragg et al, 2012). Because the Bdcesa8 mutant failed to form seed when the T-DNA insertion was homozygously inherited, the homozygous mutant could not be used to derive embryos for callus generation to create host tissue for the phenotypic rescue Agrobacterium mediated transformation. Instead, embryos were harvested from heterozygous Bdcesa 8 mutants for callus generation. This meant that in order for phenotypic rescue to be validated, the initial transformed regenerants would need to be allowed to self-pollinate, so that progeny which were homozygous for the presence of the T-DNA insertion in the BdCESA8 gene and also had at least one copy of the phenotypic rescue T-DNA inherited to be identified prior to biochemical analysis for cellulose content in comparison to Bdcesa8 homozygous and heterozygous mutants, the B258p910ACT empty vector control, and wildtype plants. Homozygous Bdcesa8 mutants were both stunted in height and exhibited the expected decreased cellulose content, whereas heterozygous Bdcesa 8 mutants exhibited a growth habit and cellulose content similar to wildtype (Supplemental Figures S13 and S14). Therefore, successful phenotypically rescued Bdcesa 8 mutants should exhibit both normal height and cellulose levels at determined by the Updegraff method (Updegraff, 1969). Although cellulose quantitation of rescued plants is not yet available due to plant are still senescing, genomic DNA PCR was performed to confirm inheritance of the Bdcesa8 mutation and the successful integration of the BdCESA8 phenotypic rescue T-DNA (Supplemental Figure S16). This analysis indicated that ten transgenic lines were obtained which are homozygous for inheritance of the Bdcesa 8 mutation, and they have integrated at least one allele of the $B d C E S A 8$ phenotypic rescue T-DNA. These ten lines can therefore be directly analyzed upon their senescence, (rather than having to analyze the progeny of their 
self-pollination) for cellulose content compared to the Bdcesa8 mutant and wildtype plants as controls.

\section{Discussion}

For this study, we generated utility promoter vectors that can be used for transforming monocot plant species, for driving gene-of-interest expression in secondary cell wall forming cells. Histochemical assessment of Brachypodium distachyon plants transgenic for the BdPMT, BdCESA7, and BdCESA8 promoter::GUSPLUS constructs showed expected expression in xylem vessels, tracheids, interfascicular fiber cells, and trichomes.

Although expression patterns were consistently similar between independent transgenic plants for each promoter tested, the strength of expression varied considerably between the transgenic lines (Supplemental Figures S8-S12). This was likely due to the effects of cis- and trans- regulatory elements in the surrounding native genomic DNA proximal to the integrated T-DNA insertion. This "positional effect" has been reported previously (Ziemienowicz, 2010). Further, the number of copies of the transgene inserted into the genome can certainly affect transgene expression levels in the plant, and copy number was not assessed in these transgenic lines. Although Agrobacterium tumefaciens typically inserts its T-DNA in a single copy or two copy fashion, copy number effect may certainly be causing expression level differences across transgenic lines of a given construct. Transgene zygosity differences in different progeny individuals within one transgenic line can also cause differences between them in strength of transgene expression. Gene expression differences between transgenic lines may be desirable in instances where 
complete loss-of-function or too-high overexpression causes severe phenotypes or lethality. Efforts to mediate transgene expression variation across transgenic lines have included flanking the transgene with scaffold/matrix attachment regions (S/MARs; Breyne et al, 1992). However, although S/MAR inclusion often increased transgene expression levels overall, variation across transgenic lines still occurred (Nowak et al, 2001).

$B d P M T, B d C E S A 7$, and BdCESA8 promoter::GUSPLUS-derived staining was also observed in floral tissues at the base of the ovary, in the internal tissue of the feathery style, and within pollen grains. GUS expression driven by the $B d C E S A 7$ and $B d C E S A 8$ promoters could indicate that the $B d C E S A 7$ and $B d C E S A 8$ genes are involved in cellulose biosynthesis within pollen grain walls (Ferguson et al, 1998). BdPMT expression may be related to biosynthesis of phenolics in the intine of the pollen grain, which is composed of pectin, cellulose, and hemicellulose (Quilichini et al, 2015). Previous work by Grienenberger et al demonstrated the activity of a BAHD acyltransferase in the tapetum layer of the Arabidopsis thaliana anther, allowing synthesis of hydroxycinnamoyl spermidines (Grienenberger et al, 2009). These compounds may become a component of the pollen grain exine, as the outerwall of the pollen grain lies adjacent to the tapetum layer of the anther during development. This indicates a role of BAHD expression in developing floral tissues, which may be an area of future study in regards to $B d P M T$ expression and enzymatic function. It is important to note that the GUS enzyme produced by these constructs localizes cytoplasmically by default, given that it does not contain targeting sequences. As such, in the case of pollen grain GUS staining, no data can be gleaned as to whether the BdCESA7, BdCESA8, and BdPMT proteins are involved in intine formation or exine formation. 
The use of spatiotemporal promoters to drive ectopic expression of genes of interest can, in some instances, circumvent phenotypic abnormalities such as altered plant growth, activation of defense pathways, and related fitness costs resulting from strong constitutive overexpression (Yang et al., 2012; Hernandez-Garcia and Finer, 2014). By definition, spatiotemporal gene promoters restrict gene expression to specific tissues at different stages of development throughout the life cycle of the plant. Although seed specific, fruit specific, root or tuber specific, and anther specific gene promoters have been identified (Potenza et al, 2004), few vascular specific promoters have been cloned and characterized for grass species. One example is the Oshoxl gene from Oryza sativa, in which proximal and distal sequences within the 1,600 bp upstream sequence region were found to convey vascularspecific GUS expression patterns in multiple tissues and organs via modular combinations of repeated subsequences (Scarpella et al., 2000). The expression pattern driven by the Oshoxl gene promoter fragment differs from those driven by the promoter fragments characterized in this study in that it is more specific to the vasculature and is modulated by sucrose and auxin (Scarpella et al., 2000).

Secondary cell wall-specific gene promoters are available and have been utilized in dicot species. Recently, the poplar PtrCesA8 promoter was used to drive the poplar R2R3 MYB transcription factor PtrMYB152 in Arabidopsis thaliana to demonstrate the ability of this transcription factor to upregulate lignin biosynthesis-related genes, leading to increased secondary cell wall thickness (Wang et al, 2014). Another example in transgenic poplar was the use of the $C 4 H$ promoter to drive expression of the FERULATE 5-HYDROXYLASE $(F 5 H)$ gene. This secondary cell wall-specific expression of $F 5 H$ caused an increase in the syringyl/guaicyl $(\mathrm{S} / \mathrm{G})$ monolignol ratio in the transgenic poplar compared to 
nontransformed controls, which led to wood more resistant to wood decaying fungi (Skyba et al, 2013). More promising to the application of easing vegetative biomass recalcitrance to conversion to bioethanol was the recent success in using the Poplulus trichocarpa PtrCesA8 promoter to drive expression of a non-native FERULOYL MONOLIGNOL TRANSFERASE (AsFMT) gene from Angelica sinensis in poplar. The AsFMT enzyme functions to esterconjugate ferulate to sinapyl or coniferyl monolignol alcohols. When these ferulated monolignols are incorporated by radical oxidative coupling into the backbone of the growing lignin polymer, the ester bond serves as a easily broken linkage between adjacent monolignols. Due to the facility of breaking this ester bond, lignin modified in this way has been termed "zip lignin", and this technology holds promise as a means to lower the cost of biomass pretreatment due to a lesser requirement for high heat or chemical treatments (Wilkerson et al, 2014).

The creation of synthetic promoters is still in its infancy, due to the laborious study of regulatory elements within gene promoters either by promoter deletion or sequence synthesis followed by testing of function by fusion to reporter genes in a whole plant or cell culture system (Rushton et al, 2002). However, the fruits of these approaches would be the synthesis of designer promoters with combined spatiotemporal expression patterns. Although the use of cell culture systems to study gene promoters offers the advantages of speed of growth compared to the life cycle of an entire plant, as well as ease of isolation of desired cell types, its main disadvantage is the removal of adjoining cells which may alter cell wall deposition in the desired cell type (as seen in the "good neighbor" hypothesis described by Smith et al, 2013). The bioinformatic comparison of multiple promoter sequences to identify common regulatory elements (Molina and Grotewold, 2005), 
combined with thorough cell and developmental specificity assays of expression of their respective genes, may allow sufficient and necessary sequences to be identified for desired expression patterns.

In conclusion, it is anticipated that the utility promoter binary vector constructs characterized in this study could be used to drive gene-of-interest expression in secondary cell wall forming tissues of various grass species such as switchgrass, wheat, rice, or maize, given that other monocot promoter sequences have been shown to be functional in related species (Coussens et al., 2012). Therefore, these utility vectors should hold value in application in both model species, such as Brachypodium distachyon, and monocot crops of commercial interest. 


\section{REFERENCES}

Bragg, J., Wu, J., Gordon, S., Guttman, M., Thilmony, R., Lazo, G., Gu, Y., Vogel, J. (2012). Generation and Characterization of the Western Regional Research Center Brachypodium T-DNA Insertional Mutant Collection. PLOS ONE, 7(9), Article e41916, 1-7.

Breyne, P., van Montagu, M., Depicker, N., \& Gheysen, G. (1992). Characterization of a plant scaffold attachment region in a DNA fragment that normalizes transgene expression in tobacco. The Plant Cell, 4(4), 463-471.

Chen, Z., Hong, X., Zhang, H., Wang, Y., Li, X., Zhu, J.K., Gong, Z. (2005).

Disruption of the cellulose synthase gene, AtCesA8/IRX1, enhances drought and osmotic stress tolerance in Arabidopsis. Plant J., 43(2), 273-283.

Chiniquy, D., Varanasi, P., Oh, T., Harholt, J., 5, Katnelson, J., Singh, S., Auer, M., Simmons, B., Adams, P.D., Scheller, H.V., Ronald, P.C. (2013) Three novel rice genes closely related to the Arabidopsis IRX9, IRX9L, and IRXI4 genes and their roles in xylan biosynthesis. Frontiers in Plant Science, 4(83), 1-13.

Creux, N.M., Ranik, M., Berger, D.K., Myburg, A.A. (2008) Comparative analysis of orthologous cellulose synthase promoters from Arabidopsis, Populus, and Eucalyptus: evidence of conserved evolution in angiosperms. New Phytol., 179 (3), 722-37.

Eudes, A., Liang, Y., Mitra, P., Loqué, D. (2014) Lignin bioengineering. Curr Opin Biotechnol., 26,189-198.

Ferguson, C., Teeri, T.T., Siika, A.M., S.M. Read, S.M., Bacic, A. (1998) Location of cellulose and callose in pollen tubes and grains of Nicotiana tabacum. Planta, 206, 452-460. 
Garvin, D. (2009) Illustrated guide to crossing Brachypodium distachyon. Garvin Lab Methods.

http://www.ars.usda.gov/SP2UserFiles/person/1931/BrachypodiumCrossing.pdf.

Grienenberger, E., Besseau, S., Geoffroy, P., Debayle, D., Heintz, D., Lapierre, C., Pollet, B., Heitz, T., Legrand, M. (2009) A BAHD acyltransferase is expressed in the tapetum of Arabidopsis anthers and is involved in the synthesis of hydroxycinnamoyl spermidines. The Plant Journal, 58, 246-259.

Handakumbura, P.P., Matos, D.A., Osmont, K.S., Michael J Harrington, M.J., Heo, K., Kafle, K., Kim, S.H., Baskin, T.I., Hazen, S.H. (2013) Perturbation of Brachypodium distachyon CELLULOSE SYNTHASE A4 or 7 results in abnormal cell walls. BMC Plant Biology, 13(131), 1-15.

Hernandez-Garcia, C.M., Finer, J. (2014) Identification and validation of promoters and cis-acting regulatory elements. Plant Science, 217-218, 109-119.

Himmelbach, A., A., Zierold, U., Hensel, G., Riechen, J., Douchkov, D., Schweizer, P., Kumlehn, J. (2007) A Set of Modular Binary Vectors for Transformation of Cereals. Plant Physiol., 145(4), 1192-1200.

Lovegrove, A., Wilkinson, M.D., Freeman, J., Pellny, T.K., Tosi, P., Saulnier, L., Shewry, P.R., Mitchell, R.A. (2013) RNA interference suppression of genes in glycosyl transferase families 43 and 47 in wheat starchy endosperm causes large decreases in arabinoxylan content. Plant Physiol., 163(1), 95-107.

Mann, D.G.J., King, Z.R., Liu, W., Joyce, B.L., Percifield, R.J., Hawkins, J.S., LaFayette, P.R., Artelt, B.J., Burris, J.N., Mazarei, M., Bennetzen, J.L., Parrott, W.A., Stewart, C.N., Jr. (2011) Switchgrass (Panicum virgatum L.) polyubiquitin gene $(P v U b i l$ and $P v U b i 2)$ promoters for use in plant transformation. BMC Biotechnol., 11(74), 1-14.

Mascarenhas, D., Mettler, I.J., Pierce, D.A., Lowe, H.W. (1990) Intron-mediated enhancement of heterologous gene expression in maize. Plant Molecular Biology; 15(6), 913-920. 
Matos D.A., Whitney I.P., Harrington, M.J., Hazen, S.P. (2013) Cell walls and the developmental anatomy of the Brachypodium distachyon stem internode. PLOS ONE, 8(11):e80640, 1-9.

Molina, C., Grotewold, E. (2005) Genome wide analysis of Arabidopsis core promoters. BMC Genomics, 6(25), 1-12.

Molinari, H.B., Pellny, T.K., Freeman, J., Shewry, P.R., Mitchell, R.A.(2013) Grass cell wall feruloylation: distribution of bound ferulate and candidate gene expression in Brachypodium distachyon. Front Plant Sci.,4(50), 1-10.

Moose, S.P., Lauter, N., Carlson, S.R. (2004) The maize macrohairless 1 locus specifically promotes leaf blade macrohair initiation and responds to factors regulating leaf identity. Genetics, 166(3), 1451-61.

Nelson, M.R., Band, L.R., Dyson, R.J., Lessinnes, T., Wells, D.M., Yang, C., Everitt, N.M., Jensen, O.E., Wilson, Z.A. (2012) A biomechanical model of anther opening reveals the roles of dehydration and secondary thickening. New Phytol., 196(4), 1030-7.

Nowak W, Gawłowska M, Jarmołowski A, Augustyniak J. (2001) Effect of nuclear matrix attachment regions on transgene expression in tobacco plants. Acta Biochim Pol., 48(3), 637-46.

Norris, S.R., Meyer, S.E., Callis, J. (1993) The intron of Arabidopsis thaliana polyubiquitin genes is conserved in location and is a quantitative determinant of chimeric gene expression. Plant Molecular Biology; 21(5), 895-906.

Petrik D.L., Karlen, S.D., Cass C.L., Padmakshan, D., Lu, F., Liu, S., Le Bris, P., Antelme, S., Santoro, N., Wilkerson, C.G., Sibout, R., Lapierre, C., Ralph, J., Sedbrook, J.C. (2014) $p$-Coumaroyl-CoA monolignol transferase (PMT) acts specifically in the lignin biosynthetic pathway in Brachypodium distachyon. Plant J., 77(5), 713-26.

Plesse, B., Criqui, M.C., Durr, A., Parmentier, Y., Fleck, J., Genschik, P. (2001) Effects of the polyubiquitin gene Ubi.U4 leader intron and first ubiquitin monomer on reporter gene expression in Nicotiana tabacum. Plant Molecular Biology; 45(6), 655-667. 
Potenza, C., Aleman, L., Sengupta-Gopalan, C. (2004) Targeting transgene expression in research, agricultural, and environmental applications: promoters used in plant transformation. In Vitro Cellular \& Developmental Biology - Plant, 40(1), 1-22.

Quilichini, T.D., Grienenberger, E., Douglas, C.J. (2015) The biosynthesis, composition and assembly of the outer pollen wall: A tough case to crack. Phytochemistry, $113,170-182$.

Robbins, M.L., Roy, A., Wang, P.H., Gaffoor, I., Sekhon, R.S., de O Buanafina, M.M., Rohila, J.S., Chopra, S. (2013) Comparative proteomics analysis by DIGE and iTRAQ provides insight into the regulation of phenylpropanoids in maize. J. Proteomics, 93, 254-275.

Rushton, P.J., Reinstadler, A., Lipka, V., Lippok, B., Somssich, I.E. (2002) Synthetic plant promoters containing defined regulatory elements provide novel insights into pathogen- and wound-induced signaling, Plant Cell 14(4), 749-762.

Scarpella, E., Rueb, S., Boot, K.J.M., Hoge, J.H.C., Meijer, A.H. (2000) A role for the rice homeobox gene Oshoxl in provascular cell fate commitment. Development 127, 3655-3669.

Sharma, A., Singh, M.B., Bhalla, P.L. (2015) Anther ontogeny in Brachypodium distachyon. Protoplasma, 252(2), 439-50.

Sivamani, E., Qu R. (2006) Expression enhancement of a rice polyubiquitin gene promoter. Plant Molecular Biology, 60(2), 225-239.

Updegraff, D.M. (1969) Semi-micro determination of cellulose in biological materials. Anal Biochem, 32, 420-424.

Vanholme, R., Morreel, K., Darrah, C., Oyarce, P., Grabber, J.H., Ralph, J., Boerjan, W. (2012) Metabolic engineering of novel lignin in biomass crops. New Phytol., 196(4), 978-1000.

Vitha, S., Beneš, K., Phillips, J.P., and Gartland, K.M.A. (1995). Histochemical GUS Analysis. In Agrobacterium Protocols, K.M.A. Gartland and M.R. Davey, eds (Totowa, NJ: Humana Press), pp. 185-193. 
Withers, S., Lu, F., Kim, H., Zhu, Y., Ralph, J., Wilkerson, C.G. (2012) Identification of grass-specific enzyme that acylates monolignols with p-coumarate. J. Biol. Chem., 287(11), 8347-55.

Yang, F., Mitra, P., Zhang, L., Prak, L., Verhertbruggen, Y., Kim, J., Sun, L., Zheng, K., Tang, K., Auer, M., Scheller, H., Loque, D. (2013) Engineering secondary cell wall deposition in plants. Plant Biotechnology Journal, 3, 325-35.

Yang, C., Xu, Z., Song, J., Conner, K., Vizcay Barrena, G., Wilson, Z.A. (2007) Arabidopsis MYB26/MALE STERILE35 regulates secondary thickening in the endothecium and is essential for anther dehiscence. Plant Cell, 19(2), 534-48.

Ziemienowicz, A. (2010) Plant transgenesis. Methods Mol Biol, 631, 253-68. 


\section{CHAPTER III TABLES}

Table 1. PCR Primers Used to Amplify Promoter Sequences of BdCESA7 Bradi4g30540, BdCESA8 Bradi2g49912, BdPMT Bradi2g36910, and to Test Inheritance of Bdcesa8 TDNA Insertion and BdCESA8 Phenotypic Rescue.

\begin{tabular}{|l|l|c|c|c|}
\hline \multicolumn{1}{|c|}{ Sequence Name } & \multicolumn{1}{|c|}{ Sequence 5' to 3' } & Len & \%GC Content & Tm \\
\hline BdCESA7proFSwaI & GAGAGATTTAAATGTCGTGGTACGGAGGAGCTAG & 35 & 45.7 & 69.4 \\
\hline BdCESA7proRAscI & GAGAGGCGCGCCCGCCGGCCGGTCGATCTCCGC & 33 & 81.8 & 83.3 \\
\hline BdCESA8proFStuI & GAGAGAGGCCTGCTGCCACGCTGGTGAAGG & 30 & 66.7 & 75.6 \\
\hline BdCESA8proRAscI & GAGAGGCGCGCCGGCTCTCCCTCCGTGCG & 29 & 79.3 & 80.2 \\
\hline BdPMTproFSwaI & GAGAGATTTAAATGATGCGGAGGAGATAG & 29 & 41.4 & 64.6 \\
\hline BdPMTproRAscI & GAGAGGCGCGCCTAAGCTTGCATGCTCTAGC & 31 & 61.3 & 73.9 \\
\hline NOST primer up & GCAAGACCGGCAACAGGATT & 20 & 55 & 54.69 \\
\hline BdCESA8 EX13 F1 & CCTGGTGCTCAACCTTGTCG & 20 & 60 & 55.34 \\
\hline T3 T-DNA LB & AGCTGTTTCCTGTGTGAATTG & 22 & 41 & 52.42 \\
\hline GSP R Mandy & GAAGACTGCCCAAACGACTT & 20 & 50 & 52.34 \\
\hline JJ18282 F1 & TTGATGCTTGCTGATCCTTCCTAG & 24 & 46 & 57.58 \\
\hline JJ18282 R1 & CTGGTCCTTGGATGCCATCAAGC & 23 & 57 & 58.42 \\
\hline
\end{tabular}

Note: Tm calculated using Nearest Neighbor method. 
Table 2. BdPMT Promoter Annotation of Cell Wall, Vascular Expression, and Responsive Element Related Motifs.

\begin{tabular}{|c|c|c|c|}
\hline Motif Name & \# & Sequence & Putative function \\
\hline CACTFTPPCA1 & 50 & YACT & Mesophyll-specific expression \\
\hline ACGTATERD1 & 38 & ACGT & Etiolation-induced expression; early response to dehydration \\
\hline CURECORECR & 30 & GTAC & Copper-response element; Also involved in oxygen-response \\
\hline WRKY71OS & 30 & TGAC & Giberrillin-responsive \\
\hline MYCCONSENSUSAT & 28 & CANNTG & dehydration-responsive; cold-responsive \\
\hline GATABOX & 27 & GATA & Required for high level, light regulated, and tissue specific expression \\
\hline CAATBOX1 & 23 & CCAAT & CCAAT box found in the promoter of heat shock proteins genes \\
\hline ARR1AT & 21 & NGATT & "ARR1-binding element" found in Arabidopsis; ARR1 is a response regulator \\
\hline POLLEN1LELAT52 & 21 & AGAAA & Pollen specific activation \\
\hline GTGANTG10 & 17 & GTGA & May confer pollen specificity \\
\hline WBOXNTERF3 & 14 & TGACY & Wounding responsive \\
\hline GT1CONSENSUS & 12 & GRWAAW & Light regulated \\
\hline CBFHV & 9 & RYCGAC & Dehydration-responsive \\
\hline P1BS & 8 & GNATATNC & Phosphate-responsive \\
\hline WBOXATNPR1 & 8 & TTGAC & W-box; recognized specifically by salicylic acid (SA)-induced WRKY DNA binding proteins \\
\hline ABRELATERD1 & 7 & ACGTG & Etiolation-induced expression; early response to dehydration \\
\hline IBOXCORE & 7 & GATAA & Conserved sequence upstream of light-regulated genes \\
\hline INRNTPSADB & 7 & YTCANTYY & Light-responsive transcription \\
\hline TATABOX5 & 7 & TTATTT & TATA box \\
\hline ASF1MOTIFCAMV & 6 & TGACG & Transcriptional activation by salicylic acid or auxin; Also may be light responsive \\
\hline NTBBF1ARROLB & 6 & ACTTA & Required for tissue-specific expression and auxin induction \\
\hline WBOXNTCHN48 & 6 & CTGACY & $\begin{array}{l}\text { W box; NtWRKY1, NtWRKY } 2 \text { and NtWRKY4 bound to W box; NtWRKYs possibly involved in } \\
\text { elicitor-responsive transcription of defense genes }\end{array}$ \\
\hline DPBFCOREDCDC3 & 5 & ACACNNG & May confer embryo and ABA specificity \\
\hline MYB1AT & 5 & WAACCA & Dehydration responsive \\
\hline MYB2CONSENSUSAT & 5 & YAACKG & Dehydration responsive \\
\hline OSE2ROOTNODULE & 5 & СТCT & Organ-specific elements (OSE) activated in infected cells of root nodules \\
\hline RHERPATEXPA7 & 5 & KCACGW & Root Hair Cell-Specific cis-Element \\
\hline ABRERATCAL & 4 & MACGYGB & $\mathrm{Ca}(2+)$-responsive upregulation \\
\hline CCAATBOX1 & 4 & CCAAT & CCAAT box found in the promoter of heat shock proteins genes \\
\hline RYREPEATBNNAPA & 4 & CATGCA & Required for seed specific expression \\
\hline TBOXATGAPB & 3 & ACTTTG & Light-activation \\
\hline ARFAT & 2 & TGTCTC & ARF (auxin response factor) binding site \\
\hline CGCGBOXAT & 2 & VCGCGB & Ca++/calmodulin responsive \\
\hline CRTDREHVCBF2 & 2 & GTCGAC & Temperature-responsive \\
\hline EECCRCAH1 & 2 & GANTTNC & $\mathrm{EEC}$; Consensus motif of the two enhancer elements, $\mathrm{EE}-1$ and and $\mathrm{EE}-2$ \\
\hline ELRECOREPCRP 1 & 2 & TTGACC & EIRE (Elicitor Responsive Element) \\
\hline EMHVCHORD & 2 & TGTAAAGT & Endosperm motif (EM) \\
\hline GT1GMSCAM4 & 2 & GAAAAA & Pays a role in pathogen- and salt-induced \\
\hline MYBATRD22 & 2 & CTAACCA & Dehydration and $\mathrm{ABA}$ responsive \\
\hline
\end{tabular}

(Table Continues) 


\begin{tabular}{|c|c|c|c|}
\hline Motif Name & \# & Sequence & Putative function \\
\hline MYBPLANT & 2 & MACCWAMC & $\begin{array}{l}\text { Plant MYB binding site; Consensus sequence related to box } P \text { in promoters of } \\
\text { phenylpropanoid biosynthetic genes }\end{array}$ \\
\hline MYCATERD1 & 2 & CATGTG & Dehydration-responsive \\
\hline OSE1ROOTNODULE & 2 & AAAGAT & organ-specific elements (OSEs); activated in infected cells of root nodules \\
\hline PYRIMIDINEBOXOSRAMY1A & 2 & CCTाT & Giberrillin-responsive \\
\hline REALPHALGLHCB21 & 2 & AACCAA & Required for phytochrome regulation \\
\hline SORLIP1AT & 2 & GCCAC & Light-Induced \\
\hline SORLIP2AT & 2 & GGGCC & Light-Induced \\
\hline "T/GBOXATPIN2" & 1 & AACGTG & Jasmonate $(\mathrm{JA})$ induction \\
\hline ABREATRD22 & 1 & RYACGTGGYR & ABA and dehydration responsive \\
\hline ABREOSRAB21 & 1 & ACGTSSSC & $A B A$ responsive element ( $A B R E)$ \\
\hline ACGTABREMOTIFA2OSEM & 1 & ACGTGKC & ABA responsive element (ABRE) \\
\hline ACGTOSGLUB1 & 1 & GTACGTG & Required for endosperm-specific expression \\
\hline BOXLCOREDCPAL & 1 & ACCWWCC & $\begin{array}{l}\text { Consensus of the putative "core" sequences of box-L-like sequences in the carrot (D.c.) PAL1 } \\
\text { promoter region }\end{array}$ \\
\hline CANBNNAPA & 1 & CNAACAC & Seed specificity; activator and repressor \\
\hline CIACADIANLELHC & 1 & CAANNNNATC & Region necessary for circadian expression \\
\hline CMSRE1IBSPOA & 1 & TGGACGG & CMSRE-1 (Carbohydrate Metabolite Signal Responsive Element 1) \\
\hline CPBCSPOR & 1 & TATTAG & Cytokinin-responsive \\
\hline GADOWNAT & 1 & ACGTGTC & Giberrillin-downregulated \\
\hline GARE2OSREP1 & 1 & TAACGTA & Gibberellin-responsive element (GARE) \\
\hline GAREAT & 1 & TAACAAR & GARE (GA-responsive element) \\
\hline L1BOXATPDF1 & 1 & TAAATGYA & Involved in L1 layer-specific expression \\
\hline LTRECOREATCOR15 & 1 & CCGAC & Core of low temperature responsive element (LTRE) \\
\hline MYB2AT & 1 & TAACTG & Water-stress responsive \\
\hline PALBOXAPC & 1 & CCGTCC & $\begin{array}{l}\text { Box A; Consensus; One of three putative cis-acting elements (boxes P, A, L) of the } \\
\text { phenylalanine ammonia-lyase (PAL); These elements appear to be necessary but not } \\
\text { sufficient for elicitor- or light-mediated PAL gene activation }\end{array}$ \\
\hline SORLIP3AT & 1 & CTCAAGTGA & Light-Induced \\
\hline SORLIP5AT & 1 & GAGTGAG & Light-Induced \\
\hline SORLREP3AT & 1 & TGTATATAT & Light-Induced \\
\hline SREATMSD & 1 & ТTATCC & sugar-repressive element (SRE) \\
\hline SV4OCOREENHAN & 1 & GTGGWWHG & SV40 core enhancer \\
\hline TATABOX2 & 1 & TATAAAT & Putative TATA box \\
\hline TATABOX4 & 1 & TATATAA & Putative TATA box \\
\hline TATABOXOSPAL & 1 & TATTTAA & $\begin{array}{l}\text { Binding site for OsTBP2, found in the promoter of rice pal gene encoding phenylalanine } \\
\text { ammonia-lyase. }\end{array}$ \\
\hline TELOBOXATEEF1AA1 & 1 & AAACCCTAA & Required for the activation of expression in root primordia \\
\hline XYLAT & 1 & ACAAAGAA & Cis-element identified among the promoters of the "core xylem gene set" \\
\hline CRPE5 & 1 & GNCA(C/G)TGA & $\begin{array}{l}\text { Primary cell wall associated CesA motif in A.t., P.t., and E.g.; Jasmonic acid responsive } \\
\text { element }\end{array}$ \\
\hline CRPE8 & 2 & GGNGGTGG & Primary cell wall associated CesA motif in A.t., P.t., and E.g.; Anthocyanin regulatory element \\
\hline CRPE9 & 9 & CNCNNCNC & Primary cell wall associated CesA motif in A.t., P.t., and E.g.; Vascular-specific expression \\
\hline CRPE12 & 6 & ATN(A/T)ATTA & Primary cell wall associated CesA motif in A.t., P.t., and E.g.; Phosphate response domain. \\
\hline CRPE13 & 25 & $\mathrm{GC}(\mathrm{A} / \mathrm{T}) \mathrm{NGC}$ & Primary cell wall associated CesA motif in A.t., P.t., and E.g.; Abscisic acid responsive element \\
\hline CRPE14 & 3 & $N G(A / G) C N G T G$ & Primary cell wall associated CesA motif in A.t., P.t., and E.g.; Function not avaliable. \\
\hline CRPE16 & 2 & GAGCG(A/C) & Primary cell wall associated CesA motif in A.t., P.t., and E.g.; Light repression element \\
\hline CRPE17 & 2 & $\mathrm{GTC}(\mathrm{G} / \mathrm{T}) \mathrm{GT}$ & Primary cell wall associated CesA motif in A.t., P.t., and E.g.; Function not avaliable. \\
\hline CRPE18 & 5 & ANNGA(C/T)AG & Primary cell wall associated CesA motif in A.t., P.t., and E.g.; Function not avaliable. \\
\hline CRPE19 & 3 & ACAGNCNG & Primary cell wall associated CesA motif in A.t., P.t., and E.g.; Function not avaliable. \\
\hline CRPE 20 & 7 & TाTाT & Primary cell wall associated CesA motif in A.t., P.t., and E.g.; AT-rich element \\
\hline CRPE 23 & 33 & $\operatorname{TNNCN}(\mathrm{G} / \mathrm{T}) \mathrm{NC}$ & Primary cell wall associated CesA motif in A.t., P.t., and E.g.; Function not avaliable. \\
\hline CRPE 28 & 4 & NNGCATGC & $\begin{array}{l}\text { Secondary cell wall associated CesA motif in A.t., P.t., and E.g.; Iron defiency responsive } \\
\text { element }\end{array}$ \\
\hline CRPE 30 & 13 & NNNT(C/G)AAG & Secondary cell wall associated CesA motif in A.t., P.t., and E.g.; Function not avaliable. \\
\hline CRPE31 & 3 & GNGNAGNG & Secondary cell wall associated CesA motif in A.t., P.t., and E.g.; Function not avaliable. \\
\hline CRPE 32 & 13 & $(A / G) N(C / G)(C / T) T(A / G)(C / G) C$ & Secondary cell wall associated CesA motif in A.t., P.t., and E.g.; Function not avaliable. \\
\hline
\end{tabular}

Note: Annotation of over-represented motifs in the promoters of primary and secondary cell wall-associated CESA genes of Arabidopsis thaliana (A.t.), Populus trichocarpa (P.t.), and Eucalyptus grandis (E.g.). These motifs are abbreviated CRPE (CESA-related promoter element). In addition, vascular, cell wall related, and responsive element motifs identified using the PLACE database have been included. 
Table 3. BdCESA7 Promoter Annotation of Cell Wall, Vascular Expression, and Responsive Element Related Motifs.

\begin{tabular}{|c|c|c|c|}
\hline Motif Name & \# & Sequence & Putative Function \\
\hline MYCCONSENSUSAT & 22 & CANNTG & Dehydration-responsive \\
\hline GTGANTG10 & 21 & GTGA & May confer pollen-specific expression \\
\hline WRKY71OS & 20 & TGAC & A core of TGAC-containing W-box; Giberrillin-responsive \\
\hline ACGTATERD1 & 18 & ACGT & Etiolation-induced expression \\
\hline CGCGBOXAT & 18 & VCGCGB & Signal-responsive \\
\hline CACTFTPPCA1 & 16 & YACT & Mesophyll expression module 1 \\
\hline WBOXNTERF3 & 11 & TGACY & May be wounding responsive \\
\hline CBFHV & 10 & RYCGAC & dehydration-responsive element \\
\hline GATABOX & 10 & GATA & Required for high level, light regulated, and tissue specific expression \\
\hline GT1CONSENSUS & 9 & GRWAAW & Consensus GT-1 binding site in many light-regulated genes \\
\hline LTRECOREATCOR15 & 8 & CCGAC & Core of low temperature responsive element (LTRE) \\
\hline SORLIP1AT & 8 & GCCAC & Light-Induced \\
\hline DRECRTCOREAT & 6 & RCCGAC & Dehydration-responsive element \\
\hline GT1GMSCAM4 & 6 & GAAAAA & Pathogen- and salt-induced \\
\hline OSE2ROOTNODULE & 6 & СТСTT & Organ-specific elements (OSE); activated in infected cells of root nodules \\
\hline POLLEN1LELAT52 & 6 & AGAAA & Pollen specificity \\
\hline ABRELATERD1 & 5 & ACGTG & etiolation-induced \\
\hline INRNTPSADB & 5 & YTCANTYY & Light-responsive \\
\hline SORLIP2AT & 5 & GGGCC & Light-Induced \\
\hline WBOXATNPR1 & 5 & TTGAC & Recognized specifically by salicylic acid (SA)-induced WRKY DNA binding proteins \\
\hline "-300ELEMENT" & 4 & TGHAAARK & Endosperm-specific gene expression \\
\hline DRE2COREZMRAB17 & 4 & ACCGAC & May confer ABA-responsiveness \\
\hline MYB1AT & 4 & WAACCA & Dehydration-responsive \\
\hline MYB2CONSENSUSAT & 4 & YAACKG & Dehydration-responsive \\
\hline WBOXNTCHN48 & 4 & CTGACY & $\begin{array}{l}\text { "W box"; NtWRKY1, NtWRKY2, and NtWRKY4 bound to W box; NtWRKYs possibly involved in elicitor- } \\
\text { responsive transcription of defense genes }\end{array}$ \\
\hline CAATBOX1 & 3 & САAT & CAAT promoter consensus sequence \\
\hline MYBPLANT & 3 & MACCWAMC & Consensus sequence related to box $P$ in promoters of phenylpropanoid biosynthetic genes \\
\hline RHERPATEXPA7 & 3 & KCACGW & Right part of RHEs (Root Hair-specific cis-Elements) \\
\hline RYREPEATBNNAPA & 3 & CATGCA & Required for seed specific expression \\
\hline CANBNNAPA & 2 & CNAACAC & Embryo- and endosperm-specific transcription \\
\hline CATATGGMSAUR & 2 & CATATG & Auxin responsiveness \\
\hline DPBFCOREDCDC3 & 2 & ACACNNG & Embryo-specific, and also can be induced by ABA \\
\hline EECCRCAH1 & 2 & GANTTNC & Consensus motif of the two enhancer elements, EE- 1 and EE- 2 \\
\hline GLMHVCHORD & 2 & RTGASTCAT & Nitrogen responsive element \\
\hline MYCATERD1 & 2 & CATGTG & Early responsive to dehydration \\
\hline MYCATRD22 & 2 & CACATG & \\
\hline PALBOXAPC & 2 & CCGTCC & $\begin{array}{l}\text { Box A; Consensus; One of three putative cis-acting elements (boxes } \mathrm{P}, \mathrm{A} \text {, and } \mathrm{L} \text { ) of phenylalanine ammonia } \\
\text { lyase (PAL); These elements appear to be necessary but not sufficient for elicitor- or light-mediated PAL } \\
\text { gene activation }\end{array}$ \\
\hline PROLAMINBOXOSGLUB1 & 2 & TGCAAAG & Involved in quantitative regulation \\
\hline PYRIMIDINEBOXHVEPB1 & 2 & ताTाTाCC & Required for GA induction \\
\hline RYREPEATLEGUMINBOX & 2 & CATGCAY & May confer seed-specific expression \\
\hline SORLREP3AT & 2 & TGTATATAT & \\
\hline "-300MOTIFZMZEIN" & 1 & RTGAGTCAT & May confer endosperm specificity \\
\hline "T/GBOXATPIN2" & 1 & AACGTG & Involved in jasmonate $(\mathrm{JA})$ induction \\
\hline ABREOSRAB21 & 1 & ACGTSSSC & \\
\hline ACGTABREMOTIFA2OSEM & 1 & ACGTGKC & ABA-responsive \\
\hline ACGTOSGLUB1 & 1 & GTACGTG & Required for endosperm-specific expression \\
\hline AMMORESIVDCRNIA1 & 1 & CGAACTT & Ammonium responsive \\
\hline ARE1 & 1 & RGTGACNNNGC & Antioxidant response element \\
\hline BOXIIPCCHS & 1 & ACGTGGC & Essential for light regulation \\
\hline ССААТВOX1 & 1 & ССAAT & CCAAT box found in the promoter of heat shock proteins genes \\
\hline CIACADIANLELHC & 1 & CAANNNNATC & Region necessary for circadian expression \\
\hline GARE1OSREP1 & 1 & TAACAGA & Gibberellin-responsive element (GARE) \\
\hline GCCCORE & 1 & GCCGCC & Pathogen-responsive \\
\hline
\end{tabular}

(Table Continues) 


\begin{tabular}{|c|c|c|c|}
\hline Motif Name & \# & Sequence & Putative Function \\
\hline GCN4OSGLUB1 & 1 & TGAGTCA & Required for endosperm-specific expression \\
\hline LTRE1HVBLT49 & 1 & CCGAAA & LTRE-1 (low-temperature-responsive element \\
\hline OSE1ROOTNODULE & 1 & AAAGAT & Organ-specific elements (OSE) characteristic of the promoters activated in infected cells of root nodules \\
\hline POLLEN2LELAT52 & 1 & TCCACCATA & pollen specific activation \\
\hline QELEMENTZMZM13 & 1 & AGGTCA & May be involved in up-regulation of genes in pollen \\
\hline TATABOX3 & 1 & TATTAAT & TATA box \\
\hline TATABOX5 & 1 & TТАТT & TATA box \\
\hline TBOXATGAPB & 1 & ACTTTG & Light-activated gene transcription \\
\hline XYLAT & 1 & ACAAAGAA & cis-element identified among the promoters of the "core xylem gene set" \\
\hline CRPE 4 & 1 & (A/C)TGTCGG & Primary cell wall associated CesA motif in A.t., P.t., and E.g.; Abscisic acid (ABA) responsive element \\
\hline CRPE 8 & 1 & GGNGGTGG & Primary cell wall associated CesA motif in A.t., P.t., and E.g.; Anthocyanin regulatory element \\
\hline CRPE 9 & 30 & CNCNNCNC & $\begin{array}{l}\text { Over-represented in promoters of the primary cell wall-associated CesA genes in A.t., P.t., and E.g.; } \\
\text { Function not available }\end{array}$ \\
\hline CRPE 10 & 2 & $\operatorname{CCNC}(\mathrm{A} / \mathrm{C}) \mathrm{CCC}$ & Primary cell wall associated CesA motif in A.t., P.t., and E.g.; Vascular-specific expression \\
\hline CRPE 13 & 17 & $\mathrm{GC}(\mathrm{A} / \mathrm{T}) \mathrm{NGC}$ & Primary cell wall associated CesA motif in A.t., P.t., and E.g.; Abscisic acid (ABA) responsive element \\
\hline CRPE 15 & 1 & $\mathrm{G}(\mathrm{C} / \mathrm{T}) \mathrm{GCTC}$ & Primary cell wall associated CesA motif in A.t., P.t., and E.g.; Phloem-specific expression \\
\hline CRPE 16 & 2 & GAGCG(A/C) & Primary cell wall associated CesA motif in A.t., P.t., and E.g.; Light repression element \\
\hline CRPE 17 & 6 & GTC(G/T) GT & $\begin{array}{l}\text { Over-represented in promoters of the primary cell wall-associated CesA genes in A.t., P.t., and E.g.; } \\
\text { Function not available }\end{array}$ \\
\hline CRPE 18 & 2 & ANNGA(C/T)AG & $\begin{array}{l}\text { Over-represented in promoters of the primary cell wall-associated CesA genes in A.t., P.t., and E.g.; } \\
\text { Function not available }\end{array}$ \\
\hline CRPE 19 & 1 & ACAGNCNG & $\begin{array}{l}\text { Over-represented in promoters of the primary cell wall-associated CesA genes in A.t., P.t., and E.g.; } \\
\text { Function not available }\end{array}$ \\
\hline CRPE 20 & 16 & TाTाT & Primary cell wall associated CesA motif in A.t., P.t., and E.g.; AT-rich element (AT1BOX) \\
\hline CRPE 22 & 1 & $C(C / T) C(C / G) N C C C$ & $\begin{array}{l}\text { Over-represented in promoters of the primary cell wall-associated CesA genes in A.t., P.t., and E.g.; } \\
\text { Function not available }\end{array}$ \\
\hline CRPE 23 & 35 & $\operatorname{TNNCN}(\mathrm{G} / \mathrm{T}) \mathrm{NC}$ & $\begin{array}{l}\text { Over-represented in promoters of the primary cell wall-associated CesA genes in A.t., P.t., and E.g.; } \\
\text { Function not available }\end{array}$ \\
\hline CRPE 28 & 2 & NNGCATGC & Secondary cell wall associated CesA motif in A.t., P.t., and E.g.; Iron deficiency responsive element \\
\hline CRPE 30 & 29 & NNNT(C/G)AAG & Secondary cell wall associated CesA motif in A.t., P.t., and E.g.; Function not available \\
\hline CRPE 31 & 7 & GNGNAGNG & Secondary cell wall associated CesA motif in A.t., P.t., and E.g.; Function not available \\
\hline CRPE 32 & 10 & $(A / G) N(C / G)(C / T) T(A / G)(C / G) C$ & Secondary cell wall associated CesA motif in A.t., P.t., and E.g.; Function not available \\
\hline
\end{tabular}

Note: Annotation of over-represented motifs in the promoters of primary and secondary cell wall-associated CESA genes of Arabidopsis thaliana (A.t.), Populus trichocarpa (P.t.), and Eucalyptus grandis (E.g.). These motifs are abbreviated CRPE (CESA-related promoter element). In addition, vascular, cell wall related, and responsive element motifs identified using the PLACE database have been included. 
Table 4. BdCESA8 Promoter Annotation of Cell Wall, Vascular Expression, and Responsive Element Related Motifs.

\begin{tabular}{|c|c|c|c|}
\hline Motif Name & \# & Motif sequence & Putative Function \\
\hline MYCCONSENSUSAT & 20 & CANNTG & Dehydration-responsive gene \\
\hline GTGANTG10 & 19 & GTGA & Might confer pollen specific gene expression. \\
\hline WRKY71OS & 12 & TGAC & Binding site of rice WRKY71, a transcriptional repressor of the giberrellin signaling pathway \\
\hline CURECORECR & 10 & GTAC & Copper-response element \\
\hline OSE2ROOTNODULE & 9 & СТСТT & Organ-specific elements of root nodules \\
\hline WBOXNTERF3 & 8 & TGACY & May be involved in wounding-activated expression \\
\hline GT1CONSENSUS & 7 & GRWAAW & Consensus GT- 1 binding site in many light-regulated genes \\
\hline INRNTPSADB & 7 & YTCANTYY & Light-responsive transcription \\
\hline ACGTATERD1 & 6 & ACGT & Etiolation-induced expression (early responsive to dehydration) in At \\
\hline BS1EGCCR & 5 & AGCGGG & BS1 (binding site 1) found in E. gunnii Cinnamoyl-CoA reductase (CCR) gene promoter; Required for vascular expression \\
\hline CBFHV & 4 & RYCGAC & Dehydration-responsive elements (DRE) \\
\hline GATABOX & 4 & GATA & Required for high level, light regulated, and tissue specific expression \\
\hline LTRECOREATCOR15 & 4 & CCGAC & ABA responsiveness; Involved in cold induction; drought- induced gene expression. \\
\hline MYB1AT & 4 & WAACCA & Dehydration-responsive \\
\hline SORLIP1AT & 4 & GCCAC & One of "Sequences Over-Represented in Light-Induced Promoters (SORLIPs) in At \\
\hline WBOXATNPR1 & 4 & TGGAC & They were recognized specifically by salicylic acid (SA)-induced WRKY DNA binding proteins \\
\hline ABRELATERD1 & 3 & ACGTG & Etiolation-induced expression \\
\hline ABRERATCAL & 3 & MACGYGB & $\mathrm{Ca}(2+)$-responsive upregulated genes \\
\hline GT1GMSCAM4 & 3 & GAAAAA & Plays a role in pathogen- and salt-induced ScaM- 4 gene expression \\
\hline LTRE1HVBLT49 & 3 & CCGAAA & LTRE-1 (low-temperature-responsive element) in barley (H.v.) \\
\hline BOXLCOREDCPAL & 2 & ACCWWCC & Consensus of the putative "core" sequences of box-L-like seqeunces in the carrot (D.c.) PAL1 promoter region \\
\hline ССААТВOX1 & 2 & ССAAT & $\begin{array}{l}\text { Common sequence found in the 5'-non-coding regions of eukaryotic genes; "CCAAT box" found in the promoter of heat shock } \\
\text { proteins genes }\end{array}$ \\
\hline ELRECOREPCRP1 & 2 & TTGACC & EIRE (Elicitor Responsive Element) core of parsley (P.c.) PR1 genes; Required for elicitor responsiveness \\
\hline OSEIROOTNODULE & 2 & AAAGAT & Organ-specific elements (OSEs) characterisitc of the promoters activated in infected cells of root nodules \\
\hline RHERPATEXPA7 & 2 & KCACGW & Root Hair Cell-Specific cis-Element in Angiosperms \\
\hline SORLIP5AT & 2 & GAGTGAG & One of "Sequences Over-Represented in Light-Induced Promoters (SORLIPs) in At \\
\hline SURECOREATSULTR11 & 2 & GAGAC & Core of sulfur-responsive element (SURE) \\
\hline "T/GBOXATPIN2" & 1 & AACGTG & Involved in jasmonate (JA) \\
\hline AACACOREOSGLUB1 & 1 & AACAAAC & Endosperm-specific expression \\
\hline CIACADIANLELHC & 1 & CAANNNNATC & Circadian expression \\
\hline ERELEE4 & 1 & AWTTCAAA & ERE (ethylene responsive element) \\
\hline GAREAT & 1 & TAACAAR & GARE (GA-responsive element) \\
\hline GCCCORE & 1 & GCCGCC & $\begin{array}{l}\text { Core of GCC-box found in many pathogen-responsive genes; Has been shown to funtion as an ethylene-responsive element; } \\
\text { jasmonate-responsive gene expression }\end{array}$ \\
\hline IBOX & 1 & GATAAG & Light-regulated \\
\hline IBOXCORE & 1 & GATAA & Light-regulated \\
\hline IRO2OS & 1 & CACGTGG & Induced by Fe deficiency \\
\hline MYB2CONSENSUSAT & 1 & YAACKG & Dehydration-responsive \\
\hline MYBGAHV & 1 & TAACAAA & Central element of gibberellin (GA) response complex \\
\hline MYBPLANT & 1 & MACCWAMC & Consensus sequence related to box $P$ in promoters of phenylpropanoid biosynthetic genes such as PAL, CHS, CHI, DR, CL, Bz1 \\
\hline MYCATERD1 & 1 & CATGTG & Early responsive to dehydration \\
\hline MYCATRD22 & 1 & CACATG & Dehydration responsive \\
\hline PALBOXAPC & 1 & CCGTCC & One of three putative cis-acting elements (boxes $P, A, L$ ) of the phenylalanine ammonia-lyase (PAL \\
\hline PALBOXPPC & 1 & YTYYMMCMAMCMMC & $\begin{array}{l}\text { Box P; Consensus; One of three putative cis-acting elements (boxes P, A, L) of the phenylalanine ammonia-lyase (PAL) necessary } \\
\text { but not sufficient for elicitor- or light-mediated PAL gene activation. }\end{array}$ \\
\hline QARBNEXTA & 1 & AACGTGT & QAR (quantitative activator region) \\
\hline RYREPEATBNNAPA & 1 & CATGCA & Required for seed specific expression \\
\hline SORLIP2AT & 1 & GGGCC & Light-Induced Promoters (SORLIPs) in At \\
\hline TATABOX 5 & 1 & ПТАПТ & TATA Box \\
\hline TBOXATGAPB & 1 & ACTTG & Light-activated gene transcription \\
\hline WBOXNTCHN48 & 1 & CTGACY & $\begin{array}{l}\text { NtWRKY1, NtWRKY2 and NtWRKY4 bound to W box; NtWRKYs possibly involved in elicitor-responsive transcription of defense } \\
\text { genes }\end{array}$ \\
\hline
\end{tabular}

(Table Continues) 


\begin{tabular}{|c|c|c|c|}
\hline Motif Name & \# & Motif sequence & Putative Function \\
\hline CRPE 7 & 2 & GGGGC(A/G)NGNN & Primary and Secondary cell wall associated CesA motif in A.t., P.t., and E.g.; Ethylene Response Element \\
\hline CRPE 8 & 2 & GGNGGTGG & Primary cell wall associated CesA motif in A.t., P.t., and E.g.; Anthocyanin regulatory element \\
\hline CRPE 9 & 32 & CNCNNCNC & Primary cell wall associated CesA motif in A.t., P.t., and E.g.; Function not avaliable. \\
\hline CRPE 10 & 8 & $\operatorname{CCNC}(\mathrm{A} / \mathrm{C}) \mathrm{CCC}$ & Primary cell wall associated CesA motif in A.t., P.t., and E.g.; Vascular-specific expression \\
\hline CRPE 13 & 5 & GC(A/T)NGC & Primary cell wall associated CesA motif in A.t., P.t., and E.g.; Abscisic acid responsive element \\
\hline CRPE 14 & 1 & NG(A/G)CNGTG & Primary cell wall associated CesA motif in A.t., P.t., and E.g.; Function not avaliable. \\
\hline CRPE 15 & 3 & G(C/T)GCTC & Primary cell wall associated CesA motif in A.t., P.t., and E.g.; Phloem-specific gene expression \\
\hline CRPE 16 & 2 & GAGCG(A/C) & Primary cell wall associated CesA motif in A.t., P.t., and E.g.; Light repression element \\
\hline CRPE 17 & 1 & GTC(G/T)GT & Primary cell wall associated CesA motif in A.t., P.t., and E.g.; Function not avaliable. \\
\hline CRPE 19 & 2 & ACAGNCNG & $\begin{array}{l}\text { Primary cell wall associated CesA motif in A.t., P.t., and E.g.; Over-represented motifs in the promoters of the primary and } \\
\text { secondary cell wall-associated CESA genes; Function not avaliable. }\end{array}$ \\
\hline CRPE 20 & 5 & ताTाT & Primary cell wall associated CesA motif in A.t., P.t., and E.g.; AT-rich element \\
\hline CRPE 22 & 9 & $C(C / T) C(C / G) N C C C$ & $\begin{array}{l}\text { Primary cell wall associated CesA motif in A.t., P.t., and E.g.; Over-represented motifs in the promoters of the primary and } \\
\text { secondary cell wall-associated CESA genes; Function not avaliable. }\end{array}$ \\
\hline CRPE 23 & 25 & $\operatorname{TNNCN}(G / T) N C$ & $\begin{array}{l}\text { Primary cell wall associated CesA motif in A.t., P.t., and E.g.; Over-represented motifs in the promoters of the primary and } \\
\text { secondary cell wall-associated CESA genes; Function not avaliable. }\end{array}$ \\
\hline CRPE 24 & 5 & $G G(C / G)(A / T)(C / G) G(A / G)(G / C)$ & $\begin{array}{l}\text { Primary cell wall associated CesA motif in A.t., P.t., and E.g.; Over-represented motifs in the promoters of the primary and } \\
\text { secondary cell wall-associated CESA genes; Function not avaliable. }\end{array}$ \\
\hline CRPE 26 & 1 & $\operatorname{TCCTGC}(\mathrm{C} / \mathrm{T}) \mathrm{G}$ & Secondary cell wall associated CesA motif in A.t., P.t., and E.g.; Function not avaliable. \\
\hline CRPE 30 & 12 & NNNT(C/G)AAG & Secondary cell wall associated CesA motif in A.t., P.t., and E.g.; Function not avaliable. \\
\hline CRPE 31 & 9 & GNGNAGNG & Secondary cell wall associated CesA motif in A.t., P.t., and E.g.; Function not avaliable. \\
\hline CRPE 32 & 3 & $(A / G) N(C / G)(C / T) T(A / G)(C / G) C$ & t., and E.g.; Function not avaliable. \\
\hline
\end{tabular}

Note: Annotation of over-represented motifs in the promoters of primary and secondary cell wall-associated CESA genes of Arabidopsis thaliana (A.t.), Populus trichocarpa (P.t.), and Eucalyptus grandis (E.g.). These motifs are abbreviated CRPE (CESA-related promoter element). In addition, vascular, cell wall related, and responsive element motifs identified using the PLACE database have been included. 


\section{CHAPTER III FIGURES}
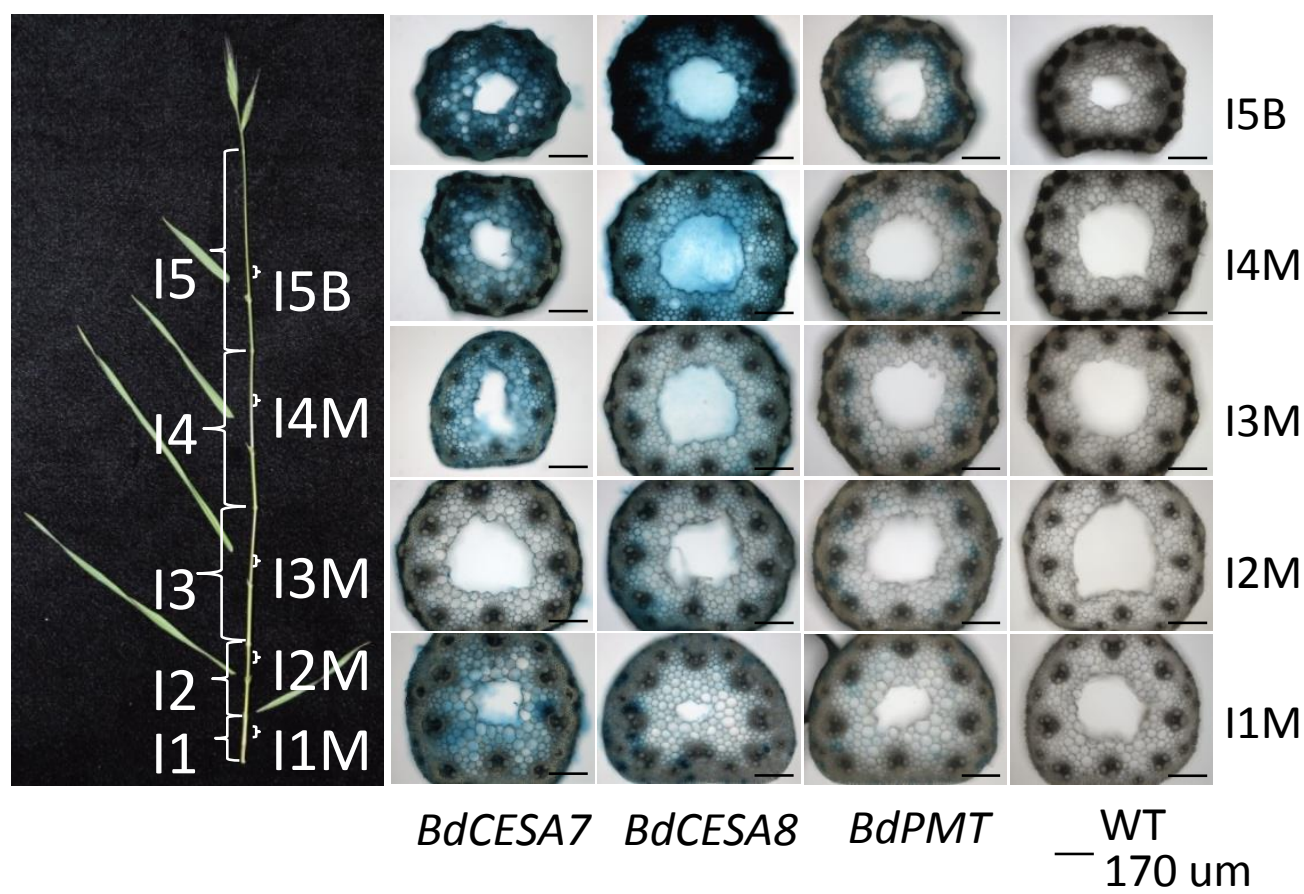

Figure 1. X-Gluc stained Brachypodium distachyon stem cross sections of plants transformed with the $B d C E S A 7, B d C E S A 8$, and $B d P M T$ promoter sequences driving expression of the GUSPLUS reporter gene. A) One culm of a Brachypodium distachyon plant, 32 days after transfer of hygromycin selected seedlings to soil. Stem sections were taken from the longitudinal median of the first internode (I1M), second internode (I2M), third internode (I3M), fourth internode (I4M), and the bottom just above the leaf collar of the fifth internode (I5B). Sections were also taken from the middle and top of the apical internode (not shown), which were less intense staining than the bottom of the apical internode. Note that not all plants, whether transgenic or wild type had the same number of internodes. Therefore, the median of each internode, and the bottom, median and top of the apical internode were sampled and assayed for GUS activity. B) Stem sections of $B d C E S A 7$ promoter, $B d C E S A 8$ promoter, $B d P M T$ promoter, and wildtype $\mathrm{Bd} 21-3$ first, second, third, fourth and fifth internodes. Sections shown are from the median of each internode, with the exception of the apical internode 5, in which sections just above the flag leaf are shown. Note that addition of potassium ferricyanide or ferro-cyanide was not performed, as lesser expression in more basal internodes was desired to be seen if present. (Addition of these compounds not only reduces leakage of blue product from the X-Gluc assay, but also decreases intensity of staining seen on a per cell basis). Scale bar for stem sections represents $170 \mathrm{um}$. 


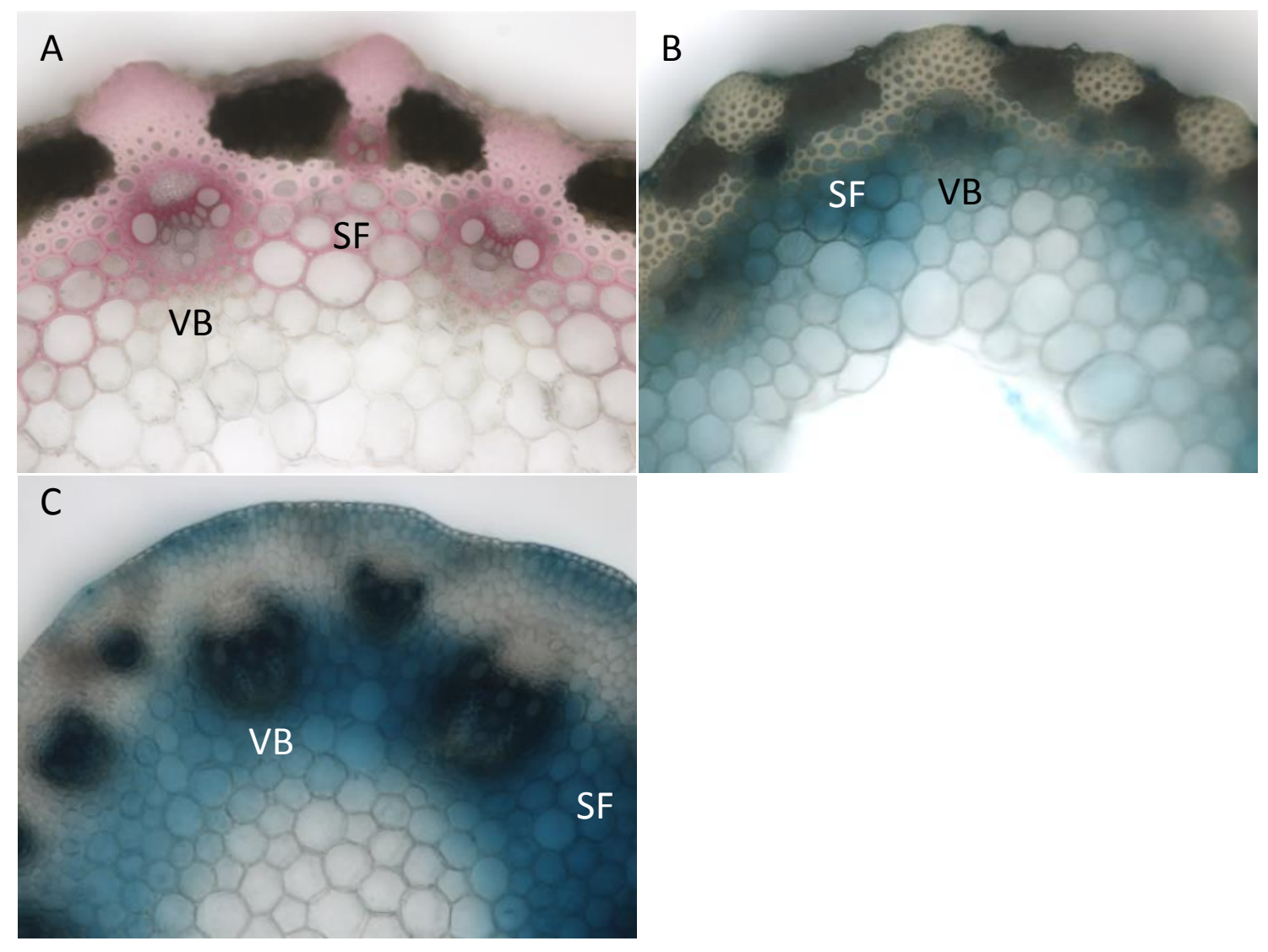

Figure 2. BdPMT promoter::GUSPLUS expression in adult plant apical internode stem sections as compared to lignin deposition as evidenced by phloroglucinol staining. A) Wild-type Brachypodium distachyon $\mathrm{Bd} 21-3$ stem section stained with phloroglucinol for the presence of lignin, 200X. B) BdPMT promoter::GUSPLUS Line 2, plant 3, 200X. C) BdPMT promoter::GUSPLUS Line 2, plant 10, 200X. Potassium ferri- and ferro-cyanide was added to the X-Gluc staining solution for this plant to allow clear delineation of GUSPLUS expressing cells versus adjacent nonexpressing cells. 
18 DAP
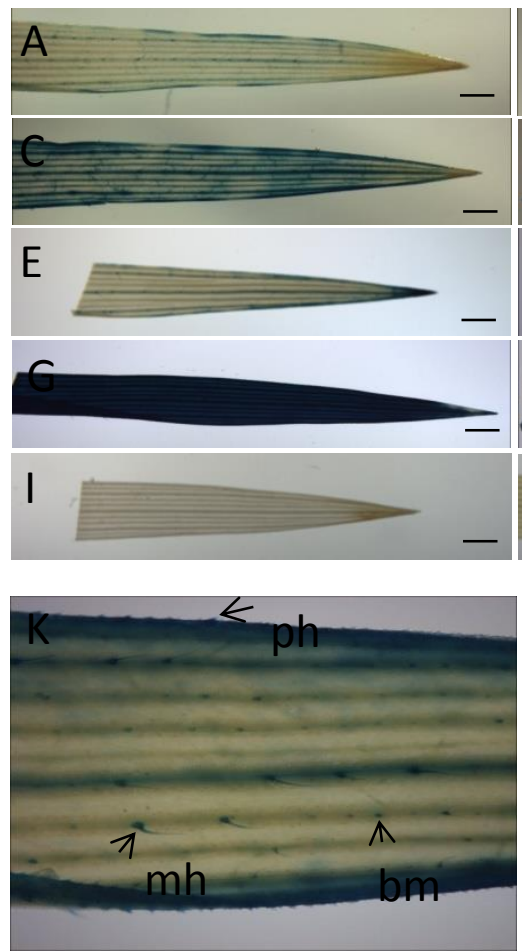

32 DAP
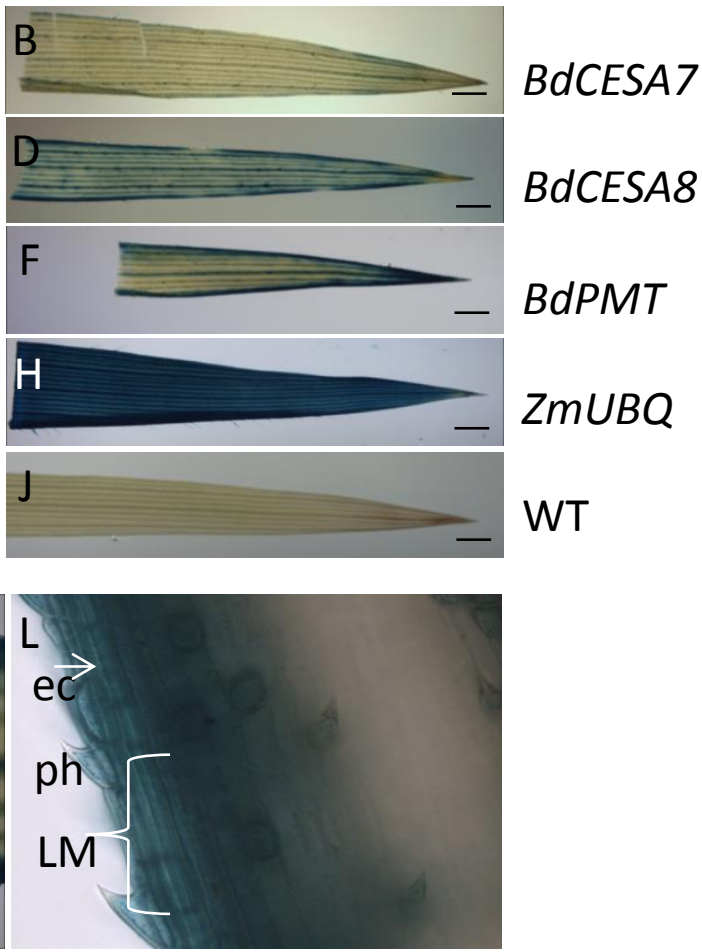

Figure 3. Apical leaf snippet X-glucuronidase treated to monitor GUS activity driven by the BdCESA7, BdCESA8, and BdPMT promoters cloned. (A,C,E,G,I) Apical leaf snips taken 18 days after planting of BdCESA7, BdCESA8, BdPMT, ZmUBQpro, and WT transgenic lines, respectively. (B, D, F, H, J) Leaf snips taken from the flag leaf of the same transgenic lines, sampled 32 days after planting. (K) BdPMT promoter::GUSPLUS Line 2, viewed at 64X magnification. Trichome macrohairs $(\mathrm{mh})$, bicellular microhairs (bm), and prickle hair (ph) cells are noted. (L) BdPMT promoter::GUSPLUS Line 3, viewed under 400X magnification. Staining at the leaf margin (LM) can be seen of both prickle hair cells (ph) as well as epidermal cells (ec) at the leaf margin. Note that at this developmental stage, the peduncle of the sampled culm was fully elongated, and a young, unfilled spikelet was present. Scale bar represents $1.0 \mathrm{~mm}$. 


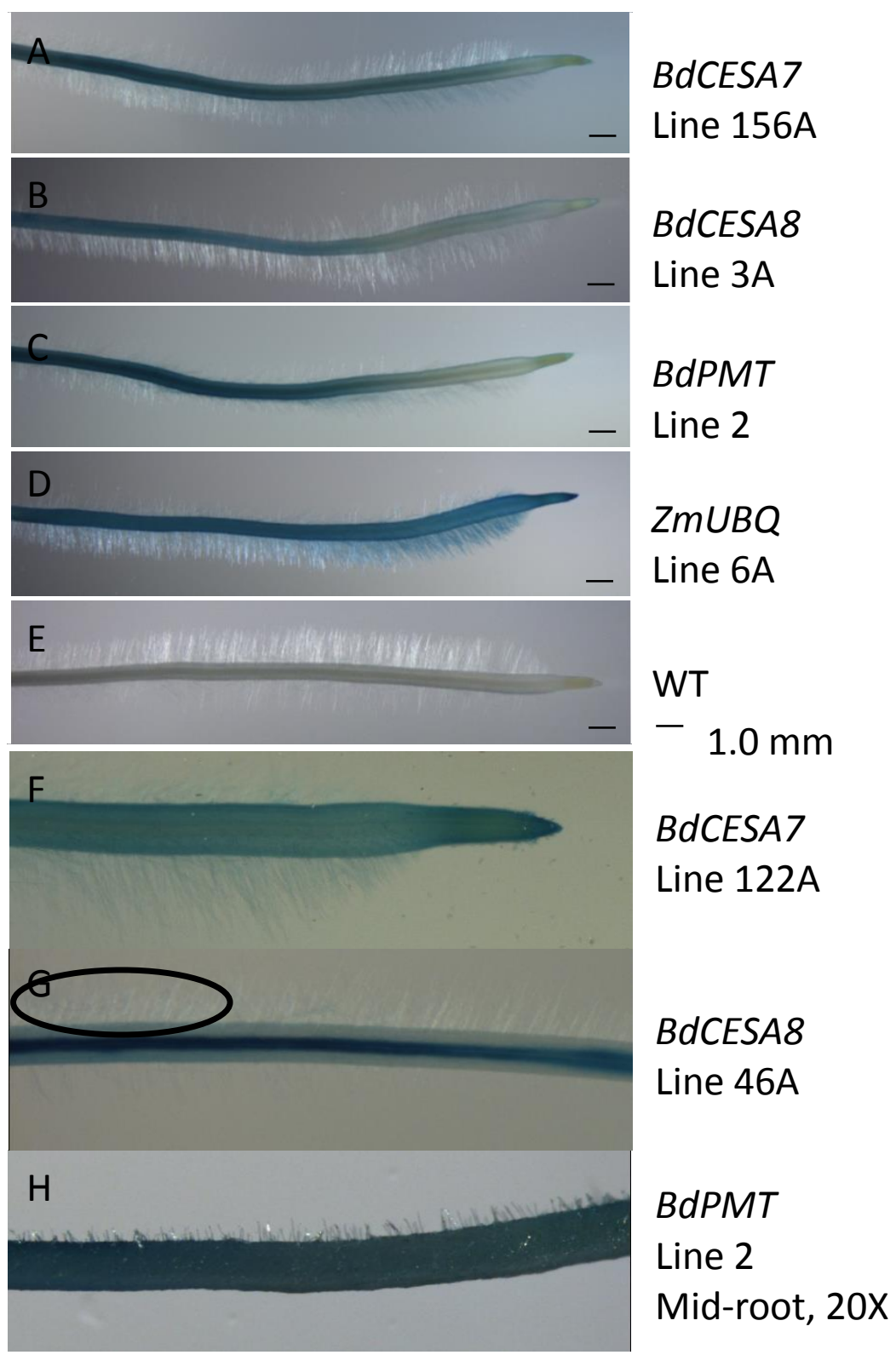

Figure 4. BdCESA7 promoter, BdCESA 8 promoter, $B d P M T$ promoter, $Z m U B Q$ promoter driving GUSPLUS expression in seedling roots X-Gluc stained for GUS Activity 3 days after germination. Seedling roots sampled 3 days after germination on MS plates including 40 $\mathrm{ug} / \mathrm{ml}$ hygromycin (except WT control, which was germinated without antibiotic selection). A) BdCESA7 promoter::GUSPLUS Line 156A. B) BdCESA8 promoter::GUSPLUS. Line 3A. C) BdPMT promoter::GUSPLUS. Line 2. D) ZmUBQpro::GUSPLUS Line 6A. E) WT \#2. All samples viewed under 11.2X magnification. F) Strongly expressing $B d C E S A 7$ promoter::GUSPLUS Line 122A viewed under 20X magnification to see staining root hairs. G) Strongly expressing BdCESA8 promoter::GUSPLUS viewed under $20 \mathrm{X}$ magnification to see staining root hairs. H) Strongly expressing BdPMT promoter::GUSPLUS Line 2 viewed under 20X magnification to see staining root hairs. Scale bar indicates $1.0 \mathrm{~mm}$. 


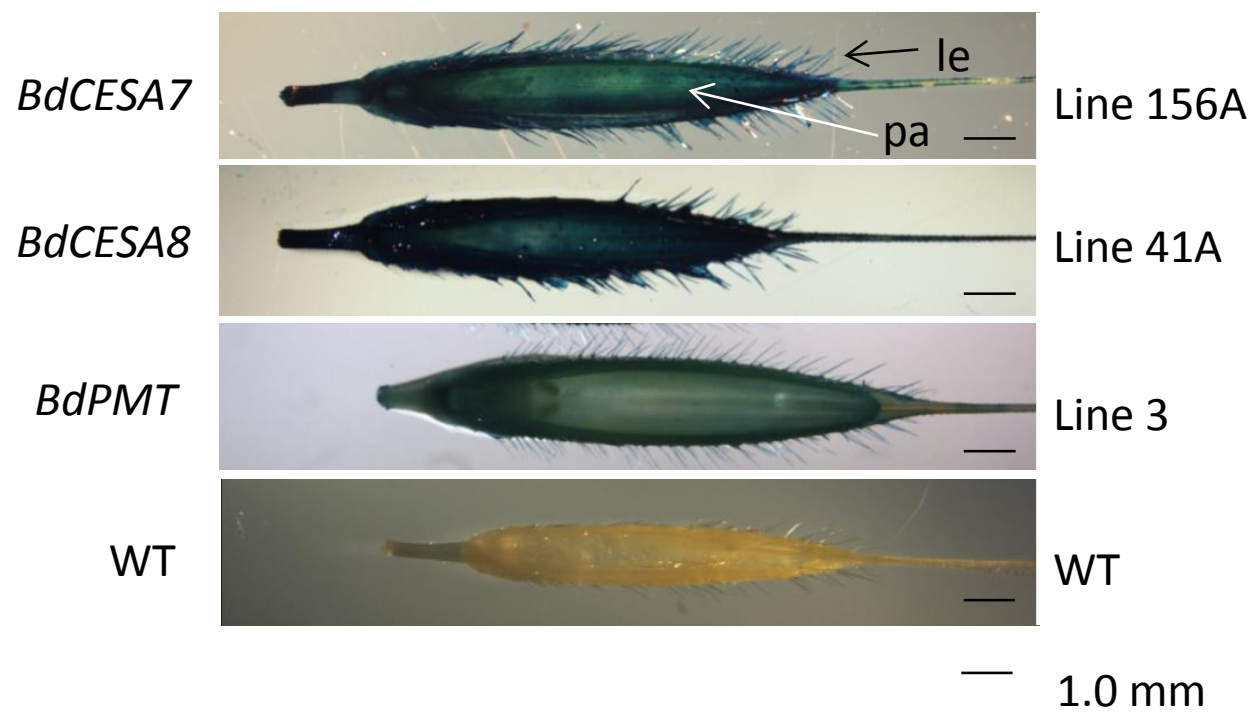

Figure 5. Florets stained for GUS enzymatic activity, prior to seed fill. Unfilled florets were removed from spikelets and X-Gluc stained overnight at 37C. Chlorophyll was removed using $70 \%$ Ethanol prior to imaging. Potassium ferri- and ferro-cyanide was added to the X-Gluc staining solution when staining samples BdCESA7 promoter::GUSPLUS Line 156A and BdCESA8 promoter::GUSPLUS Line 41A to decrease the amount of leakage of blue product previously seen collecting between trichomes on the lemma when staining these lines overnight at 37C. Florets viewed at 11.2X; scale bar represents $1.0 \mathrm{~mm}$. 


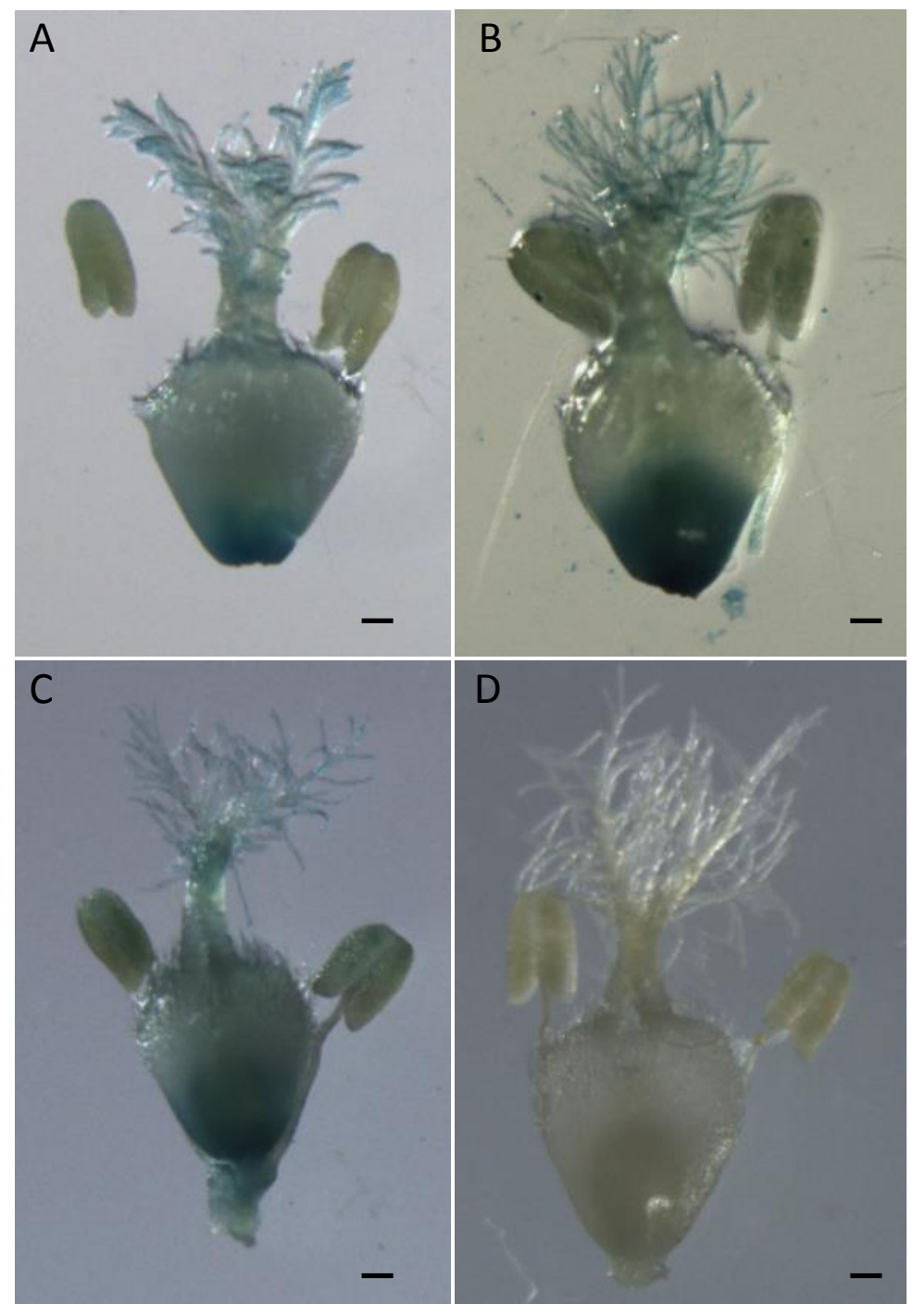

Figure 6. GUS activity of internal floral organs. Scale bar indicates $0.1 \mathrm{~mm}$. A) BdPMT promoter::GUSPLUS Line 3, 20X. B) BdCESA7 promoter::GUSPLUS Line 122A, 20X. C) BdCESA8 promoter::GUSPLUS Line 113A, 20X. D) WT, 20X. 

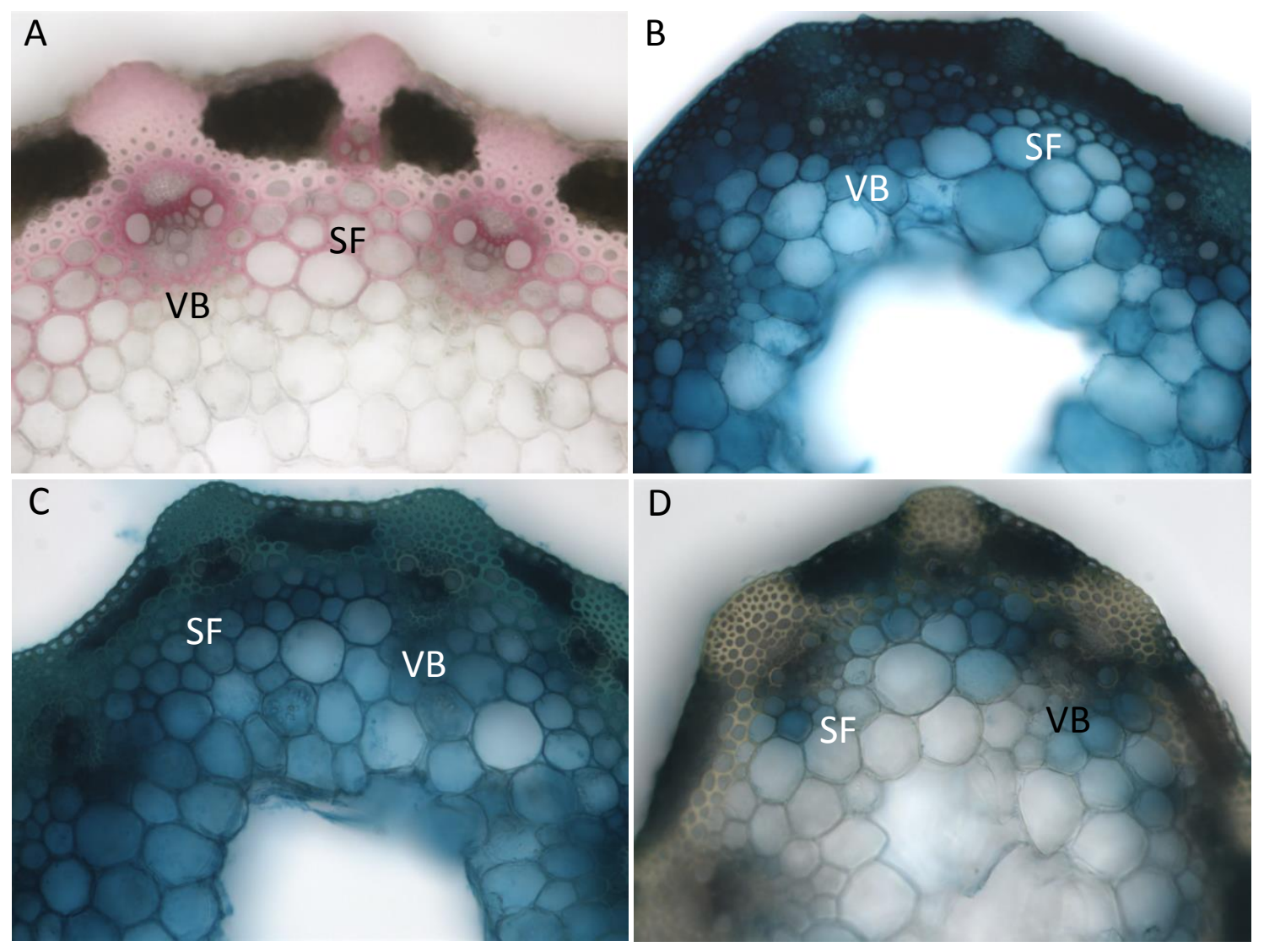

Figure 7. Stem sections taken from the bottom region of the apical internode of BdCESA7 promoter::GUSPLUS and WT adult plants. 200X magnification. A) WT Bd21-3 stained with phloroglucinol; (B-D) BdCESA7 promoter driving GUSPLUS expression. B) BdCESA7 promoter::GUSPLUS Line 38A. C) BdCESA7 promoter::GUSPLUS Line 71B. D) BdCESA7 promoter::GUSPLUS Line 153A. Addition of potassium ferri- and ferro-cyanide to the X-Gluc staining solution was performed for BdCESA7 promoter::GUSPLUS Lines 38A and 71B to decrease leakage of blue product between adjacent cells and out into the staining solution previously seen in these very strongly expressing transgenic lines. 

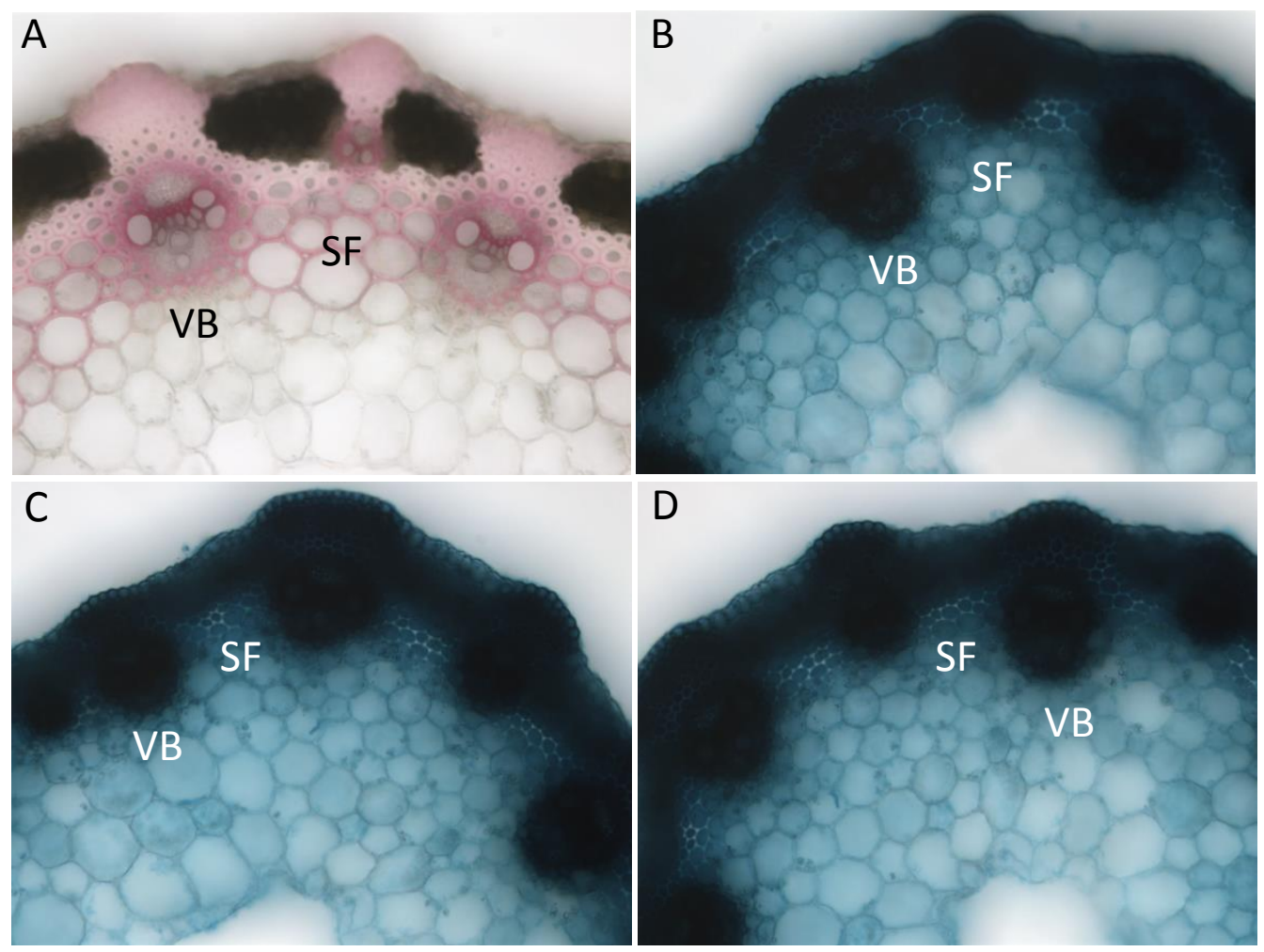

Figure 8. Stem sections taken from the bottom region of the apical internode of BdCESA8 promoter::GUSPLUS and WT adult plants. 200X magnification A) WT stained with phloroglucinol, (B-D) BdCESA8 promoter::GUSPLUS Line 89A (Potassium ferri- and ferro-cyanide added to X-Gluc solution to decrease leakage of blue product between cells). 


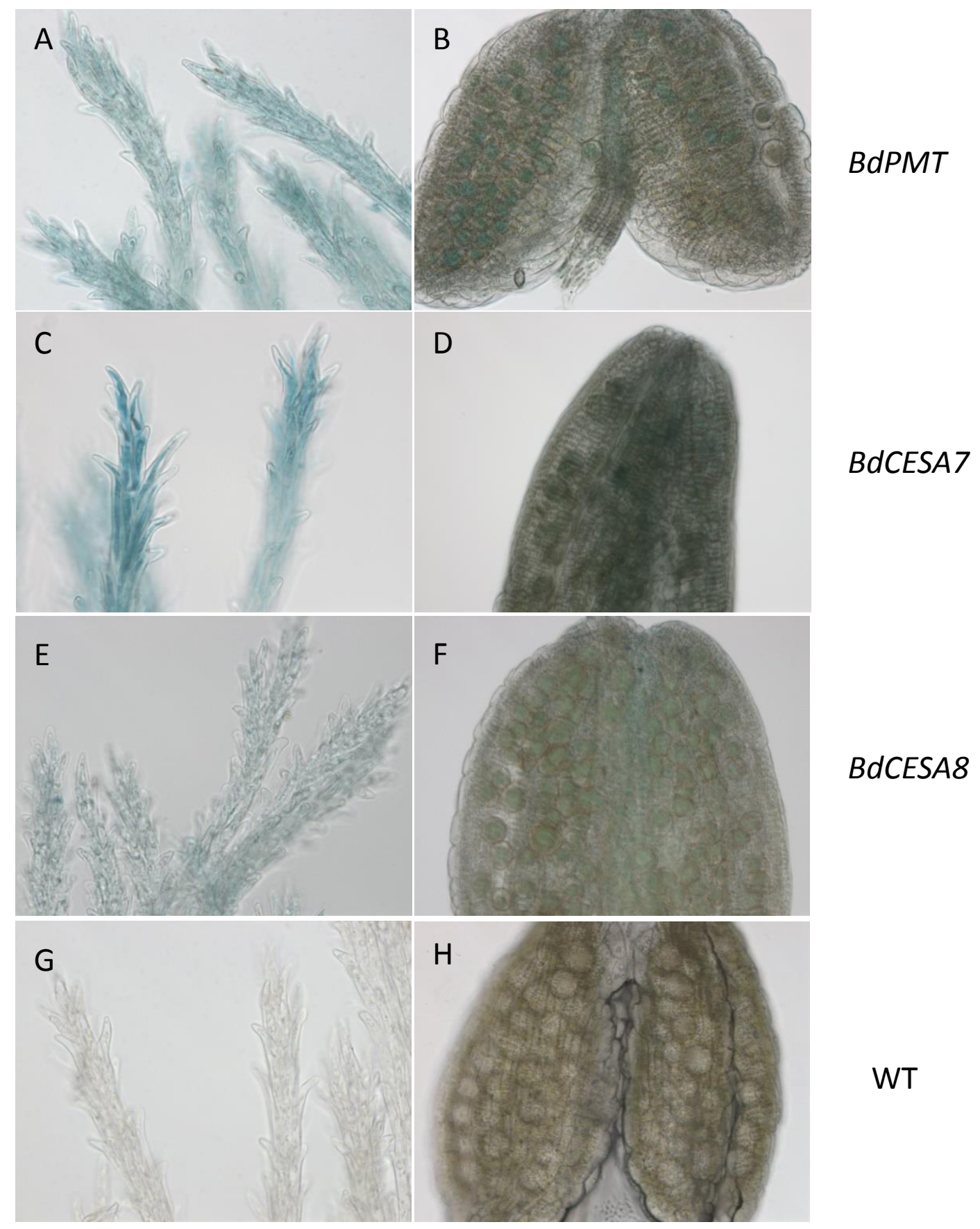

Figure 9. X-Gluc staining to examine GUS activity driven by the BdPMT, BdCESA7 and $B d C E S A 8$ promoters in floral stigmas and anthers. Stigma and styles viewed at 400X; anthers of same plant viewed at 200X. (A) BdPMT promoter::GUSPLUS stigmas and styles. (B) BdPMT promoter::GUSPLUS anther with pollen grains. (C) $B d C E S A 7$ promoter::GUSPLUS stigmas and styles. (D) BdCESA7 promoter::GUSPLUS anther with pollen grains. (E) BdCESA8 promoter::GUSPLUS stigmas and styles. (F) BdCESA8 promoter::GUSPLUS anther with pollen grains. (G) Wildtype stigmas and styles. $(\mathrm{H})$ Wildtype anthers with pollen grains. 


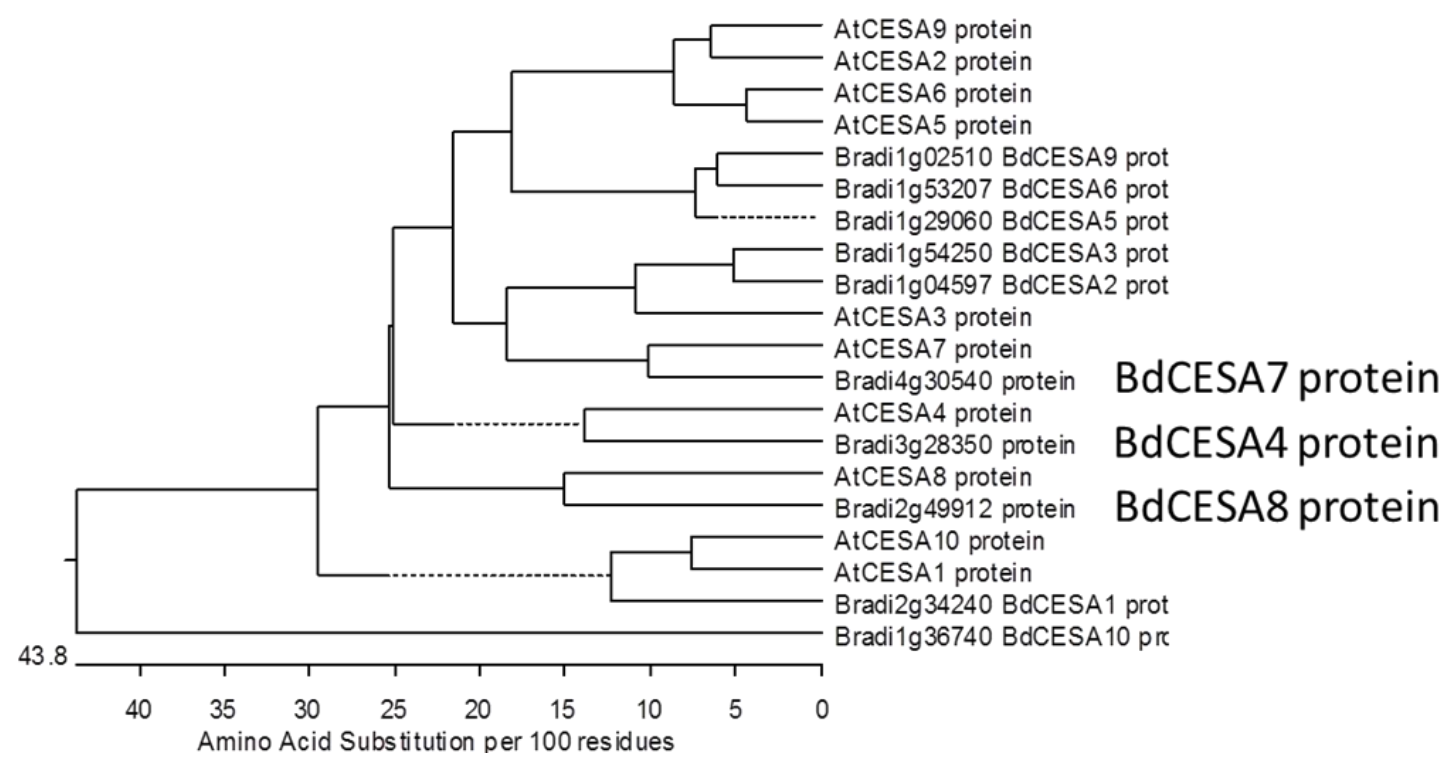

Figure 10. Phylogenetic tree of the Brachypodium distachyon and Arabidopsis thaliana CESA genes based on amino acid similarity. Relatedness is based on amino acid similarity determined using ClustalW algorithm within the MegAlign program of LaserGene 8. 
CHAPTER III SUPPLEMENTAL FIGURES

GATGCGGAGGAGATAGAAATGCAAAAGAGAAAAATAATTTACTTTTTGTGTC GATCAAAAGTCAGCTAAGAGCCAACCTTGTAACCATTATACACCATCAGATT TAATGTGTTATCAAATTATGTAGAGTTAATTTAAAGACACAACTCATTGTATG TTTTATTTTATTGTTGACTCTAGATGACACAAAGAGTCAGTACTATAACTATA GATGCCCTAAATAAACATTAGAAATGGAGAAGATAACGATGGTAGGGCTGCC TTAATTATACCAGATGTGTCTTCCTTCTACGTTTTCTTGTTATCCGTATACTGG ATATCCTGATCCCTACACCCTCGACCGTCATCGTCTCATTAATTAATTTCCCAT TTCCTAACGAACTATAATTTCTAGTTTAGACTTTAGAGATGCAAGCGAGATCC CGTTTATGTCTCGTTTCTAGGATTAGTGACTTGCTAGTTCAAAATATATATTG GCTCCAAATTTGACTTGAAAATTATTTTAGCGATTGGTCTAGCTATAAACGGG ACATCTTGCATCCCTTGGTCCTAGCTAGTAACATCATGGCTGTGGTAGTAGTA CGTAGTACATGTACCTACGTTCGTGCATCCATTGTCTTGTCACAAGGCAAAAC GAATTTTTGTTCGCTCCAAACAGTGTCGACATACAATCATGCATTAGGTGCAA TTGTATTACTTGCTGTCAGTGTCTGACTGTAGCTAGGTCTGTCGTAGGCTATCT ATCTATATATAGTCGCCAAATGCATCTTCATCTTCACTTGAGCAGCACGCGAC GTACGTGGTGCCATCGCTGCAGGTGGTAGGTCGCGGCCTATCGATCGGAACA ACGATGGACGGATAGACAGGAACATATTACGGAGTAATTAAATTGACCCATC GATCGCTCAACTAATTACTCGATCAACAGCCAGTTGACAGGGATCGGTCGAT CGATCATGACAAACCCTGTTGTATAGTACTCTACATGAAGAAGTCGATGAGA CGATGACGACTCATCAGGCCTACCACCTACGGTCTCCTGCACAGCACAGTCT GACCCGTTTCGAAAACAACATGGCGACTTTGCACCTAACGACTCCTTCCGTCT TGGAATAGCAGTCAGTTTAGATTTGTTCTGTATATGTTAAACTTCTCAAAATT GAAACAAGTTTATAAATTAAAATTATATATACTCACTTCAATCCATAGTAAGT TTATATTATCAGATTTCTACGTGGTTAGTATAAAGTTGTAATAAATCTGAGAT ACTTATATGAATCGGAGGAAGGGAGTACCGTACAACATCAAATTAGTTTTCA AACGTCGATCACGGGTGGTCAGAGAGTTGTTCAGACACATCTTCGATTAAGT GTTATTTTCTCTCAACTTGGTTAAGACCTGATGTTTCTTGGATTATCAGTGCGA GGGCTATATATGCGCACTCCCTATGCATTGGTCCGAGTCGATAAAAGCTTTCT TTATTGAAAAGAAAAGAACTCTCCAATTGCTAGCTCTAGGAGACGACAATCC TAGCTAATGCGTCGTCAGTCGTCACCAAGAGAAACCAACTGTGAATATATAT TGTGAGTGGATCAAGATAGATGATGCAGCTTTCTTCAACAATGTAACTAACG CGTATTCCTCGCAAAAAGATTGATAACTAATGCGTAACTTGAGATGGATAGA TGGACTAGTTTATGACATATATATGTTATGACCGCCTTTCAGTTTTTTCTTGCA 
ATATTTCTATGTTGCCTTAACGTACGTCAACTGATGAACGCACAAGCTAGCAA ACCCTTGATCTGATCTCTCTAGCTTGCAAAGTGGACTAACCAGCTACCCCGAG TTAAAAAAAGGAATAATTGATCCATCAGCTATATCCCTTGTCTCATCCCTTAG AAACCGCACAGACTATGTTATGTACTTTTCTTTTAAGAAACACGGTACAAACG TCAGACACTCACAAAATGCACGCACGCTCACAGATCGACACTCACAAACACG CTGTGACATGTTTAATCCATGCCGAACCTTTTATAGACTAAAGTGACATGGTA ATCTCAGTTTAGGGTTTATTAAGTGTGCGTTTTCTGAATTCATGAACTAAAGT GTTCATTTTACTCTTAATTATTTAAACTAAATCAAGTGGTGGCACGTTCAAAA TACAACGGACCACCACCACCGATGGATATCTTTTACCGGAGCAACAAAGACG TGAGCTAGAAAGCACGATAGGTGCAGCTTGCAAGATCTCTGAAAACATGCAA AACTTCTCCACCGCCACTATGATGACACAAGCGTGCCGTGTACGGCCGTAGT GGAGTTAATGACTACATCAAGCACGACGTCCGTATATGCGATTCCATGGAGG CCGGCTAATTTACTTTACATCAACGTATGTATTTGTACACATGTATATACCAG GAGGCTGGCTAATTTACTTTACATCAACGTATGTATATGTACACATGTATATA CCAGTAAATGCAGAGATCGATATCCTTCTGATCCATCCTAAATTCTTGCCCAA ATATGCGTATATCTATTCTTAAAAAACGTTTAGATACATGTAATATTTCGACA ACAATTTAAAATCCGACAAAGAAGTAGTCAACACCGTTCAATTTATTTCTACT CTCACTCGATTGACCTAGCTAGTTCGAACAACCACGCCCACGTCTGGCCGTAT ATATCCAAAGTGCAACGTAGGGCCCACACGTGTCGATCTCATTTGCTCTCCCT TCACCTACTACCCGCGAAAACAAGTCCACACGCTTGACATTAATTATACGATT TACCATGAGTACAAGCAACGCACACCAAACTAAACTTAATTAACTGCCCCTA GCTAGCTGCATGCTCCCTCAAAAAAAGAAAAGTAAAAAATCACTCCACCTAG CTAGCTGAGCTCCGAAGTCCTGAACTAATAACCCAGCCCGTCTATATATAC ACAGAGCATATATATCCATACACTCATCGCAGCTAGAGCATGCAAGCTTA

Supplemental Figure S1. Sequence of 3,000 bp cloned BdPMT promoter fragment. Begins at (-) 3,045 and extends to (-) 45 of Bradi2g36910.1. Included 5' UTR sequence is marked in boldface. 
TGTCGTGGTACGGAGGAGCTAGATTCGCGAGACTTGGAAAGCGCCGGCGGGT TCCCGATGTCGGCCAGCGTGGGGAGGATGCGATTCGTAGTAATGATGGGTTC ACTACGTCGGTCAGCCGCCCGCGGTCGTGGTGATCGCTGAAACGGAGCCCGG GCGCGGCGTCGCAGCCGGGAAAAAACCGATCTGGGAGGAACGCGACGCGGA GCGGCTGATCTGATCGTTTCATGAGTGCACGCACCGACGCACGCATCCGATC CGACACGATGCGGTGCCCATTTCGGGCCGGATCGGCGATGGGCCGGTTCTTT GCCGCTTCACCTGAAGAGTCAAGATTCGCTAAAAAAAAAGCATGAAGAGTCA AGACTTTTGTTTTGGAGAGGTCAAGAACTATCAAGACTTTTGTTTTGGAGAGT TTCAATGAAGGCACAGACTGAGTCTACGGTGGTGGCCTATCTGCCGACGCCT TGAGAGAGAAATGGTTGAAACGGGCTTGCCATTCTGGCTACATTAACTTTTGC AACTTCGGCCCAGTTTGACGAAGATTATGATGCCGATGAAAGGAAGGCCTTA CGGGTCTGGAACGAATATGAGCTTGTAAGCCGGTCCGACCGCGATCATAGCG TAGTCTAGCCAGGCCACCCTCACATGAGTCATGAGTGACCCATCAAAGCCCA AATCGCTATCTCTTTTTCATTTTAGCACCTGACTTCCCTGACGCTTCGATCTCA AAAAAAAAAAGGTTGCGCTGCATGTACCTACTCTCTGACGTGGTCAGATTAA TAGATGATGCGTCCTGAAGATGAATTGAGGTCTTAGAAGGAGTAAAGATCCA CCATATATACACCGACGTAAAGCAACAAAGCAAGAGGACCAGAGATCCGAA GAGAATTAGCACAAGACCAGATCAGGCCAGAACGAGCGGTGATGCTTCCAC GTCCGTACGTGTTTGGAACGATTTTGAAGCAGTTGATGGCTTGTCACCGGCGC CGCGGCAGATCACCACTCGGTTCCATGCTTTGGTTCACGCCATTTTGTTCAGC ATTTGAAGCATATTATGCCCAATATATATACATGCCCGCCTCGAGTCCTCAAG CAGGCCAGGAGCGTGACAAAGAAACTACGAATCATACGGCCATATGCCCTGC CGCGCTTATGCTTCACACCAAGCCACCGACGGTAACGTGCTGCCCATATTTTT GCCCTGACGCGTGCAAATTAAAGGCCGATCAGTCGTCCAGTACAACAGTGGC ATGATCGATCGACCACCAGCAAAAACTAAAACCAAGGCTTGCATCCTACGAT GCTTCAGCTTCGCGCCTGCCTGCGTTTCGCATTCAGGACGGGGACATTTCGCC TCCTCCTCCTAATCGACCGGCCAGCTTAATTAATTTTTTCATAATAAAATAAA AAGGAAAGAGTACTTTGCAGAGGATACATTTGGTGCTTGGTTTCCTCGTGAC GGTTCTCGCGCATGTGGGATATCTGTTACACGATCATAGGCGTTGGTAGGTGG CGGGCCAAAAATTTAAGGTGCCTGGTCACCTTCTCCATATCACTCGGGTCAAA CTGAAAAGGTGACGCGTCTCGTTTGCTTCGTGCGTGCTCAACCCTTACCCGAT GGGCTGAGCCTCAAACACGGGTCGCATGGAAACGGACAGAGATCAAAACTT GAAGGCGAGCGACGACCATTTGATTACCGGAAGCGTACGGCTAGAGAGCGA TGGTATTTGCTTTTTTTCCTTGATGTACACAAGATCTTGAAAGACTTCACGGA TTACGATTCTGGTACTGGATGGTTTTCTATCATATCTGTAGCTGCGTAGCACA AATGTACAAGAAACGAATGCTGGGCCAAGCTCGCGAGCTAGAACAACGGGT GCATGCATTTTTTCAAATGTTCTTTGCAAGGATACTCGTACGTACGTACAACC CACCGATCACCATTAGTTTTCTCAAAAAATCGAAAAAAGGAGATGGCGGGAG ACCCAAGCTTGGGTTGGTCTGGAAGGGGGTTGGTCAGGACTCAGGAGAGACG CGCGCACCTTGCCTGAGCCTGACAACGGCAGCAGAATCCAGCGCAGCGCACC 
GGCAAAACCAAACCTTTCGCTTCACTTCGCGGCAACGGGGACTCCACACCCA ACCCGCCAAGCTCCCCCTCACCGTCCGGCCACGTCGATCCACAGACCAAATC ACAACTCCTTTCTTCGAACTTCGAACAGCCACCCCTCACCTCTCCCCCACCCG CCAAAACACCTAACCCTCTCATATAGCCCCCCAGCCCCTGCCACAAGCGAAC CAACTAAGCACCCACACTTAGCCCCCGTCTCCTCTCGCCCTGCGCTGCGCTGC ACCGGCGCTGCGGCGGAGATCGACCGGCCGGCG

Supplemental Figure S2. Sequence of 2,385 bp cloned BdCESA7 promoter fragment. Begins at (-) 2,385 and extends to (-) 1 of Bradi4g30540.1. Annotated 5' UTR sequence was unavailable in either Phytozome or Gramene. 
ACCACCAAATTTGTTTTCACATAGATTTCCCTGGTTTTAGCTGCCACGCTGGT GAAGGATTGACTCCGGCCATCTTCTTCTCCCCCGCGCGGTGTTGTTCTGCCAC CAAGAGGCTGGTCCTTTTTTGTCGAATGATCTGGTTCTTGCGTGAGTGCCCCC GCCCCCCCACCCCACCCCCCACACTACCTGCAAGAACCCTAGAGCCGCAACA CAGCAAGTTGGTCGATTCGGCACTGGTGGTGGCCATTGAGCACGGCGGTTGG TCGATTCAGCACTGGCAGCGGCGCCGGCAATTCAGCAGCAGCAACTCCCGCT CTTCCCCTCCTGCAGCAGGTTGGGGAAAAGAACCGAGAGAGAGAGAGCGGG AGAGTGTGTGTGTGTGTGTGTGTGTGTGTGTGTGAGAGAGAGAGAGAGAGAG AGAGAGGGGGGGAGGTGAGGAGGGGGGGAGGGAAGGAAGAGAAGGCATTT GCCGGCATGGCGGTCAAGCCAGGTCAAGGTGCCAACGCTACGGCCAAAACC AAGTAAATTGAGGGGAAACAGGTCCGGGGGTATAGGTGAATGGTATGACAA GTCGGGAGGGGGGGTATTTTGCCTGTGGTTTTAGAGTTTAGGGTTAGATTTGG ACTTTGCCAATAGTTGAGGGGGGGAGGGGGGGTTTGTTAAAATAGAGTTACT TTTTTTCTCTAGAATACAAAATAGAGTTACTTCATGTACAAATAATTCAAATG TACCCACATGTTCTCACTCTCGAGCTTTAATTGGTATAAGGATTATTGATGCT TGATGGTACAAAGATGAAGAGTGCGTATAAGGTCTTTTAAGAGAAGGTTGTC GTATACTCAATAGAATTGACACAACAGTGTTTTTTGAATAGTTCCGGTCGCCT CGTTGGAGCACGACCTACTCCTACGTTGGAAGAGGTATCGAGGGGACTGTTA GCCGGGCATTTTTGAGTAACTTATCAAGTGACCTTTCGGAGCCCTTTTGAGAT CGGATGGAACGGGTCTGCTAGAGAAACGAGGTAAGTATACTCTCTGCATTCT AAGTCGATCCCTCGAGCTCGAGTCTCACTTGAACGTGTATTTCCGAAAAATTG AAACTGCGAAACTCTAACGCTATTCACTTGGGTTTATTCAAATGAGATTAAAT TGTTACATGACAACTGACCATGGAAATGCATGGTCACTCATGAAACTGTAAC CACACACTCTTTGCAACCACGTGAACTTCAAGTACCAGGACACAGACTGCAC ACCATGAAAACTGAAAAAAGTGCCGCAAAATTCATTCTCCACGGAGCACAGG TCTCCTGCTGAAGCTATTCTCTCGGCCCTCGCCGTGGTGACTCGCGAGTCCGA AAACGGGCTGTCATCTCAAACAAGAGCGACGCCTCAACGCGAGCGATTTCTT CCATCTTTCTTCAGTTCTTGCTCTCACCGTCCTGAGGGACCCACCCCACCACA CCCCCGTTTCACCAACCGGCGCCCCCGACCTCCGACCCTCCCGCCTTGCAG CTCACGCCCCTCCTCGCCGCGGTCACCTTCGCTTCGAAACCCCGCAAAA ATCCCGCGAGAAACATCTGCCGCACGCCGCCCCСCTCTTCCTCCCATCC CATGCCCGCTCAGGCGCCCAACCCTTTGCTTCCATTCTTTCCATCCTCCA CCCGCCGGTACGATGCCGACGCCCCAACCCCACACCCACCGGCCTCCTG CCAGCGCCACACCACCGCGCGGCTATGGCTATATCACCACGCATCCAAC CTCCGGCACGCTTAGCCTCTCCCTCCСТCССТCTCTCACTCССССССТAC CCGTTCGCCCGCTGCCGCTCGCGATACCCCGGAGCCGCGTTGGGGGAG CGGGCGAGTAGTGCGCGCACGGAGGGAGAGCC

Supplemental Figure S3. Sequence of 1,890 bp cloned BdCESA8 promoter fragment. Begins at (-) 1,896 and extends to (-) 1 of Bradi2g49912.1. Included 5' UTR sequence is marked in boldface. 


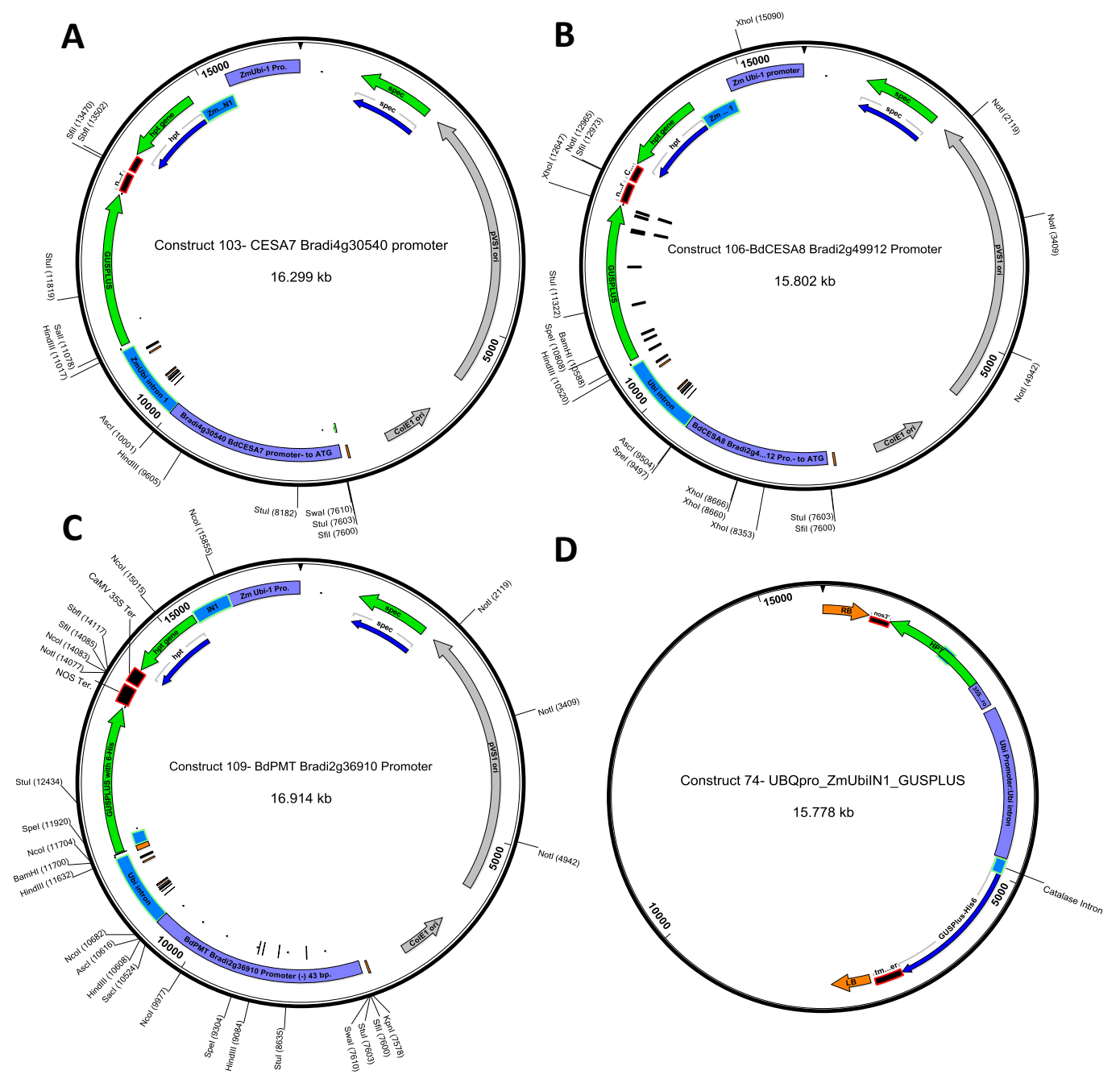

Supplemental Figure S4. Plasmid maps of utility vectors housing the GUSPLUS gene in order to examine expression patterns of the cloned promoters in transgenic

Brachypodium distachyon. A) BdCESA7 Bradi4g30540 promoter (-2385 to -1) plus ZmUBQIN1 driving expression of GUSPLUS. B) BdCESA8 Bradi2g49912 promoter (1890 to -1) plus ZmUBQIN1 driving expression of GUSPLUS. C) $B d P M T$

Bradi2g36910 promoter (-3045 to -45) plus ZmUBQIN1 driving expression of $G U S P L U S$. D) ZmUBQ1 promoter plus intron driving expression of GUSPLUS, the promoter being a commercially available constitutive expression promoter serving as a positive control. 


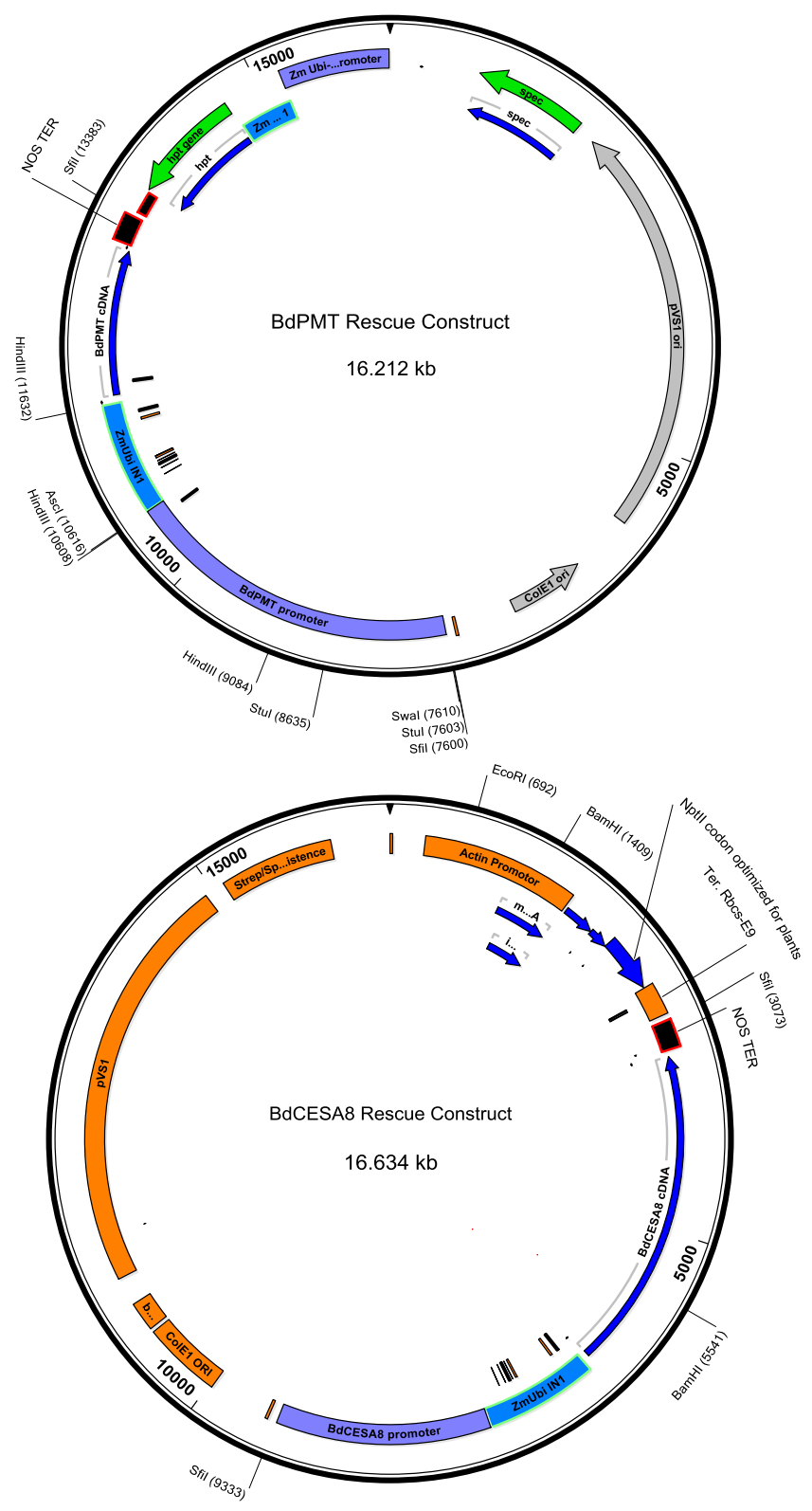

Supplemental Figure S5. BdPMT and BdCESA8 phenotypic rescue constructs plasmid maps. The $B d P M T$ and $B d C E S A 8$ cDNA sequences were Gateway recombination based LR cloned into the $B d P M T$ and $B d C E S A 8$ promoter empty vector constructs shown in Supplemental Figure S2. The entire expression cassette was then removed from each construct using SfiI and cloned into the B258 p9io ACT vector from DNA cloning services. This vector allowed for paromomycin to be used for transgenic plant selection, as the mutant genetic background into which these T-DNAs were to be inserted already had hygromycin resistance from the incorporation of the T-DNA insertion in the native $B d C E S A 8$ gene. Further, the use of the rice Actin promoter rather than the maize Ubiquitin promoter to drive the plant selectable marker reduced the chance of silencing due insertion of repetitive sequence elements. 

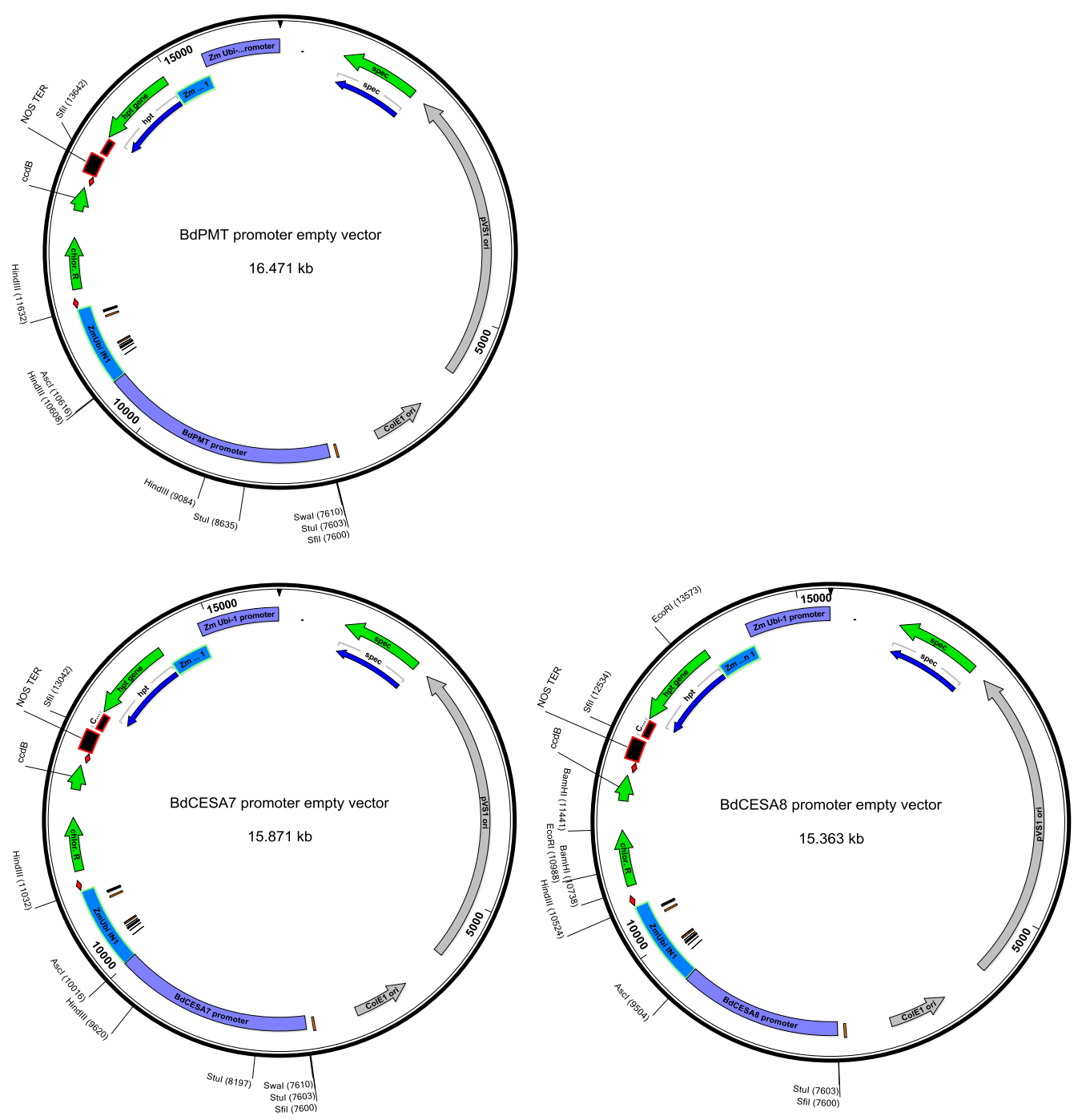

Supplemental Figure S6. BdPMT, BdCESA7, and BdCESA8 promoter empty vector constructs. These plasmids have the cloned promoter sequences described, followed by the ZmUbi Intron 1. This is followed by the $c c d B$ gene flanked by Gateway recombinations sites to allow LR cloning to be used to insert a desired gene of interest downstream of the promoter plus intron. The backbone vector is pIKb001, which uses hygromycin as the plant selectable marker. 


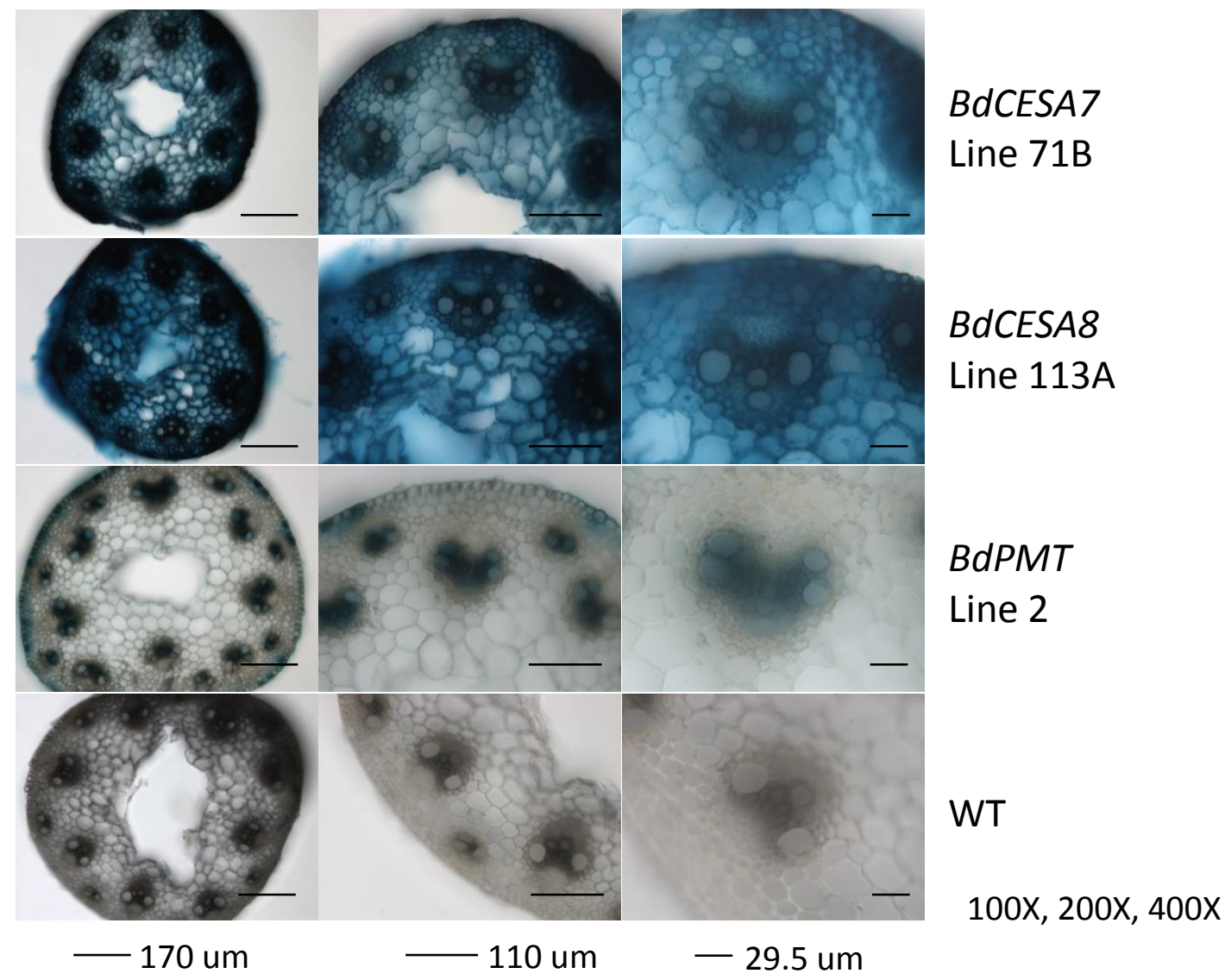

Supplemental Figure S7. X-Gluc stained juvenile stage stem cross sections taken from the longitudinal median of the first basal internode 18 days after transfer from Hygromycin selection plates to soil. Note that at 18 DAP, there was only one internode present, and it was covered by a leaf sheath. To make sectioning easier and less damaging to the stem, the leaf sheath was often removed prior to cross-sectioning of the young stem. Left panels' scale bars represent 170 um, center panels' scale bars represent $110 \mathrm{um}$, right panels' scale bars represent $29.5 \mathrm{um}$. 

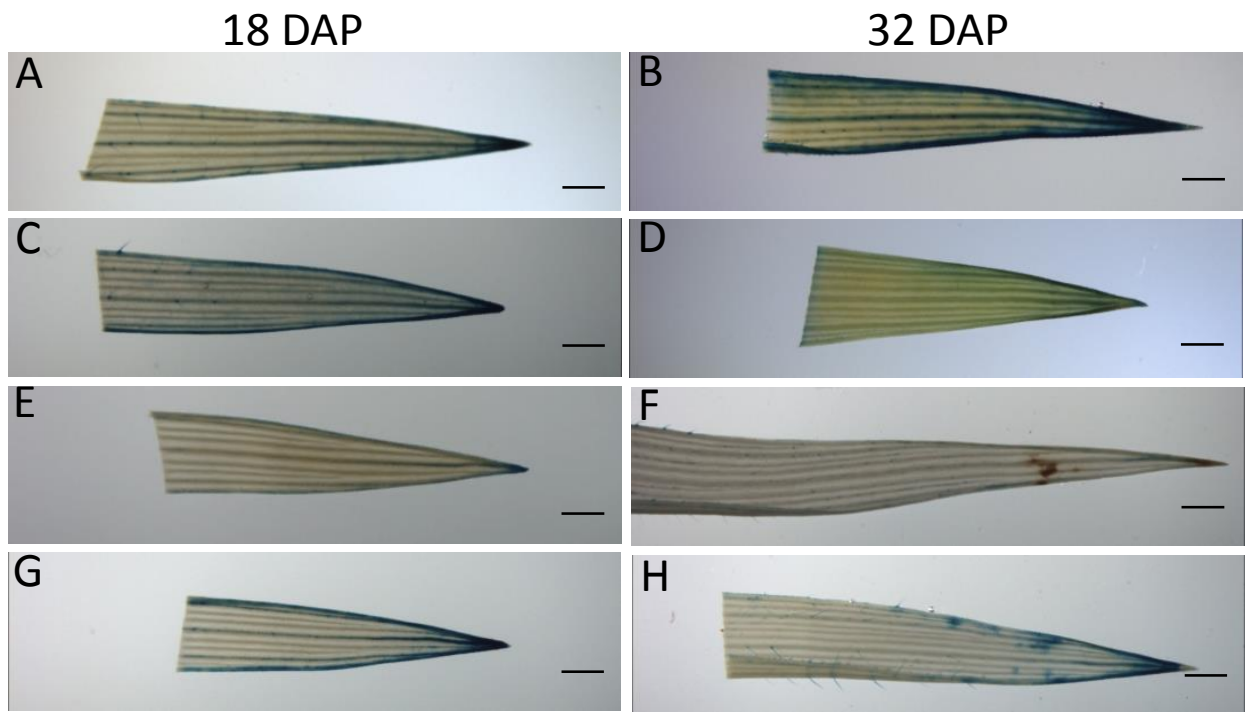

$\mathrm{H}$

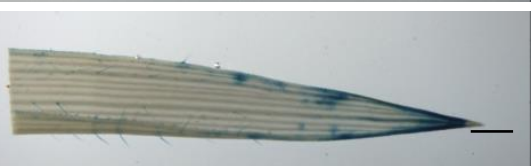

Supplemental Figure S8. Comparison of expression of BdPMT promoter driving GUSPLUS expression across transgenic lines in juvenile and adult leaves. Differences are likely due to positional effects of the transgenic cassette within the genome, including enhancer and repressor sequences located distal from the insertion sites. (A, C, E, G) Apical leaf snips of BdPMT promoter::GUSPLUS Lines 2, 3, 6A, and 11A, respectively, taken 18 days after planting. (B, D, F, H) Leaf snips taken from the flag leaf of the same transgenic lines sampled 32 days after planting. Scale bar represents $1.0 \mathrm{~mm}$. 

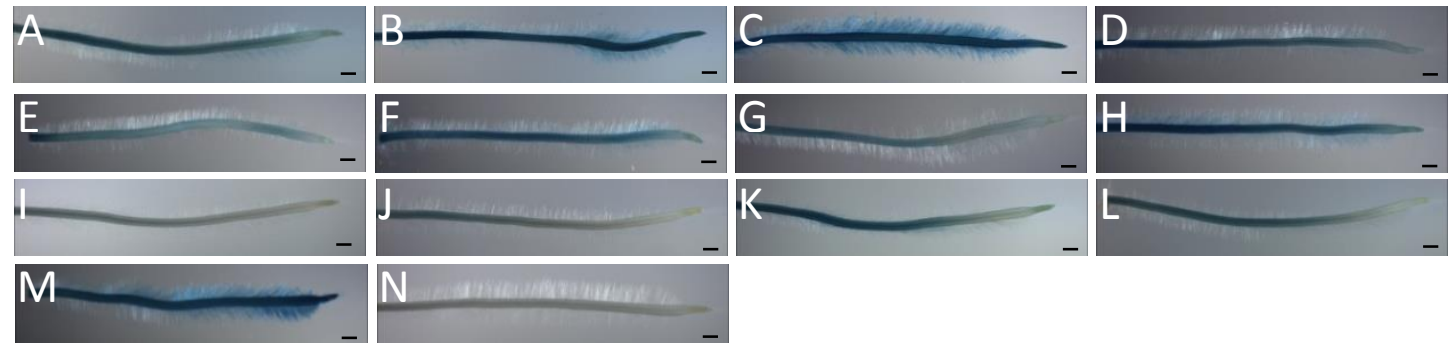

Supplemental Figure S9. Range of GUSPLUS expression in 3 days after germination seedling roots across multiple transgenic lines of BdCESA7 promoter (A-D), BdCESA8 promoter (E-H), and $B d P M T$ promoter (I-L). (M) ZmUBQ promoter, (N) WT. Differences in expression are likely due to positional effects of the transgene in the genome. Scale bar represents $1.0 \mathrm{~mm}$. 


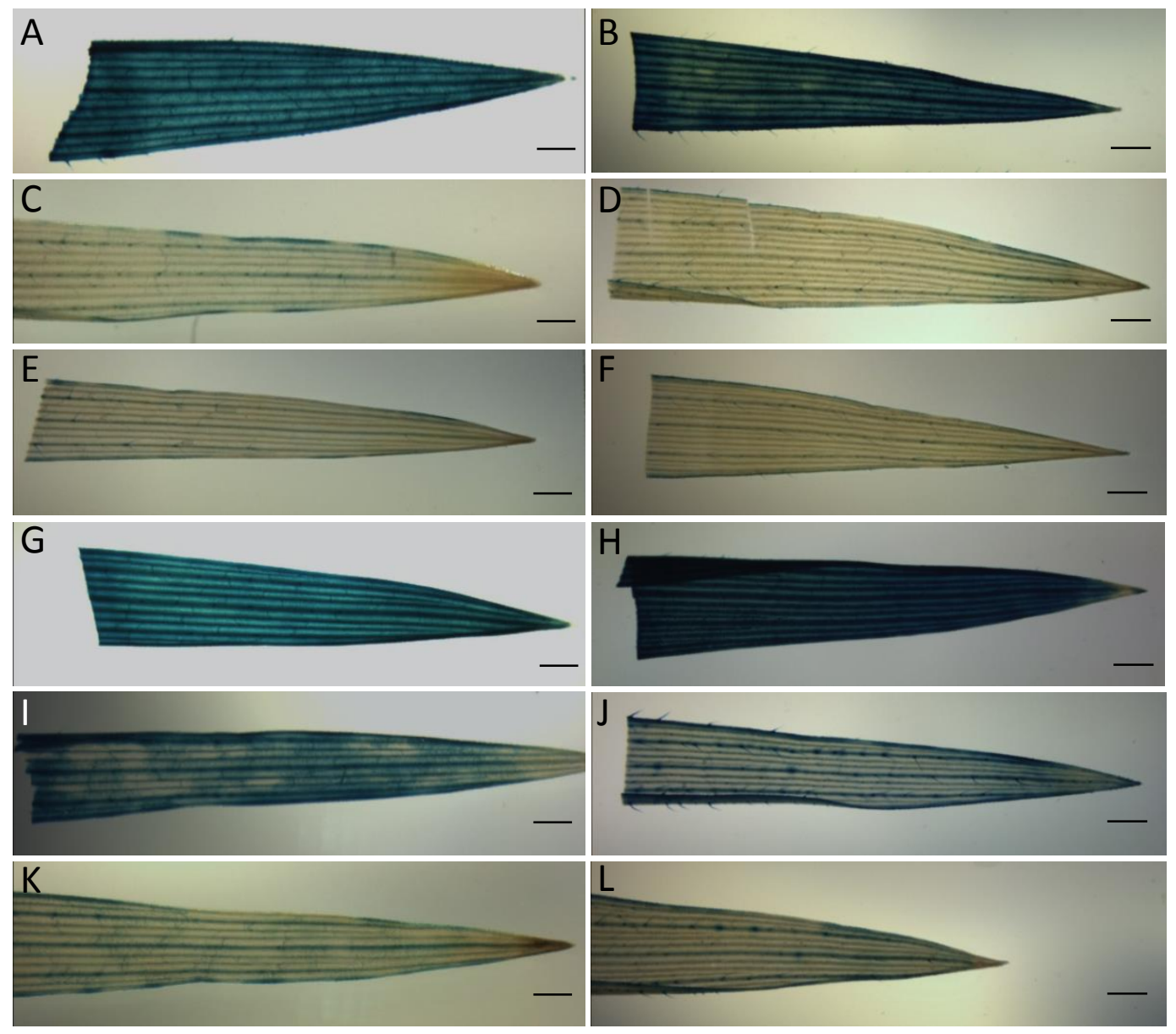

Supplemental Figure S10. Comparison of expression across BdCESA7 promoter driving GUSPLUS transgenic lines in adult leaves. Differences are likely due to positional effects of the transgenic cassette within the genome, including enhancer and repressor sequences located distal from the insertion sites. (A,B) BdCESA7 promoter::GUSPLUS. Line 149A. (C,D) BdCESA7 promoter::GUSPLUS. Line 153A. (E,F) BdCESA7 promoter::GUSPLUS. Line 156A. (G,H) BdCESA7 promoter::GUSPLUS. Line 122A. (I,J) BdCESA7 promoter::GUSPLUS. Line 38A. (K,L) BdCESA7 promoter::GUSPLUS. Line 91A. All leaves were viewed at 11.2X. Scale bar represents $1.0 \mathrm{~mm}$. Addition of potassium ferri- and ferro-cyanide to the X-Gluc staining solution was performed when staining BdCESA7 promoter::GUSPLUS Lines 149A and 122A to limit blue product diffusion into neighboring cells and outward into the staining solution. 


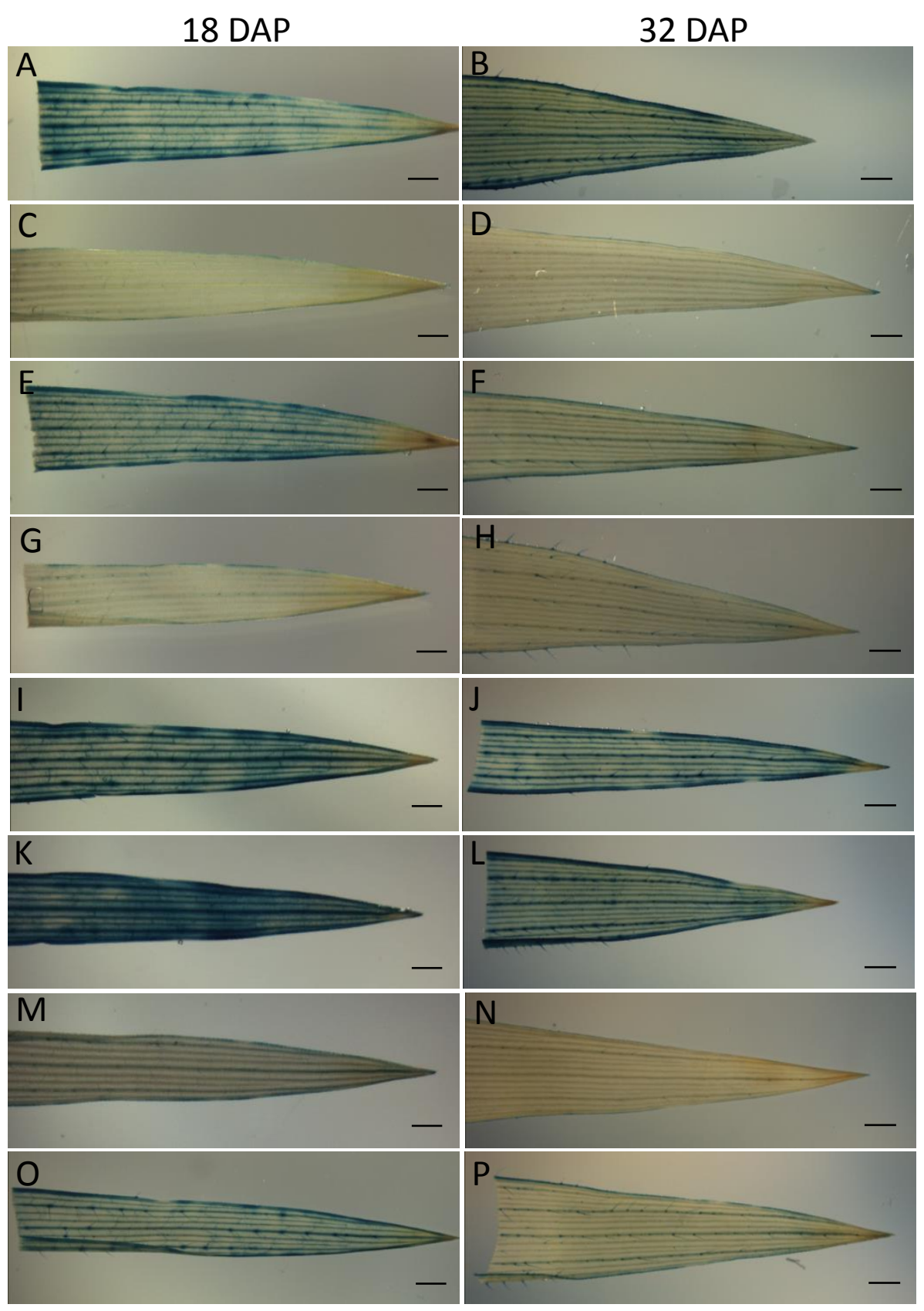

Supplemental Figure S11. Comparison of expression across BdCESA8 promoter driving GUSPLUS transgenic lines in adult leaves. Differences in expression are likely due to positional effects of the transgene in the genome, including the presence of distally located cis-acting enhancers or repressors. (A,B) BdCESA8 promoter::GUSPLUS. Line 113A. (C,D) BdCESA8 promoter::GUSPLUS. Line 111A. (E,F) BdCESA8 promoter::GUSPLUS. Line 41A. (G,H) BdCESA8 promoter::GUSPLUS. Line 3A. (I,J) BdCESA8 promoter::GUSPLUS. Line 5B. (K,L) BdCESA8 promoter::GUSPLUS. Line 46A. (M,N) BdCESA8 promoter::GUSPLUS. Line 55A. (O,P) BdCESA8 promoter::GUSPLUS. Line 89A. Scale bar represents 1.0 $\mathrm{mm}$. 

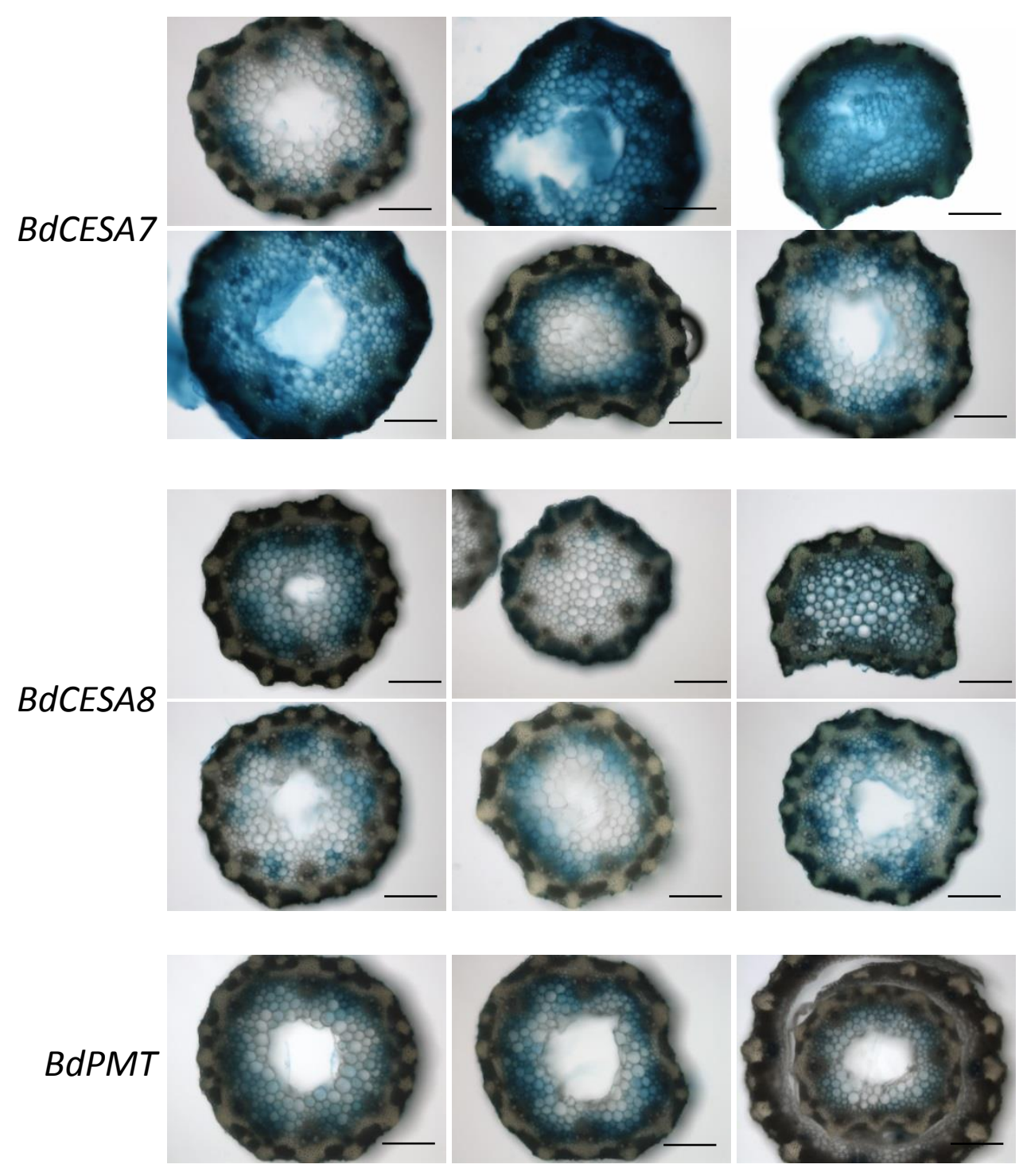

Supplemental Figure S12. Range of expression across multiple transgenic lines of BdCESA7 (Top panel), BdCESA8 (Center panel), BdPMT (Bottom panel), promoters driving GUSPLUS expression in adult stems. Stem sections were taken from the apical internode, $2 \mathrm{~cm}$ above the apical node of adult Brachypodium distachyon, 32 days after planting. Samples viewed at 100X magnification; scale bar represents $170 \mathrm{um}$. 
Homozygous Heterozygous

Bdcesa8 Bdcesa8 WT

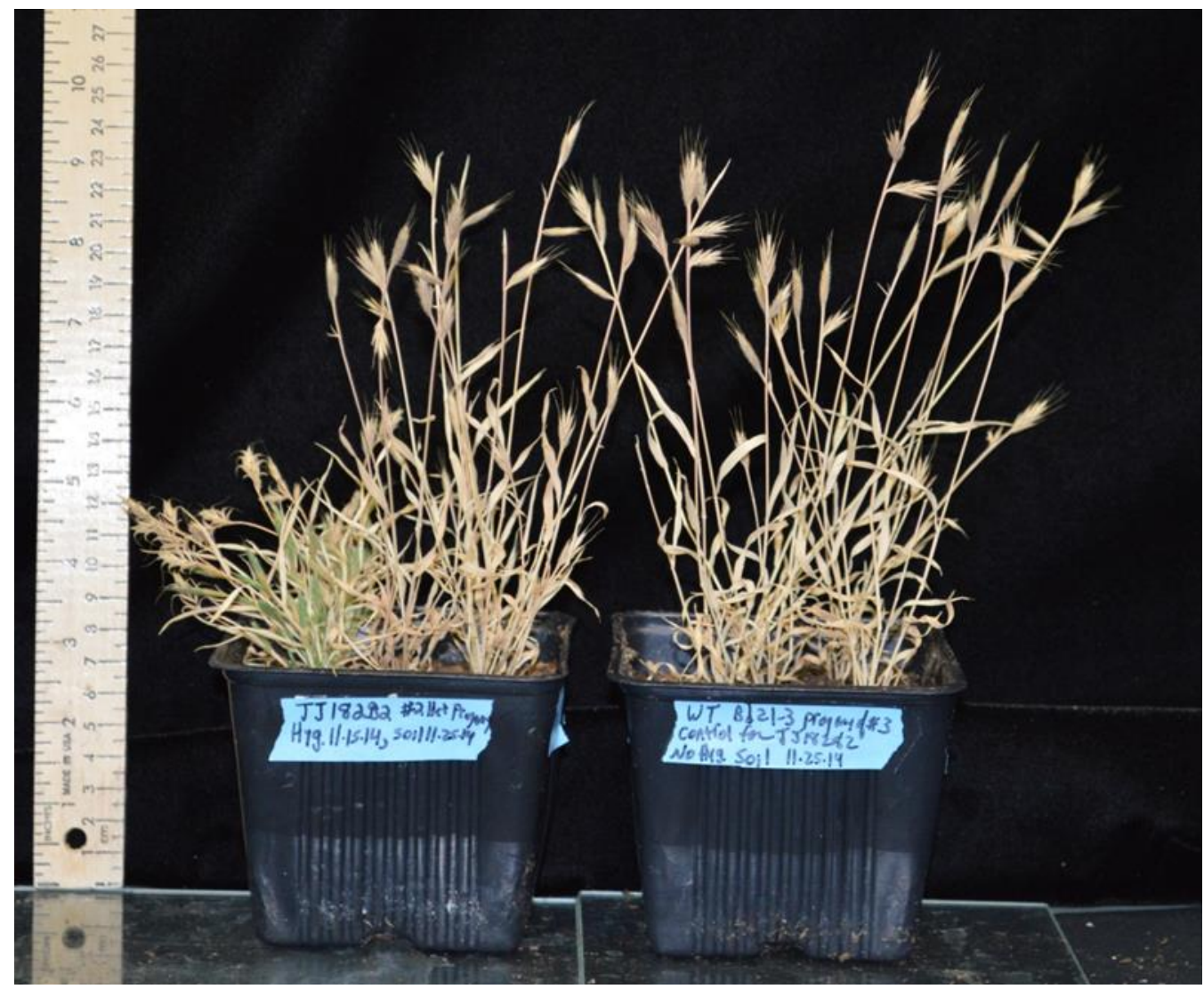

Supplemental Figure S13. Height comparison of homozygous Bdcesa8 mutant, heterozygous Bdcesa8 mutant, and wild-type control Brachypodium distachyon. Homozygous Bdcesa 8 mutants are stunted, whereas the Bdcesa 8 heterozygous mutant appears similar to wildtype height. 


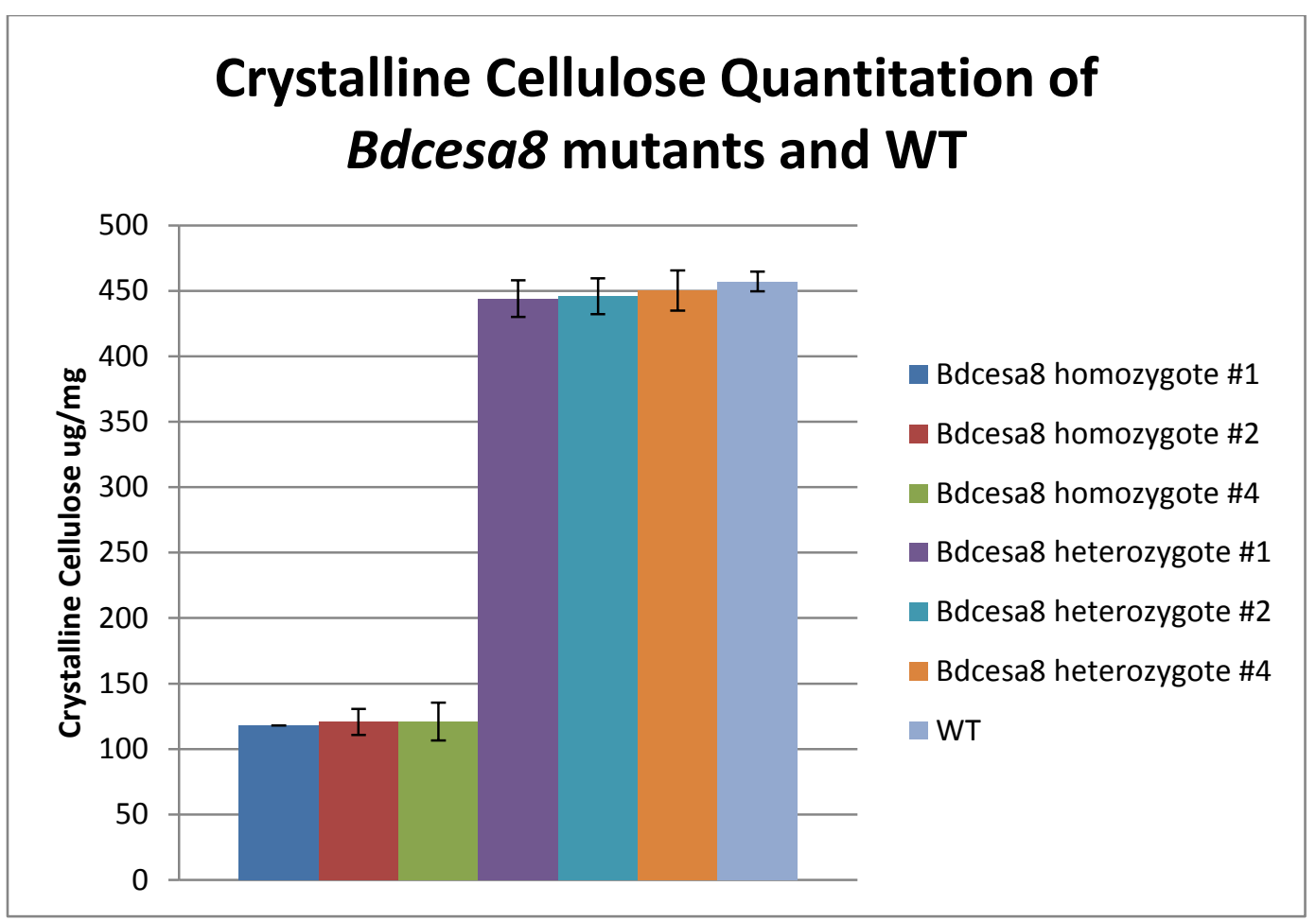

Supplemental Figure S14. Crystalline cellulose quantitations as performed by Updegraff assay on homozygous Bdcesa 8 mutants, heterozygous Bdcesa 8 mutants, and wild-type controls. Homozygous $B d c e s a 8$ demonstrate a decreased amount of cellulose, whereas Bdcesa8 heterozygotes contain a similar amount of cellulose as wild-type controls. 


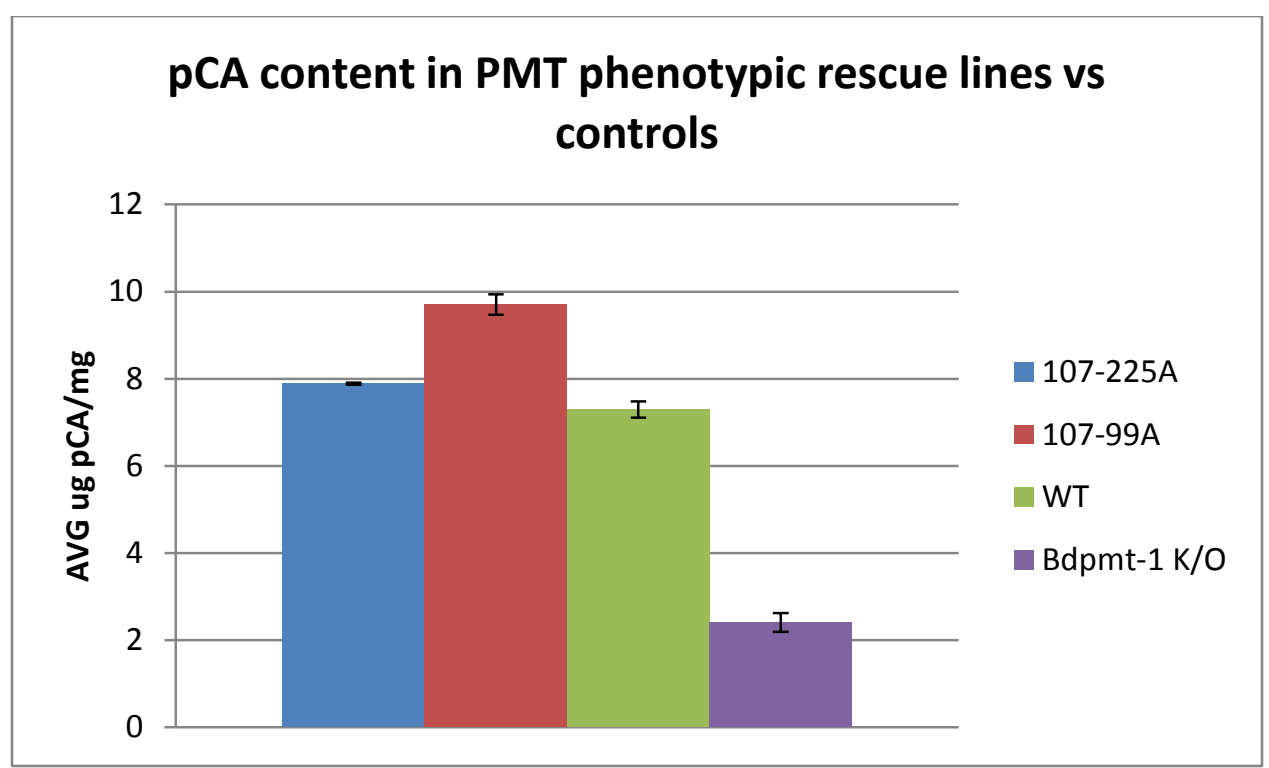

Supplemental Figure S15. Quantitation of $u \mathrm{~g}$ pCA/ mg extracted sample of PMT phenotypic rescue transgenic lines versus wild-type and Bdpmt-1 knockout controls. 

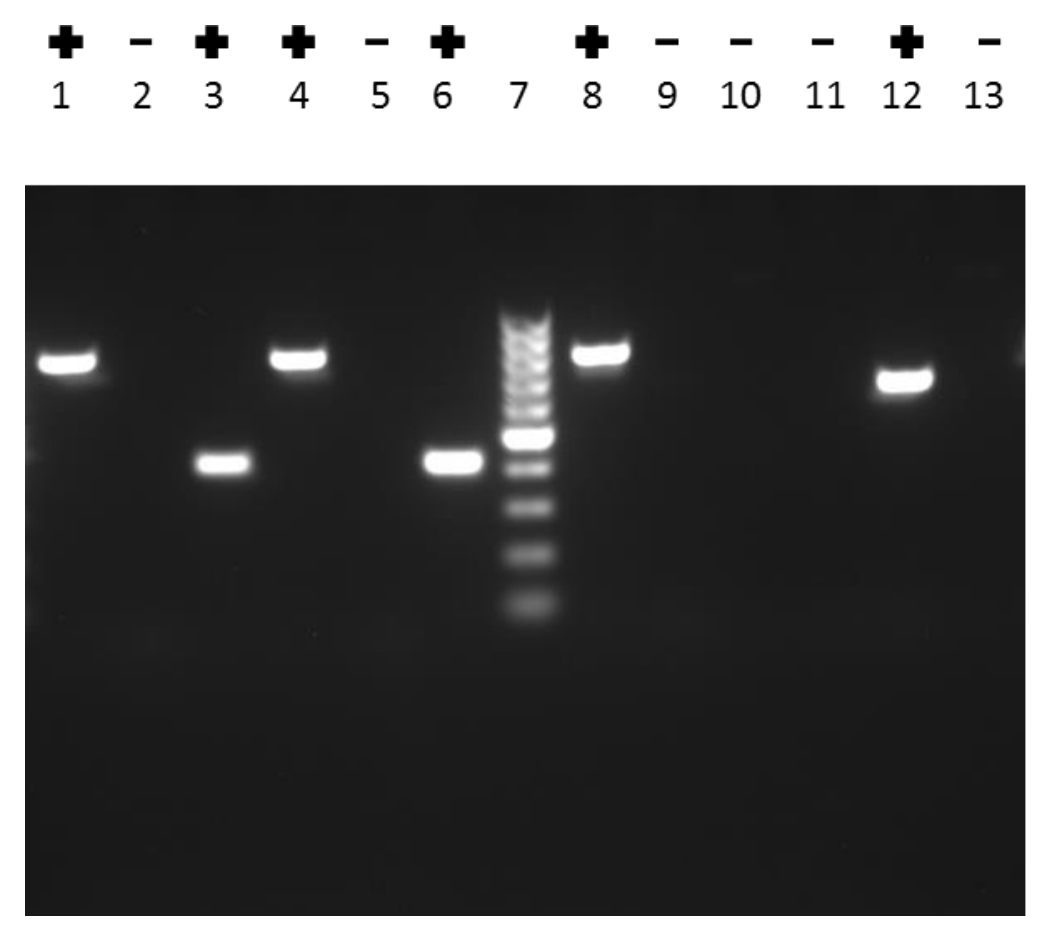

Supplemental Figure S16. Genomic DNA PCR results of BdCESA8 phenotypic rescue transgenic lines compared to B258p9ioACT empty vector and wild-type plant controls. The PCR product for the presence of the Bdcesa 8 T-DNA insertional mutation using the T3 TDNA LB and GSP R Mandy primer pair is approximately $800 \mathrm{bp}$ due to partial trunctation of one of the two tandem insertions. The PCR product for the presence of the endogenous, unaltered BdCESA8 gene (WT allele) is 628 bp using the JJ18282 F1 and $\mathrm{R} 1$ primer pair. The PCR product which indicates the integration of the BdCESA8 phenotypic rescue T-DNA, obtained using the NOST primer up and BdCESA8 EX13 F1 primer pair, is $408 \mathrm{bp}$. Loading order is as follows: 1) $B d C E S A 8$ phenotypic rescue line 58A PCR'd for the Bdcesa 8 T-DNA insertional mutation. 2) BdCESA8 phenotypic rescue line 58A PCR'd for the endogenous $B d C E S A 8$ WT allele. 3) BdCESA8 phenotypic rescue line 58A PCR'd for the presence of the BdCESA8 Phenotypic Rescue T-DNA. 4) $B d C E S A 8$ phenotypic rescue line 57A PCR'd for Bdcesa8 T-DNA insertional mutation. 5) BdCESA8 phenotypic rescue line 57A PCR'd for the endogenous BdCESA8 WT allele. 6) $B d C E S A 8$ phenotypic rescue line 57A PCR'd for the presence of the BdCESA8 Phenotypic Rescue T-DNA. 7) 100 bp DNA ladder. 8) B258p9io empty vector transgenic line 29A PCR'd for the Bdcesa8 T-DNA insertional mutation. 9) B258p9io empty vector transgenic line 29A PCR'd for the endogenous BdCESA8 WT allele. 10) B258p9io empty vector transgenic line 29A PCR'd for the presence of the BdCESA8 Phenotypic Rescue T-DNA. 11) Wild-type (WT) PCR'd for the Bdcesa8 T-DNA insertional mutation. 12) Wild-type (WT) PCR'd for the endogenous BdCESA8 WT allele. 13) Wild-type (WT) PCR'd for the BdCESA8 Phenotypic Rescue T-DNA. For simplicity, this figure shows only 2 phenotypic rescue transgenic lines plus controls; in total, 10 such transgenic lines (independent regenerants) were obtained which were homozygous for inheritance of the $B d c e s a 8$ mutation and had integrated at least one copy of the BdCESA 8 phenotypic rescue T-DNA in a heterozygous fashion. 